\title{
DETERMINAÇÃO DE NADH UTILIZANDO ELETRODOS DE PASTA DE CARBONO MODIFICADOS COM FILMES ELETROPOLIMERIZADOS DE 3,4-DIIDROXIBENZALDEÍDO
}

C) Faxia Blávia Lelbem

Dissertação de Mestrado

Profa. Dra. Sílvia H. P. Serrano Orientadora 


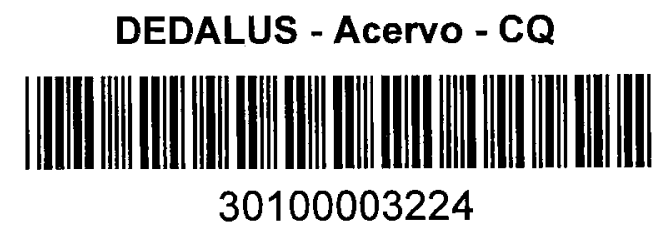

Ficha Catalográfica

Elaborada pela Divisão de Biblioteca e

Documentação do Conjunto das Químicas da USP.

D244d Determinação de NADH utilizando eletrodos de pasta de carbono modificados com filmes eletropolimerizados de 3,4diidroxibenzaldeído / Maria Flávia Delbem. -- São Paulo, 2000. $105 \mathrm{p}$.

Dissertação (mestrado) - Instituto de Química da Universidade de São Paulo. Departamento de Química Fundamental.

Orientador: Serrano. Silvia Helena Pires

1. Amperometria : Química analítica 2. Análise por injeção em fluxo: Química analitica 3. Voltametria cíclica : Química analitica : Orgânica I. T. II. Serrano, Sílvia Helena Pires, orientador. 
BIBLIOTECA INSTITUTO DE QUIMICA

Unlversidade de São Paalo

\section{"DETERMINAÇÃo DE NADH UTILIZANDO ELETRODOS DE PASTA DE CARBONO MODIFICADOS COM FILMES ELETROPOLIMERIZADOS DE 3,4-DIIDROXIBENZALDEIDO".}

\section{MARIA FLÁVIA DELBEM}

DISSERTAÇÃO DE MESTRADO SUBMETIDA AO INSTITUTO DE QUUIMICA DA UNIVESIDADE DE SÃo PAULO COMO PARTE DOS REQUISTIOS NECESSÁRIOS À OBTENÇÃO DO GRAU DE MESTRE EM CIF̂NCIAS - ÁREA: QUUÍMICA ANALÍTICA

Aprovada por:

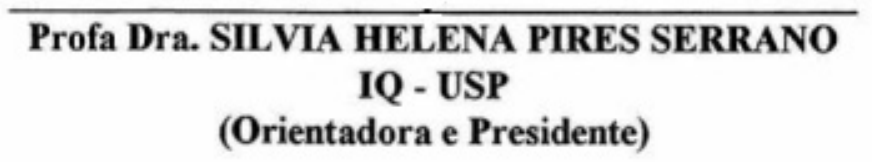

\begin{tabular}{c}
\hline Prof. Dr. LÚCIO ANGNES \\
IQ - USP \\
\\
\hline $\begin{array}{c}\text { Profa. Dra. HIDEKO YAMANAKA } \\
\text { IQ - UNESP - Araraquara }\end{array}$
\end{tabular}

SÃO PAULO

24 DE NOVEMBRO DE 2000. 
Aos meuspais 
A Professora Doutora Sílvia Helena Pires Serrano pela orientação no projeto, pela oportunidade de aprender e pela amizade. 


\section{AGRADECIMENTOS}

Aos Professores Doutores Wilhelm Josef Baader, Paulo Teng An-Sumodjo e Jairo José Pedrotti pelas valiosas colaborações durante o desenvolvimento deste trabalho.

A todos os colegas do Laboratório 273 pelo convívio e amizade.

A todos os professores do Instituto de Química da UNESPIAraraquara e do Instituto de Química da USP que, ao longo destes anos, contribuíram para o meu aprendizado.

A todas as pessoas que de alguma forma participaram da minha vida, seja nas conversas nos corredores, seja pelos cumprimentos ou sorrisos.

A FAPESP pelo suporte financeiro. 


\section{RESUMO}

O processo de eletropolimerização do 3,4 diidroxibenzaldeído (3,4-DHB) sobre eletrodos de pasta de carbono foi estudado utilizando voltametria cíclica e deposição a potencial controlado. As características dos filmes eletropolimerizados foram altamente dependentes do $\mathrm{pH}$, potencial anódico de inversão de varredura, velocidade de varredura, concentração de 3,4-DHB e número de ciclos usados durante o processo de formação.

A estabilidade dos filmes foi determinada em tampão citrato/fosfato no mesmo pH usado durante o processo de eletropolimerização. Os melhores resultados foram obtidos utilizando-se voltametria cíclica nas seguintes condições de trabalho: $\mathrm{pH} 7,8 ; 0,25 \mathrm{mmol} \mathrm{L}^{-1}$ de 3,4-DHB; $10 \mathrm{mVs}^{-1} ; 10$ ciclos e $0,0 \leq E_{a p l} \leq 0,25 V$.

O processo de eletropolimerização foi totalmente inibido na presença de soluções de 3,4-DHB contendo NADPH e parcialmente inibido na presença de NADH. Deste modo, a formação do radical livre fenoxil, para o qual o NADPH é, em sistemas biológicos, um agente supressor mais efetivo do que $\circ \mathrm{NADH}$, sendo responsável pela etapa inicial do processo de formação do filme. Estes resultados permitiram concluir que não é possivel, durante este processo, imobilizar enzimas ou co-fatores enzimáticos (NADH ou NADPH).

A superfície modificada foi rapidamente destruída após exposição a soluções de NADPH. Desde modo, a oxidação catalítica dos co-fatores pode envolver os grupos fenólicos presentes no filme modificador, de acordo com o mecanismo de eletropolimerização proposto neste trabalho. 
Os eletrodos modificados foram utilizados, durante 3 dias, para determinação amperométrica de $\mathrm{NADH}$ a $0,23 \mathrm{~V}$ (vs $\mathrm{Ag} / \mathrm{AgCl}, \mathrm{KCl}$ sat), obtendose resposta linear no intervalo de $0,015 \leq[\mathrm{NADH}] \leq 0,21 \mathrm{mmol} \mathrm{L}^{-1}$.

$\mathrm{NADH}$ foi igualmente determinado usando-se sistema de análise por injeção em fluxo (FIA). As condições otimizadas foram: alça de amostragem com volume $100 \mu \mathrm{L}$ e vazão de $0,7 \mathrm{~mL} \mathrm{~min}^{-1}$. As amostras de $\mathrm{NADH}$ foram preparadas em solução tampão PIPES $0,01 \mathrm{~mol} \mathrm{~L}^{-1}(\mathrm{pH} \mathrm{6,8),} \mathrm{enquanto} \mathrm{o} \mathrm{fluído}$ transportador utilizado foi solução $0,01 \mathrm{~mol} \mathrm{L-1}$ de tampão fosfato, $\mathrm{pH} 6,8$. Resposta linear foi observada no intervalo de $0,005 \leq[\mathrm{NADH}] \leq 0,15 \mathrm{mmol} \mathrm{L}^{-1}$, com limite de detecção estimado em $0,4 \mu \mathrm{mol} \mathrm{L} L^{-1}(3 S / R)$ e freqüência analítica de 55 determinações/hora. 


\begin{abstract}
Cyclic voltammetry and deposition at controlled potential were used to study the 3,4-dihydroxybenzaldehyde (3,4-DHB) electropolymerization process at carbon paste electrode surfaces. The electropolymerized film characteristics were highly dependent on $\mathrm{pH}$; anodic switching potential; scan rate; 3,4-DHB concentrations and scan numbers. The film stability was determined in citrate/phosphate buffer solutions at the same $\mathrm{pH}$ used during electropolymerization process. The best films were obtained by using cyclic voltammetry at the conditions: $\mathrm{pH} 7.8 ; 0.0 \leq \mathrm{E}_{\mathrm{apl}} \leq 0.25 \mathrm{~V} ; 10 \mathrm{mVs}^{-1}$; $0.25 \mathrm{mmolL}^{-1} 3,4-\mathrm{DHB}$ and 10 scans.
\end{abstract}

The electropolymerization process was totally inhibited in presence of NADPH and partially inhibited in presence of NADH containing solutions. Since NADPH is a known phenoxyl radical scavenger in biological systems, the fenoxyl free radical was the responsible specie for the initial step in the electropolymerization process. From these results were concluded that it is not possible to immobilize enzymes or co-factors (NADH and NADPH) during the electropolymerization process.

The modified surface was quickly lost after use in NADPH solutions, but showed upper stability in NADH solutions. These results were indicative that NADPH and NADH catalytic oxidations could be involve the phenolic groups present in the electropolymerized film as described by the mechanism proposed in this work. 
The modified electrodes could be used during three days to the amperometric $\mathrm{NADH}$ determinations, at $0.23 \mathrm{~V}$ (vs $\mathrm{Ag} / \mathrm{AgCl}, \mathrm{KCl}$ sat), with linear response in $0.015 \mathrm{mmol} \mathrm{L}^{-1} \leq[\mathrm{NADH}] \leq 0.21 \mathrm{mmol} \mathrm{L}^{-1}$ range. The analite was also determined in flow injection systems (FIA) by using loop size of $100 \mu \mathrm{L}$ and flow rate of $0.7 \mathrm{~mL} \mathrm{~min}^{-1}$. NADH solutions were prepared in $0.01 \mathrm{~mol} \mathrm{~L}^{-1}$ PIPES buffer solution, $\mathrm{pH} 6.8$ while the carrier stream was phosphate buffer solution $0.01 \mathrm{~mol} \mathrm{~L}^{-1}, \mathrm{pH}$ 6.8. Linear response was observed in $0.005 \mathrm{mmol} \mathrm{L}^{-1} \leq[\mathrm{NADH}] \leq 0.15 \mathrm{mmol} \mathrm{L}^{-1}$ range, with detection limit of the $0.4 \mu \mathrm{mol} L^{-1}(3 S / R)$ and analytical frequency of 55 determinations/hour. 


\section{SUMÁRIO}

$\begin{array}{ll}\text { 1. INTRODUÇÃOO } & 01\end{array}$

1.1 Eletrodos de pasta de carbono. 12

1.2 Considerações eletroquímicas. 13

1.3 Considerações sobre o sistema de análise de injeção em fluxo (FIA). 14

1.4 Objetivos $\quad 21$

2. PARTE EXPERIMENTAL 22

$\begin{array}{lll}2.1 & \text { Equipamentos utilizados. } & 22\end{array}$

2.2 Reagentes e soluções. $\quad 22$

2.3 Sistema de eletrodos. 23

2.4 Preparação do eletrodo auxiliar de Pt. 24

2.5 Preparação do eletrodo de referência ( $\mathrm{Ag} / \mathrm{AgCl})$.

2.5.1 Verificação da reversibilidade do eletrodo de referência. 25

2.6 Preparação dos eletrodos de pasta de carbono 26

2.7 Preparação dos eletrodos de trabalho modificados com filmes 27 eletropolimerizados de 3,4-diidroxibenzaldeído (3,4-DHB) obtidos por voltametria cíclica e deposição a potencial controlado.

2.7.1 Pré tratamento e ativação da superficie de pasta de carbono 26 em solução de $\mathrm{NaOH}$.

2.7.2 Escolha da faixa de potencial de ciclagem para formação de 28 filmes por voltametria cíclica

2.7.3 Avaliação da influência do potencial anódico de inversão de 29 varredura, velocidade de varredura, número de ciclos $e$ concentração da solução de 3,4-DHB na estabilidade de filmes formados por voltametria cíclica.

2.7.3.1 Modificação dos eletrodos de pasta de carbono em solução de 3,4-DHB utilizando voltametria cíclica em diversos valores de $\mathrm{pH}$. 
2.8.2 Avaliação da influência do potencial anódico de inversão de 30 varredura na estabilidade dos filmes eletropolimerizados.

2.8.3 Influência da velocidade de varredura .

2.8.4 Influência do número de ciclos.

2.8.5 Influência da concentração da solução de 3,4-DHB.

2.7.4 Eletrodos de pasta de carbono modificados em solução de 32 3,4-DHB por deposição a potencial controlado.

2.8 Influência da forma de armazenamento no desempenho analítico dos sensores

2.9 Metodologia experimental para a determinação de NADH.

2.10 Determinação de NADH e NADPH empregando sistema de análise por injeção em fluxo (FIA)

2.10.1 Sistema de remoção de bolhas

2.10.2 Influência da vazão

2.10.3 Influência do volume da alça de amostragem

2.10.4 Metodologia experimental para a determinação de NADH e $\mathrm{NADPH}$

3. RESULTADOS E DISCUSSÕES

3.1 Eletrodos de pasta de carbono modificados com filmes 40 eletropolimerizados de 3,4-DHB obtidos por voltametria cíclica.

3.1.1 Influência do potencial anódico de inversão de varredura na formação e estabilidade dos filmes de 3,4-DHB.

3.1.2 Influência da velocidade de varredura na estabilidade do filme de 3,4-DHB.

3.1.3 Influência do número de ciclos utilizados para formação do filme.

3.1.4 Influência da concentração da solução de 3,4-DHB na 56 estabilidade dos filmes de 3,4-DHB.

3.1.4 Reavaliação da influência do potencial anódico de inversão de varredura na formação e estabilidade dos filmes 3,4-DHB . 
3.2 Eletrodos de pasta de carbono modificados com filme de 3,4-DHB 63 obtidos por deposição a potencial controlado.

3.2.1 Eletrodos de pasta de carbono modificados com filme de 63 3,4-DHB preparados por deposição com potencial fixado no início do segundo processo de oxidação.

3.2.2 Eletrodos de pasta de carbono modificados com filme de 3,4-DHB preparados por deposição com potencial fixado após o término do primeiro processo de oxidação.

3.3 Melhores condições de formação de filme obtidos por voltametria cíclica e a potencial controlado.

3.4 Eletroquímica do filme de 3,4-DHB eletropolimerizado

3.5 Mecanismo proposto para formação dos filmes eletropolimerizados de 3,4-DHB.

3.6 Determinação catalítica de NADH com eletrodos de pasta de carbono modificados com filmes eletropolimerizados de 3,4-DHB.

3.7 Influência da forma de armazenamento do eletrodo na determinação catalítica de $\mathrm{NADH}$.

3.8 Influência do pré tratamento do eletrodo de pasta de carbono em 83 soluções de $\mathrm{NaOH}$

3.9 Determinação de NADH e NADPH empregando sistema de análise por injeção em fluxo

3.9.1 Sistema de remoção de bolhas.

3.9.2 Estabilidade do filme de 3,4-DHB.

3.9.3 Influência da vazão na determinação de $\mathrm{NADH}$ empregando sistema FIA.

3.9.4 Influência do volume da alça de amostragem nos sistemas em fluxo.

3.9.5 Determinação de NADH e NADPH.

3.10 Estabilidade da solução de NADH 


\section{LISTA DE FIGURAS}

Figura 1.1: Oxidação de NADH na presença de mediador

Figura 1.2: Representação esquemática do coeficiente de dispersão (D) de um sistema FIA. A zona de amostra original se dispersa durante 0 movimento em um reator tubular (no topo da figura), originando o perfil da curva (no centro da figura), no qual a concentração original, $\mathrm{C}^{\circ}$, evolui para um gradiente de concentração com valor máximo, $\mathrm{C}^{\text {máx }}$, no ápice do pico .

Figura 1.3: Geometria dos reatores de misturas mais freqüentemente utilizados em sistemas FIA: (A) tubo linear, (B) tubo em espiral, (C) câmara de mistura, (D) reator contendo uma fileira de esferas e (E) reator em formato de malha. O detector é indicado por $(0)$.

Figura 1.4: Efeito de reatores de mistura sobre a dispersão da amostra em sistema FIA: (A) tubo linear; (B) tubo espiral, (C) reator contendo uma fileira de esferas, (D) reator em formato de malha. Nos eixos: $A=$ absorbância e $D=$ coeficiente de dispersão.

Figura 2.1: Eletrodo auxiliar.

Figura 2.2: Esquema representativo do eletrodo de referência utilizado $(\mathrm{Ag} / \mathrm{AgCl})$.

Figura 2.3: Eletrodo de trabalho de pasta de carbono (área $=0,070 \mathrm{~cm}^{2}$ ).

Figura 2.4: Célula de camada delgada e separador de silicone.

Figura 3.1: Voltamogramas cíclicos registrados em solução $0,5 \mathrm{mmol} \mathrm{L}^{-1}$ de 3,4-DHB, no intervalo de $-0,2 \leq E_{\text {aplicado }} \leq 1,0 \mathrm{~V}$, velocidade de varredura $50 \mathrm{mVs}^{-1}$, em diversos valores de $\mathrm{pH}$. ( A ) $\mathrm{pH} \mathrm{2,6;} \mathrm{(B)}$ $\mathrm{pH} 3,6$; ( C ) pH 4,6; ( D ) pH 6,6; ( E ) pH 7,8; ( F ) pH 10,2.

Figura 3.2: Formação do filme de 3,4-DHB em diversos valores de $\mathrm{pH}$ por ciclagem. (A) pH 2,6; (B) pH 3,6; (C) pH 4,6; (D) pH 6,6; (E) pH 7,8 e $(F)$ pH 10,2. Condições experimentais para formação do filme: $0,5 \mathrm{mmol} \mathrm{L}^{-1}$ de 3,4-DHB; intervalo de varredura: $\left(\mathrm{E}_{\mathrm{pc}, 1}-150 \mathrm{mV}\right) \leq$ $E_{\text {aplicado }} \leq\left(E_{\mathrm{pa}, 2}+150 \mathrm{mV}\right)$; velocidade de varredura:50 mV s $\mathrm{m}^{-1}$; número de ciclos: (A) e (B) 8 ciclos, (C) e (D) 9 ciclos, (E) 10 ciclos, (F) 6 ciclos.

Figura 3.3: Influência do $\mathrm{pH}$ no perfil dos voltamogramas registrados em eletrólito suporte cujo valor do $\mathrm{pH}$ foi o mesmo utilizado na formação dos filmes preparados por ciclagem .( A ) $\mathrm{pH} 2,6$; ( B ) pH 3,6; (C) pH 4,6; (D) pH 6,6; (E) pH 7,8; (F) pH 10,2. Condições experimentais: $\left(E_{p c, 1}-150 \mathrm{mV}\right) \leq E_{\text {aplicado }} \leq\left(E_{p a, 2}+150 \mathrm{mV}\right)$; 
velocidade de varredura: $50 \mathrm{mVs}^{-1}$ e 10 ciclos.

Figura 3.4: Variação dos potenciais de pico anódico (Ep,a) e catódico (Ep,c) registrado em eletrólito suporte (no mesmo valor de $\mathrm{pH}$ em que os filmes foram formados) com eletrodos modificados por ciclagem.

Figura 3.5: Variação das correntes de pico anódica $(I p, a)$ e catódica $(I p, c)$ com o $\mathrm{pH}$ para filmes preparados por ciclagem. Os niveis de correntes correspondem ao décimo voltamograma cíclico, registrado em eletrólito suporte (tampão fosfato).

Figura 3.6: Influência do intervalo de varredura na estabilidade dos filmes (1) Filme formado no intervalo de $0 \leq E_{\text {aplicado }} \leq 0,45 \mathrm{~V}$. Estabilidade em eletrólito suporte na faixa de (1a) $0 \leq E_{\text {aplicado }} \leq 0,45 \mathrm{~V}$ e (1b) $0 \leq E_{\text {aplicado }} \leq 0,30 \mathrm{~V}$.

(2) Filme formado no intervalo de $0 \leq \mathrm{E}_{\text {aplicado }} \leq 0,25 \mathrm{~V}$. Estabilidade em eletrólito suporte na faixa de (2a) $0 \leq \mathrm{E}_{\text {aplicado }} \leq 0,45 \mathrm{~V}$ e (2b) de $0 \leq \mathrm{E}_{\text {aplicado }} \leq 0,25 \mathrm{~V}$. Condições experimentais para formação do filme: $\mathrm{pH} 7,8 ; 0,5 \mathrm{mmol} \mathrm{L}^{-1}$ de 3,4-DHB; velocidade de varredura: 50 $\mathrm{mV} . \mathrm{s}^{-1}$ e 10 ciclos. Estabilidade dos filmes: eletrólito suporte com $\mathrm{pH} 7,8$; velocidade de varredura: $50 \mathrm{mVs}^{-1}$ e 20 ciclos.

Figura 3.7: Formação dos filmes de 3,4-DHB em diferentes velocidades de varredura. (A) $10 \mathrm{mVs}^{-1}$; (B) $25 \mathrm{mVs}^{-1} ;$ (C) $50 \mathrm{mVs}^{-1}$; (D) $75 \mathrm{mVs}^{-1}$; (E) $100 \mathrm{mVs}^{-1}$. Os voltamogramas apresentados correspondem ao décimo voltamograma cíclico para cada uma das velocidades. Condições experimentais para formação do filme: $\mathrm{pH} 7,8 ; 0,5 \mathrm{mmol} \mathrm{L}^{-1}$ de 3,4-DHB; intervalo de varredura $0,0 \leq \mathrm{E}_{\text {aplicado }} \leq 0,25 \mathrm{~V}$ e 10 ciclos.

Figura 3.8: Variação dos níveis de corrente de pico anódica e catódica em solução de eletrólito suporte tampão fosfato $\mathrm{pH}=7,8$ em função da velocidade de formação do filme em solução de $0,5 \mathrm{mmol} \mathrm{L}^{-1}$ 3,4-DHB. Niveis de corrente correspondentes ao vigésimo voltamograma cíclico registrado em eletrólito suporte.

Figura 3.9: Variação dos níveis de correntes anódica e catódica como função do número de voltamogramas cíclicos utilizados para a formação do filme de 3,4-DHB. Os níveis de correntes correspondem ao vigésimo voltamograma cíclico registrado em eletrólito suporte, tampão fosfato $\mathrm{pH} 7,8$.

Figura 3.10: Estudo da influência da concentração da solução de 3,4-DHB na formação dos filmes eletropolimerizados de 3,4-DHB.(A) 0,25 $\mathrm{mmolL}^{-1}$ (B) $0,56 \mathrm{mmol} \mathrm{L}^{-1}$, (C) $0,90 \mathrm{mmol} \mathrm{L}^{-1}$; (D) $1,8 \mathrm{mmol} \mathrm{L}^{-1}$. Os voltamogramas correspondem ao do décimo ciclo. Condiçōes experimentais de formação dos filmes: $\mathrm{pH} \mathrm{7,8;} \mathrm{intervalo} \mathrm{de}$ 
varredura: $0,0 \leq E_{\text {aplicado }} \leq 0,25 \mathrm{~V}$; velocidade de varredura: $50 \mathrm{mVs}^{-1}$ e 10 ciclos.

Figura 3.11: Variação dos níveis de corrente de pico de anódica (1) e catódico (2) registradas em eletrólito suporte tampão fosfato $\mathrm{pH} 7,8$ como função da concentração da solução de 3,4-DHB $(0,25 ; 0,56 ; 0,90$ e $1,8 \mathrm{mmol} \mathrm{L}^{-1}$ ) usada para a formação dos filmes. (A) Niveis de corrente do segundo voltamograma cíclico (B) Niveis de corrente do vigésimo voltamograma cíclico.

Figura 3.12: Voltamogramas cíclicos correspondentes ao décimo ciclo de formação dos filmes de 3,4-DHB em diferentes valores de $\mathrm{pH}$. (1) $\mathrm{pH} 4,6: 0,20 \leq \mathrm{E}_{\text {aplicado }} \leq 0,38 \mathrm{~V}$; (2) $\mathrm{pH} 6,8: 0,07 \leq \mathrm{E}_{\text {aplicado }} \leq$ $0,26 \mathrm{~V}$; (3) $\mathrm{pH} 7,8: 0,02 \leq \mathrm{E}_{\text {aplicado }} \leq 0,20 \mathrm{~V}$.

Figura 3.13: Voltamogramas cíclicos correspondentes ao décimo ciclo de formação dos filmes de 3,4-DHB em diferentes valores de $\mathrm{pH}$. (1) $\mathrm{pH} 4,6: 0,17 \leq \mathrm{E}_{\text {aplicado }} \leq 0,44 \mathrm{~V}$; (2) $\mathrm{pH} 6,8: 0,05 \leq \mathrm{E}_{\text {aplicado }} \leq$ $0,32 \mathrm{~V}$; (3) $\mathrm{pH} 7,8: 0,0 \leq \mathrm{E}_{\text {aplicado }} \leq 0,25 \mathrm{~V}$.

Figura 3.14: Voltamograma cíclico, registrado em eletrólito suporte, com o eletrodo modificado por ciclagem, utilizado para cálculo do excesso superficial do agente modificador.

Figura 3.15: Mecanismo proposto para a formação do filme de 3,4-DHB em eletrodos de pasta de carbono.

Figura 3.15.1: Estruturas tautoméricas do composot (IV)

Figura 3.16: (A) 3,4 - DHB

(B) Gendiol

Figura 3.17: (A) Voltamograma cíclico registrado em tampão fosfato $\mathrm{pH} 7,8$ com o eletrodo modificado apenas em solução de 3,4-DHB (B) Voltamograma cíclico registrado com o eletrodo modificado em solução de 3,4 DHB contendo NADH e (C) Voltamograma cíclico registrado com o eletrodo modificado em solução de 3,4-DHB contendo NADPH.

Figura 3.18: (A) Voltamogramas cíclicos registrados em soluções de $0,6 \mathrm{mmol}^{-1}$ de NADPH nas melhores condiçōes de obtenção do filme de 3,4-DHB.( B ) Voltamogramas registrados em solução de $0,25 \mathrm{mmol} \mathrm{L}^{-1}$ de 3,4-DHB, após a ciclagem em solução de NADPH. (C) Voltamograma cíclico realizado em tampão fosfato $\mathrm{pH} 7,8$, após realização das etapas $(\mathrm{A})$ e (B).

Figura 3.19: (A)Voltamogramas cíclicos registrados em solução de $\mathrm{NADH}, \mathrm{pH}$ 6,8, com eletrodo modificado com 3,4-DHB: (1) branco (2) $0,16 \mathrm{mmol} \mathrm{L}^{-1}$; (3) $0,34 \mathrm{mmol} \mathrm{L}^{-1}$; (4) $0,51 \mathrm{mmol} \mathrm{L}^{-1}$; (5) 0,65 
mmol $\mathrm{L}^{-1}$. (B) Voltamogramas de pulso diferencial, registrados em soluções de $\mathrm{NADH}, \mathrm{pH} \mathrm{6,8,} \mathrm{com} \mathrm{eletrodo} \mathrm{de} \mathrm{apsta} \mathrm{de} \mathrm{carbono:} \mathrm{(1)}$ branco (2) $0,19 \mathrm{mmol} \mathrm{L}^{-1}$; (3) $0,35 \mathrm{mmol} \mathrm{L}^{-1}$; (4) $0,49 \mathrm{mmol} \mathrm{L}^{-1}$; (5) $0,62 \mathrm{mmol} \mathrm{L}^{-1}$.

Figura 3.20: (A) Amperograma registrado em soluçōes de NADH (segunda curva analítica). (B) Curvas analíticas para determinação de NADH:(preto) 1 curva analítica; (verde) 2 curva analítica e (vermelho) 3 curva analítica.

Figura 3.21: (A) Injeções da alça de amostragem contendo apenas o tampão PIPES (0 < tempo < 600s); (B) Injeções de NADH 0,025 mmol L-1 em tampão PIPES.

Figura 3.22: Fluido transportador tampão fosfato $0,010 \mathrm{~mol} \mathrm{~L}^{-1}$. (A) Tampão PIPES 0,010 $\mathrm{mol} \mathrm{L}^{-1}$ (B) Tampão PIPES 0,10 $\mathrm{mol} \mathrm{L}^{-1}$.

Figura 3.23: Influência da vazão nos sinais de corrente obtidas com injeções de $0,0024 \mathrm{mmol} \mathrm{L}^{-1}$ de NADH: (A) $0,2 \mathrm{~mL} \mathrm{~min}^{-1}$; (B) $0,4 \mathrm{~mL} \mathrm{~min}^{-1}$; (C) $0,6 \mathrm{~mL} \mathrm{~min}^{-1}$; (D) $0,8 \mathrm{~mL} \mathrm{~min}^{-1}$; (E) $1,0 \mathrm{~mL} \mathrm{~min}^{-1}$; (F) $1,4 \mathrm{~mL} \mathrm{~min}^{-1}$; (G) $1,9 \mathrm{mLmin}^{-1}$. (H) vazão $0,6 \mathrm{~mL} \mathrm{~min}^{-1}$, concentração de $\mathrm{NADH}$ 0,0067 e $0,071 \mathrm{mmol} \mathrm{L}^{-1}$.

Figura 3.24: Influência da alça de amostragem nos sinais de corrente obtidos com injeções de $0,0024 \mathrm{mmol} \mathrm{L}^{-1}$ de $\mathrm{NADH}$, vazão de $0,6 \mathrm{~mL} \mathrm{~min}^{-1}$ : (A) $50 \mu \mathrm{L}$; (B) $100 \mu \mathrm{L}$; (C) $150 \mu \mathrm{L}$; (D) $200 \mu \mathrm{L}$; (E) $250 \mu \mathrm{L}$.

Figura 3.25: Sinais de corrente obtidos na determinação de NADH em tampão PIPES $0,010 \mathrm{~mol} \mathrm{~L}^{-1} \mathrm{e}$ a respectiva curva analítica. Concentração de NADH (A) 0,0050 $\mathrm{mmol} \mathrm{L}^{-1}$; (B) 0,025 $\mathrm{mmol} \mathrm{L}^{-1}$; (C) 0,072 mmol $\mathrm{L}^{-1}$; (D) $0,15 \mathrm{mmol} \mathrm{L}^{-1}$ (preta) curva analítica sem descontar o sinal do tampão PIPES e (vermelha) após descontar o sinal do tampão PIPES. Eletrodo de pasta de carbono modificado com 3,4-DHB por ciclagem. Potencial de trabalho $0,23 \mathrm{~V}$, volume de amostra $100 \mu \mathrm{L}$; vazão: $0,6 \mathrm{~mL} \mathrm{~min}^{-1}$, eletrólito de suporte: tampão fosfato $0,010 \mathrm{molL}^{-1}$.

Figura 3.26: Sinais de corrente obtidos na determinações de NADH em tampão PIPES $0,010 \mathrm{~mol} \mathrm{~L}^{-1}$ e a respectiva curva analítica. Concentração de NADH (A) 0,0040 $\mathrm{mmol} \mathrm{L}^{-1}$; (B) 0,024 $\mathrm{mmol} \mathrm{L}^{-1}$; (C) 0,070 mmol $\mathrm{L}^{-1}$; (D) $0,13 \mathrm{mmol} \mathrm{L}^{-1}$. Eletrodo de pasta de carbono modificado com 3,4-DHB por deposição a potencial controlado. Potencial de trabalho $0,23 \mathrm{~V}$, volume de amostra $100 \mu \mathrm{L}$; vazão: $0,6 \mathrm{~mL} \mathrm{~min}^{-1}$, eletrólito de suporte: tampão fosfato $0,010 \mathrm{molL}^{-1}$.

Figura 3.27: Sinais de corrente obtidos na determinações de NADPH em tampão PIPES $0,010 \mathrm{~mol} \mathrm{~L}^{-1}$ e a respectiva curva analítica. Concentração de NADPH (A) 0,0054 $\mathrm{mmol} \mathrm{L}^{-1}$; (B) 0,024 $\mathrm{mmol} \mathrm{L}^{-1}$; 
(C) $0,073 \mathrm{mmol} \mathrm{L}^{-1}$; (D) 0,14 $\mathrm{mmol} \mathrm{L}^{-1}$; (E) 0,19 mmol L-1. Eletrodo de pasta de carbono modificado com 3,4-DHB por ciclagem Potencial de trabalho $0,23 \mathrm{~V}$, volume de amostra $100 \mu \mathrm{L}$; vazão: $0,6 \mathrm{~mL} \mathrm{~min}^{-1}$, eletrólito de suporte: tampão fosfato $0,010 \mathrm{molL}^{-1}$. 


\section{LISTA DE TABELAS}

Tabela 1.1: Comparação de diferentes mediadores para a monitoração da coenzima NADH.

Tabela 2.1: Intervalos de varredura utilizado para obtenção de filmes por ciclagem.

Tabela 2.2: Valores dos potenciais fixados para a formação do filme de 3,4DHB.

Tabela 3.1: Valores de Ep,a e Ep,c como função de pH.

Tabela 3.2: Percentagens de perda de filme ativo, registradas em eletrólito suporte, para o décimo voltamograma cíclico.

Tabela 3.3: Percentagens de perda de filme ativo para filmes formados no intervalo de $\mathrm{Ei}=0,0 \mathrm{~V}$ e $\mathrm{Ef}=0,45 \mathrm{~V}$.

Tabela 3.4: Percentagens de perda de filme ativo para filmes formados no intervalo de $\mathrm{Ei}=0,0 \mathrm{~V}$ e $\mathrm{Ef}=0,25 \mathrm{~V}$.

Tabela 3.5: Percentagens de perda de filme ativo como função da velocidade de formação em solução $0,5 \mathrm{mmol} \mathrm{L}^{-1}$ de 3,4-DHB.

Tabela 3.6: Percentagens de perda de filme ativo como função do número de ciclos utilizados durante o processo de formação do filme.

Tabela 3.7: Variações entre os potenciais de pico anódico e catódico $(\Delta E p)$, como função da concentrações de 3,4-DHB utilizada na formação dos filmes.

Tabela 3.8: Percentagens de perda de filme ativo para eletrodos modificados por ciclagem como função do potencial inversão anódico (1) Potencial de inversão de varredura fixado no início do segundo processo de oxidação ( 2 ) Potencial de inversão fixado no fim do primeiro processo de oxidação.

Tabela 3.9: Niveis de corrente anódica e catódica para filmes formados em diferentes valores de $\mathrm{pH}$.(1) Potencial de inversão de varredura fixado no início do segundo processo de oxidação. (2) O potencial de inversão de varredura fixado ao término do primeiro processo de oxidação.

Tabela 3.10: Percentagens de perda de filme ativo em tampão PIPES $\mathrm{pH}=6,8$ para eletrodos modificados a potencial controlado como função do 
$\mathrm{pH}$ de formação.

Tabela 3.11: Valores de corrente anódico e catódico obtidos com eletrodos modificados com filmes de 3,4-DHB preparados a potencial controlado como função do pH de formação.

Tabela 3.12: Valores de corrente anódica e catódica para filmes formados em diferentes valores de $\mathrm{pH}$, com o potencial fixado ao término do primeiro processo oxidação.

Tabela 3.13: Percentagens de perda de filme ativo em tampão PIPES pH 6,8 para eletrodos modificados a potencial controlado como função do $\mathrm{pH}$ de formação.

Tabela 3.14: Avaliação do desempenho analítico do eletrodo como função do método de armazenamento. Estudo da faixa linear de $0,015 \leq[\mathrm{NADH}] \leq 0,21 \mathrm{mmolL}^{-1}$, com Ip $=\mathrm{A}+\mathrm{B}[3,4 \mathrm{DHB}]$. 


\section{INTRODUÇÃO}

Os cofatores enzimáticos $\beta$-nicotinamida adenina dinucleotídeo (NADH) e nicotinamida adenina dinucleotídeo-fosfato (NADPH) são fundamentais para a ação catalítica de mais de 300 enzimas óxido redutases [1, 2]. Deste modo, a determinação deste cofator por meio de métodos eletroanalíticos tem sido bastante explorada, particularmente porque vários substratos e produtos não eletroativos podem ser indiretamente monitorados acompanhando-se 0 consumo ou produção de NADH e/ou NADPH.

O mecanismo de oxidação do NADH em eletrodos não modificados é complexo e sempre dependente das condições de superfície dos eletrodos [3-5]. Além disso, $\mathrm{NAD}^{+}$e $\mathrm{NADP}^{+}$, adsorvem na superficie dos eletrodos causando o envenenamento superficial dos mesmos [4-7]. Este problema foi parcialmente resolvido, efetuando o tratamento eletroquímico prévio da superfície dos eletrodos de acordo com o procedimento experimental descrito por Blaedel e Jenkis [3,4].

Moirux e Elving [8] utilizaram o pré-tratamento eletroquímico em dois tipos de eletrodos rotatórios: carbono vitreo e grafite pirolítico, observando uma pré onda durante a eletrooxidação do $\mathrm{NADH}$, a qual foi atribuída à redução do $\mathrm{NAD}^{+}$adsorvido no superfície do eletrodo. O recobrimento prévio da superfície dos eletrodos de carbono vítreo $[8,9]$, grafite $[8,9]$ e platina [9] com NAD ${ }^{+}$ possibilitou a determinação de $\mathrm{NADH}$ em escala de micromols $\mathrm{L}^{-1}$. 
Jaegfeldt [10] estudou a adsorção e oxidação eletrocatalítica do NADH em eletrodo de Pt. Boa reprodutibilidade nas correntes de oxidação só foi obtida após limpar eletroquimicamente o eletrodo em solução tampão na ausência de $\mathrm{NAD}^{+}$. Ciclagens prévias do eletrodo em solução do cofator oxidado causaram o deslocamento do potencial de pico de oxidação do NADH para valores mais positivos, tornando o eletrodo passivado. Este efeito foi mais pronunciado, quando o eletrodo foi previamente submetido a potenciais negativos em solução de adenosina monofosfato. Resultados similares foram obtidos por Blankespoor e Miller [11], embora estes autores tenham verificado que o potencial de pico de oxidação do NADH tornou-se constante depois do recobrimento prévio do eletrodo com $\mathrm{NAD}^{+}$. Neste caso, a superfície do eletrodo não se alterou durante os experimentos e voltamogramas cíclicos reprodutiveis foram obtidos.

A maneira mais simples de resolver estes problemas foi utilizar o prétratamento da superfície do eletrodo afim de produzir espécies que pudessem atuar como mediadores no processo de transferência de carga. Engstrom [12] descreveu o efeito do pré-tratamento anódico e catódico de eletrodo de pasta de carbono em solução tampão fosfato, demonstrando a possibilidade de avaliar a contribuição dos dois processos separadamente. Para a oxidação catalítica de $\mathrm{NADH}$ e ácido ascórbico, Cenas et al [13] utilizaram o pré tratamento eletroquímico em solução tampão fosfato para produzir grupos quinoidais na superfície do carbono vitreo. Samec e Elving [14] estudaram a velocidade de oxidação do NADH em eletrodos de ouro, platina e carbono vítreo em função da superfície do eletrodo, concluindo que os grupos ativos 
redox que estão envolvidos na. oxidação do NADH em eletrodos sólidos apresentam um comportamento irreversivel. O maior problema associado à utilização de eletrodos pré tratados eletroquimicamente para determinação de NADH e NADPH é a perda rápida da superfície modificada.

Uma vez que a adsorção do $\mathrm{NAD}^{+}$em carbono vítreo é atribuída ao grupo adenina, presente na molécula do cofator em sua forma reduzida ou oxidada [9], Samec e Elving [14] realizaram experimentos voltamétricos utilizando soluções de nicotinamida mononucleotídeo $\left(\mathrm{NMN}^{+}\right)$e seu produto de redução $(\mathrm{NMNH})$, que não continham adenina na molécula. Os autores verificaram que estes compostos adsorviam menos na superfície de eletrodos de ouro, do que aqueles que continham adenina originalmente na molécula.

O trabalho de Samec e Elving [14]; a observação de que as corrente de oxidação de NADH diminuíam à potenciais superiores a $0,9 \mathrm{~V}$ vs ECS [4]; bem como a suspeita de que em solução tampão fosfato a molécula de NADH pudesse ser degradada [16], originando produtos que atuam como inibidores enzimáticos [17], conduziram nosso grupo ao estudo da influência do eletrólito suporte na oxidação eletroquímica do NADH [18]. Neste trabalho, demonstrouse que, na presença de tampão fosfato, ocorre decomposição do cofator com produção de adenina. Esta última espécie, na presença de fosfato, forma adutos estáveis que são oxidados a potenciais da ordem de 1,0 V (vs Ag/AgCl, $\mathrm{KCl}$,sat.), com formação de produtos que adsorvem fortemente sobre a superfície do eletrodo, bloqueando a resposta do mesmo. Demonstrou-se ainda, empregando-se voltametria de pulso diferencial, eletrodos de carbono vítreo e tampão PIPES, que a oxidação do NADH ocorre a 0,6 V $(\mathrm{Ag} / \mathrm{AgCl}, \mathrm{KCl}$ 
sat.). No entanto, com o aumento da concentração do analito e número de voltamogramas realizados, o potencial de pico de oxidação desloca-se para valores mais positivos. A decomposição do cofator na presença de solução tampão fosfato, bem como a formação de adutos adenina-fosfato foi confirmada utilizando espectroscopia de absorção molecular na região do ultravioleta [19]. Espectros de absorção de soluções de NADH, preparadas em tampão fosfato apresentaram, além dos já conhecidos picos a $260 \mathrm{~nm}$ (absorção do grupo adenina) e $340 \mathrm{~nm}$ (absorção do grupo nicotinamida), um pico adicional a $215 \mathrm{~nm}$, que não foi observado em outros eletrólitos tais como tampão PIPES, HEPES e solução de $\mathrm{NaNO}_{3}$. Este último pico foi igualmente observado em soluções de adenina preparadas em tampão fosfato.

Assim, a utilização de eletrodos quimicamente modificados com mediadores está associada com a possibilidade de conduzir experimentos a potencial menor do que o obtido na oxidação dos cofatores em eletrodos não modificados, evitando a oxidação de outras espécies biológicas que poderiam, em amostras reais, atuar como interferentes (por exemplo: ácido acético, ácido úrico, acetoaminofenol) [20], além de minimizar os efeitos de envenenamento por adsorção dos produtos de oxidação do NADH e/ou NADPH.

Em função destes fatos um número elevado de eletrodos modificados, que na maioria das vezes utilizam mediadores de elétrons, tem sido propostos para a determinação destes cofatores enzimáticos. O cofator reduzido, por exemplo $\mathrm{NADH}$, reage quimicamente com a forma oxidada do mediador, produzindo o mediador reduzido na superfície do eletrodo. Este último, é então oxidado no eletrodo a um potencial aplicado constante. Deste modo a corrente 
de oxidação do mediador é proporcional à concentração do cofator reduzido, em solução (Figura. 1.1).

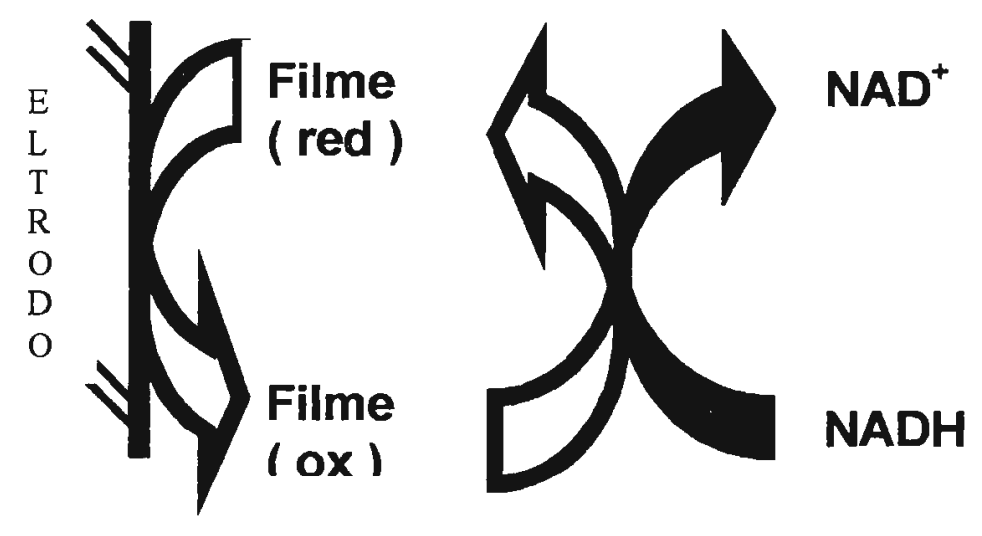

Figura 1.1: Oxidação de NADH na presença de mediador

Baseado nos relatos de Albery [21] e no conhecimento que a flavina [22] e enzimas contendo flavina possuem sítios redox [23], fenazinas [24-26] e fenotiazinas [27], compostos com estruturas semelhantes as flavinas, foram utilizados como bons mediadores para oxidação catalítica do NADH. Tortenson e Gorton [28], utilizaram pré-tratamento anódico em solução de fenazina metilsulfato (PMS) e fenazina etilsulfato (PES) para imobilizar o mediador na superfície do eletrodo de grafite. Valores menores de potencial para oxidação catalítica de $\mathrm{NADH}$, comparando-se com eletrodos sem modificação foram obtidos com derivados de fenoxazina [29] ou filmes de verde de metileno [30] eletropolimerizados em superfície de pasta de carbono.

Para que uma substância possa ser utilizada como mediador deve preencher alguns requisitos básicos [31] como: proporcionar diminuição 
considerável no sobrepotencial durante a determinação catalítica do analito; possuir grupos funcionais com resistência a efeitos indesejáveis (hidrólise, decomposição, etc); apresentar estabilidade na forma imobilizada e cinética rápida na transferência de elétrons analito/mediador e mediador/eletrodo. Sob o ponto de vista eletroquímico, o mediador deve apresentar comportamento reversível e, de preferência, potencial redox próximo de $0 \mathrm{~V}$, onde, em teoria as interferências são mínimas. Via de regra a catálise não é seletiva a ponto de antecipar apenas o potencial de oxidação do analito. Muitas vezes, o potencial de oxidação dos interferentes também é oxidado, conseqüentemente um estudo sobre os interferentes deve ser feito.

O pré- tratamento anódico de eletrodo de carbono vítreo em tampão fosfato seguido da adsorção de corantes derivados de fenotiazina [32] também apresenta bom efeito catalítico para determinação de NADH. A reação é mais eficiente em solução ácida do que em soluções neutras ou alcalinas devido a decomposição dos mediadores em meio alcalino. Em alguns casos, o pico catalítico é mais positivo do que a oxidação do mediador e um mecanismo de reação similar ao de Michaelis-Menten foi observado. Nesse caso, de acordo do Gorton et al [33,34] e Albery e Bartlett [35], forma-se um complexo intermediário Mediador-NADH, que se comporta similarmente aos complexos enzima-substrato, oxidando-se a potenciais mais positivos do que aqueles correspondentes aos mediadores. Bons resultados foram igualmente obtidos utilizando derivados de fenotiazina [36] e fenoxazina [37] adsorvidos em pasta de carbono ou carbono vítreo [38]. 
A adsorção de fenotiazinas e fenoxazinas em fosfato de zircônio para o desenvolvimento de biossensores como pasta de carbono [39] é igualmente interessante. Neste caso o potencial redox médio para o mediador adsorvido no fosfato de zircônio, ao contrário do observado quando o mesmo encontra-se em solução ou imobilizado apenas em grafite, não variou com a concentração hidrogeniônica do meio. Esta característica é importante para o desenvolvimento de biossensores, uma vez que nem sempre o $\mathrm{pH}$ mais adequado para a catálise enzimática coincide com aquele mais adequado para o bom desempenho do mediador.

A o-toluidina (TBO) incorporada em polímero de estireno também foi utilizada na oxidação de NADH. A maior eficiência catalítica foi observada quando o polímero de estireno foi modificado pela incorporação de carga positiva através da amina quaternária, de modo que a o-toluidina foi incorporada ao polímero através de pontes de fenilmetileno [40].

A utilização de eletrodos modificados com polímeros condutores para oxidação do NADH é muito usual. A atividade catalitica para oxidação do cofator foi obtida em eletrodos modificados com aminofenol [41], politionina [42], polimetaloftalocianinas [43], entre outros compostos. A determinação eletrocatalítica de NADH e NADPH foi igualmente obtida utilizando poli oaminofenol (PPD) e poli o-fenilenodiamina (PAP), como filmes condutores na superfície de eletrodos de pasta de carbono [44]. Os dados voltamétricos sugerem que o comportamento eletrocatalítico está associado com reações químicas entre sítios ativos do filme polimérico e as moléculas de NADH adsorvidas. 
Eletrodos de platina e carbono vitreo com boa resposta para NADH, paracetamol, ácido ascórbico e ácido úrico ainda foram preparados pela eletropolimerização de polímeros não condutores: 1,2-; 1,3-; 1,4diaminobenzeno, ácido-2-pirrol carboxílico e 4,4-diidroxibenzofenona, na presença de metossulfato de fenazina [45].

Na tabela 1.1 encontram-se descritos alguns medidores utilizados na monitoração do NADH, destacando-se o tipo de imobilização, potencial aplicado, tipo de eletrodo e a faixa linear de resposta. 


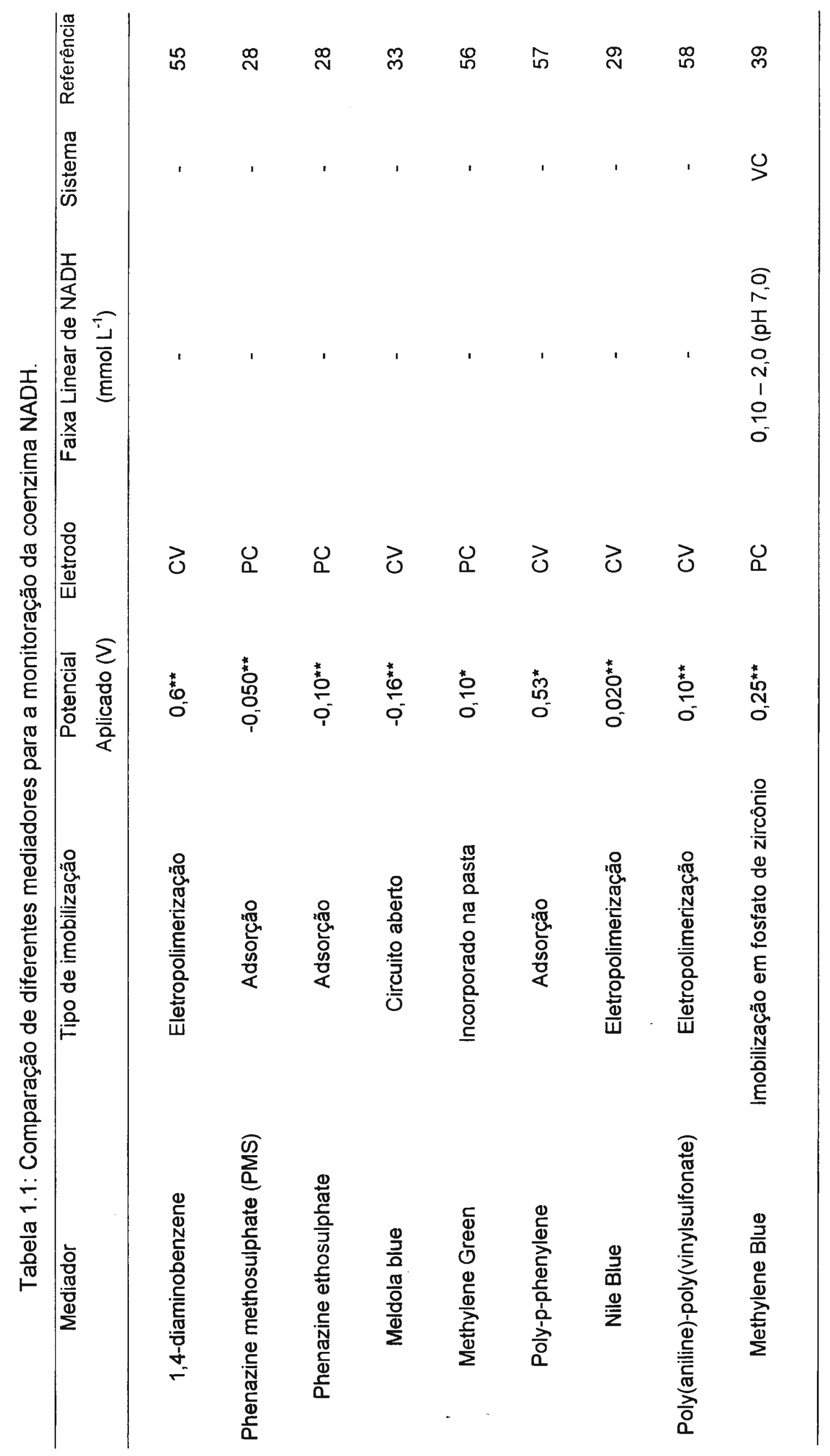




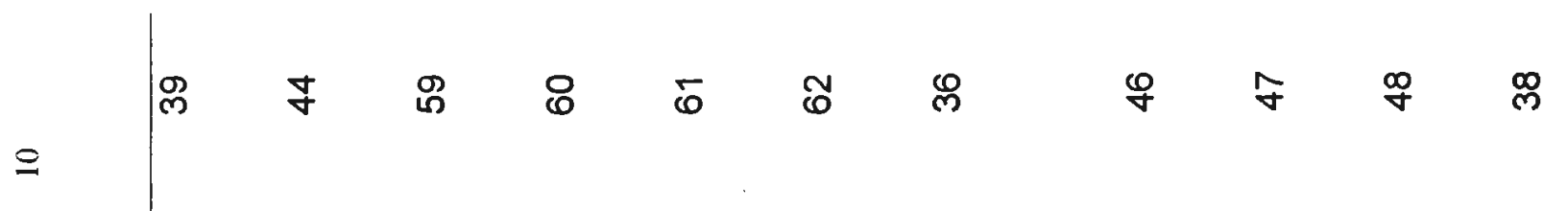

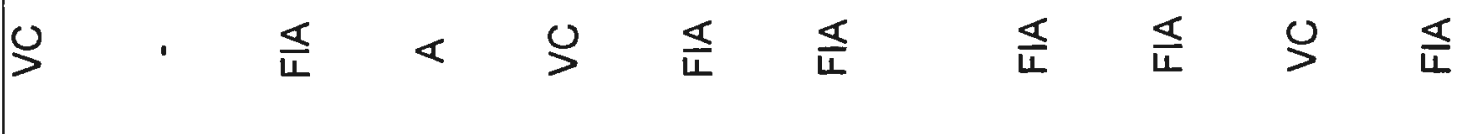

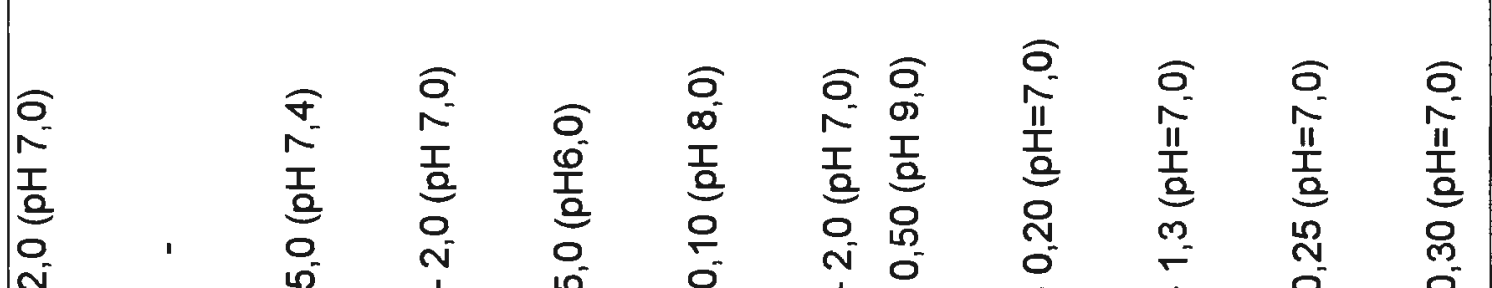

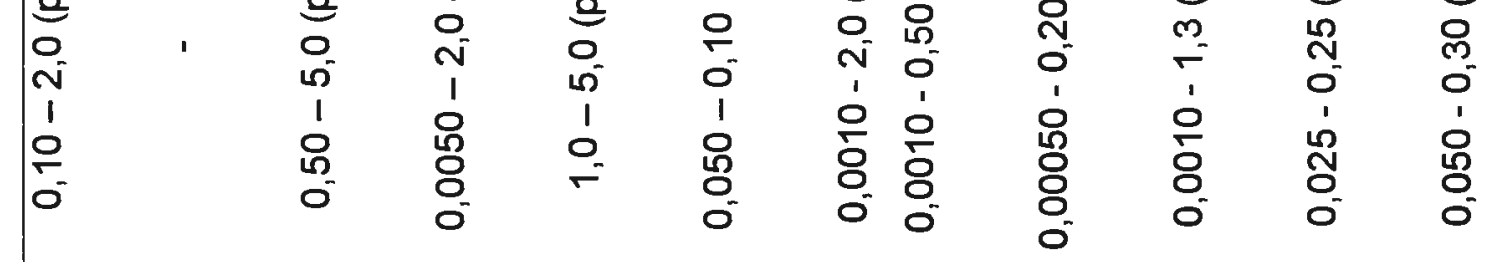

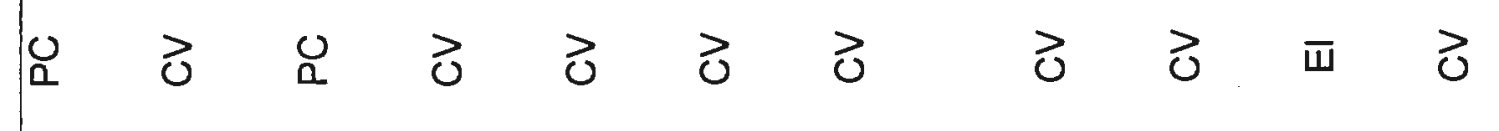

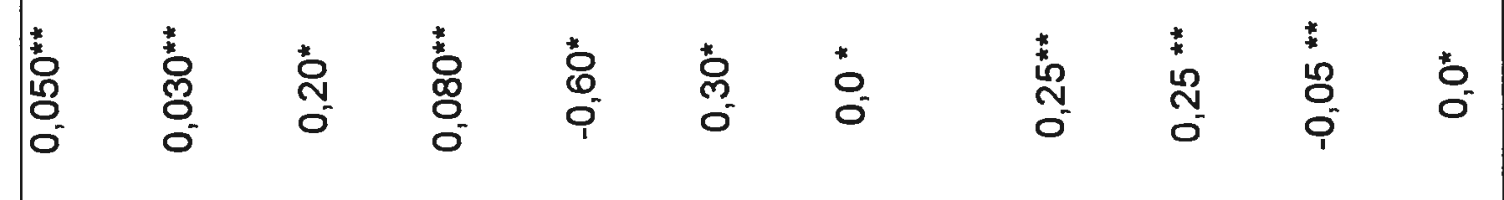

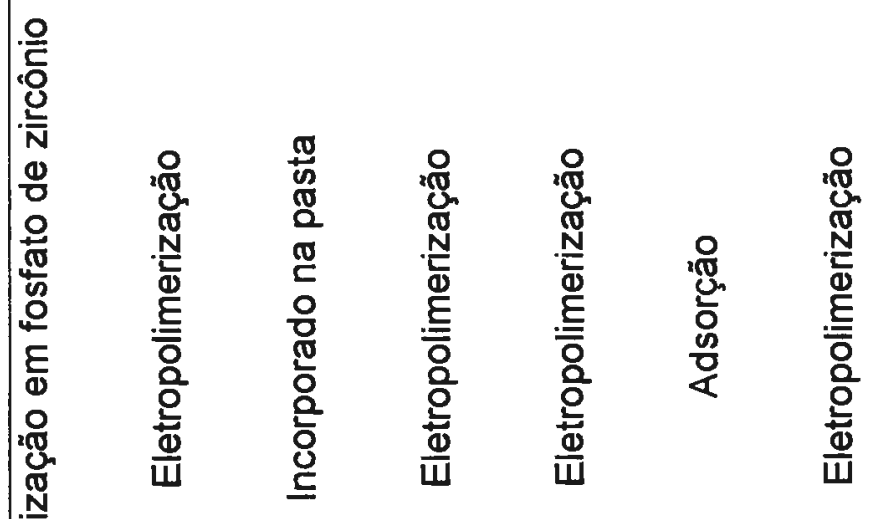

$$
\begin{aligned}
& \text { 产 }
\end{aligned}
$$

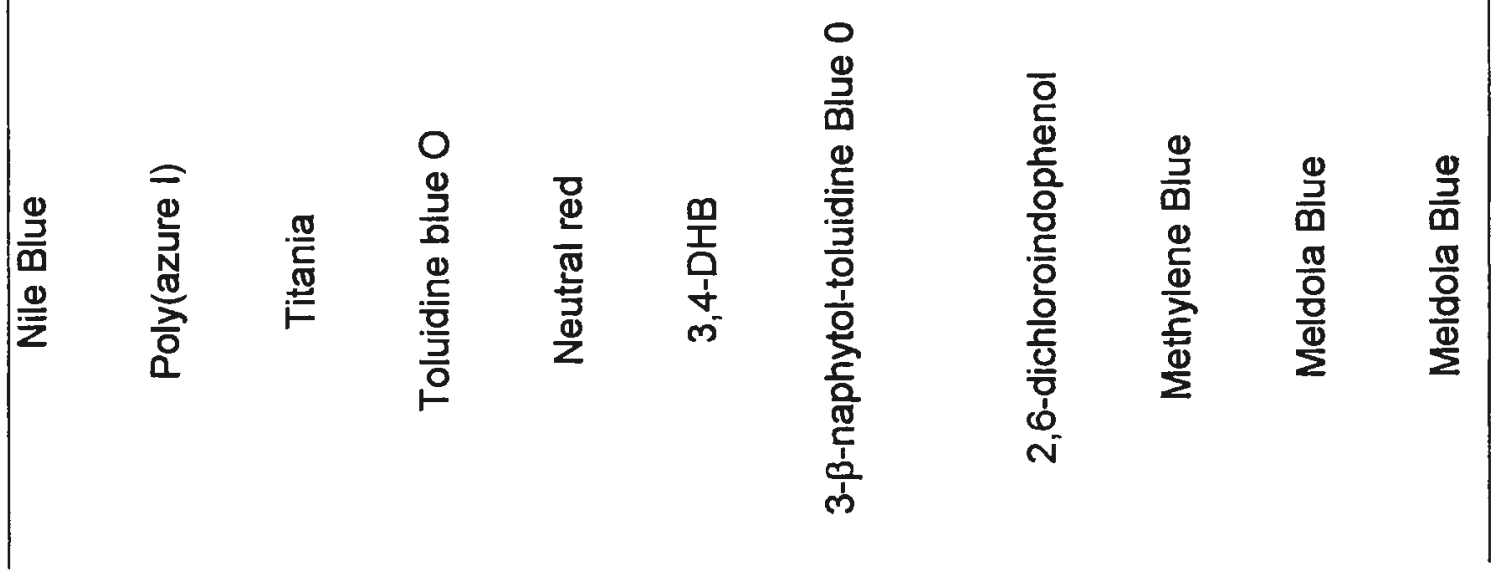




$$
\begin{aligned}
& =\mid \begin{array}{llllll}
9 & \text { in } & 8 & \text { i } & \text { i⿱ } & \text { i⿱ } \\
\varangle & \frac{\pi}{4} & 9 & \frac{\pi}{4} & 9 & \frac{\pi}{4}
\end{array}
\end{aligned}
$$

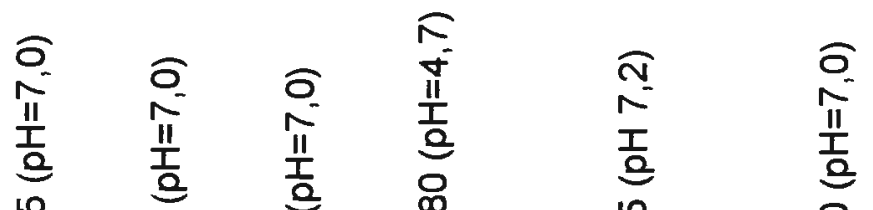

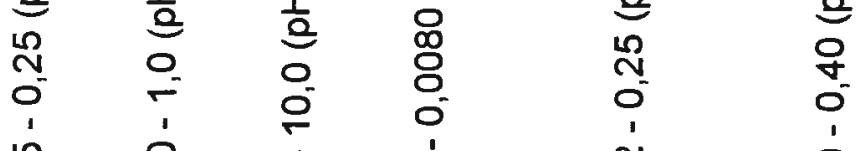

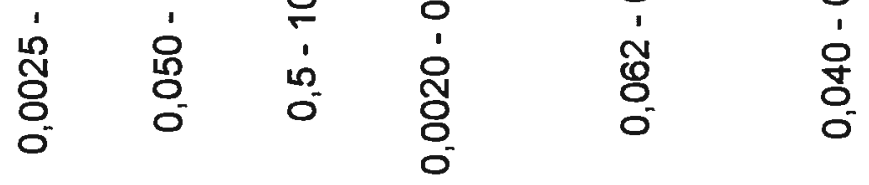

$$
\begin{aligned}
& \begin{array}{llllll} 
& 0 & \ddots & \ddots & \ddots & \ddots
\end{array}
\end{aligned}
$$

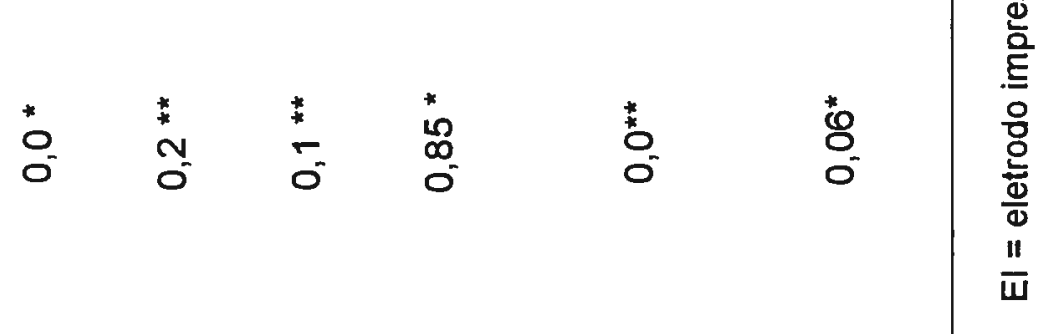

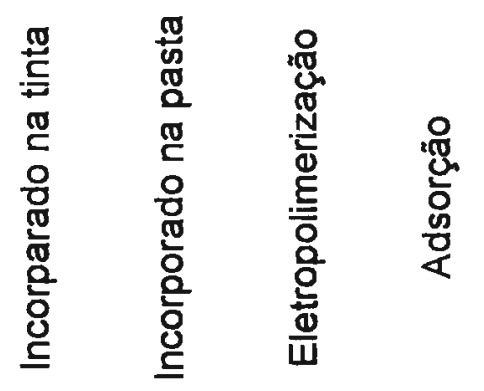

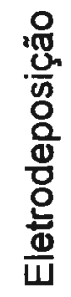

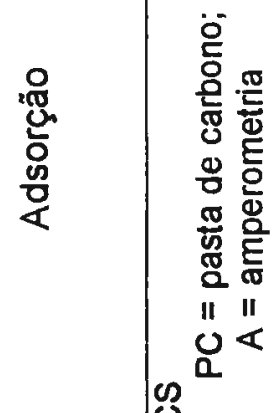

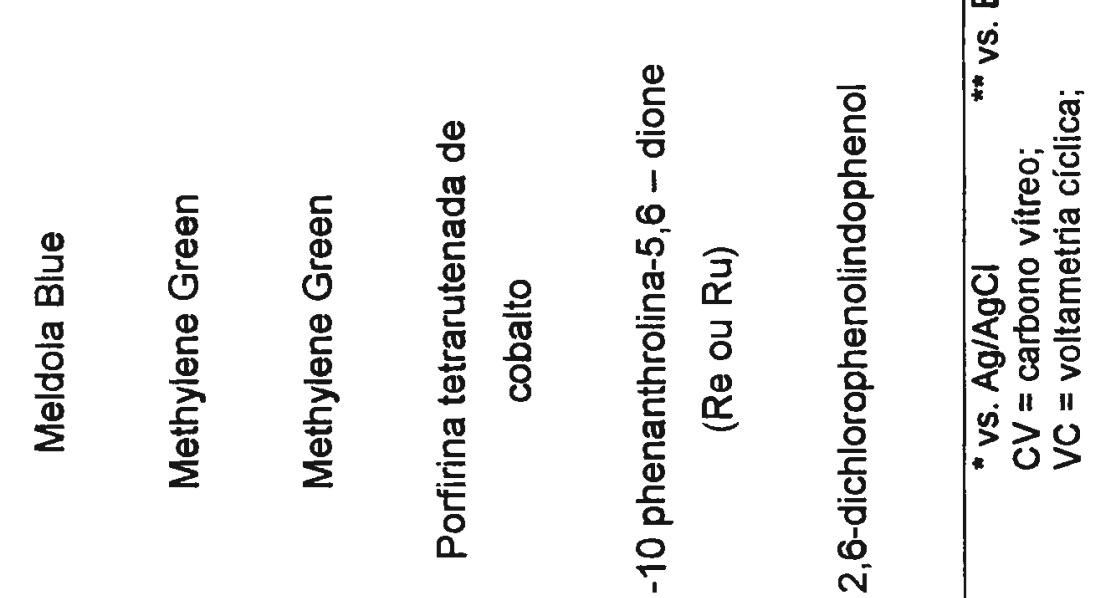




\subsection{Eletrodos de pasta de carbono}

A pasta de carbono é obtida pela mistura do carbono em pó com um agente aglutinante que promove a formação da pasta. As propriedades dos materiais variam muito devido ao tamanho das partículas de grafite, as quais variam de 1 a $20 \mu \mathrm{m}$. Alguns exemplos de tipos de grafite utilizados na preparação de eletrodos, bem como o tamanho de partículas são: Acheson G$38(10-20 \mu \mathrm{m}), \mathrm{UCP}-1-\mathrm{M}$ (ca. $1 \mu \mathrm{m}), \mathrm{RW}-\mathrm{A}(\mathrm{B})(5-10 \mu \mathrm{m})$ e CR (ca. $5 \mu \mathrm{m})$ [63].

O agente aglutinante deve ser eletroinativo, imiscivel na solução estudada e não reagir com o analito. Os agentes aglutinantes mais utilizados são hidrocarbonetos alifáticos (hexano, octano, hexadecano); misturas de hidrocarbonetos (nujol, uvasol), hidrocarbonetos aromáticos (benzeno, naftaleno) e silicone (MS, MSO) [63].

Em eletrodos de pasta de carbono, a pequena corrente de fundo é a maior vantagem em relação aos eletrodos de Pt e Au. Obviamente, a corrente de fundo aumenta com o aumento da percentagem do agente aglutinante causando a diminuição da sensibilidade do eletrodo, devido ao aumento da resistência ôhmica do material. A corrente de fundo é determinada pela área ativa do grafite, enquanto que a corrente faradaica é proporcional a área total do eletrodo e concentração da espécie ativa em solução [64]. Tem-se também, em eletrodos de pasta de carbono, a vantagem da facilidade de renovação da superfície. 


\subsection{Considerações eletroquímicas}

Quando se faz uso de técnicas como voltametria de varredura linear e a voltametria cíclica, o valor do parâmetro $\left(E_{p}-E_{p / 2}\right)$, sendo $E_{p}$ o potencial de pico e $E_{p / 2}$ potencial de pico à meia altura da corrente de pico, pode ser utilizado como um dos critérios para identificar o tipo de sistema em estudo. Para sistemas reversiveis tem-se:

$$
\left|E_{p}-E_{p / 2}\right|=2,2 R T / n F=(0,0567 / n) \quad V
$$

sendo:

$T=$ temperatura em Kelvin

$\mathrm{F}=$ constante de Faraday $(96485 \mathrm{C} / \mathrm{mol})$

$\mathrm{n}$ = número de elétrons envolvidos no processo eletroquímico

Na majoria dos casos em que o processo eletródico envolve compostos orgânicos, os potenciais de pico são dependentes do $\mathrm{pH}$ do meio. Para processos reversiveis e irreversiveis, a variação dos potenciais de pico como função de pH, é dada por [66].

$$
\Delta \mathrm{Ep} / \Delta \mathrm{pH}=0,0592 \mathrm{p} / \mathrm{n} \quad\left(25^{\circ} \mathrm{C} \text { e processo reversivel }\right)
$$

$$
\Delta \mathrm{Ep} / \Delta \mathrm{pH}=0,0592 \mathrm{p} / \alpha \mathrm{n}\left(25^{\circ} \mathrm{C} \text { e processo irreversivel }\right)
$$

sendo $p$ o número de prótons envolvidos no processo eletródico e $\alpha$ o coeficiente de transferência de carga.

Quando eletrodos quimicamente modificados são utilizados como eletrodos de trabalho, pode-se estimar a concentração superficial ou excesso 
superficial do agente modificador que recobre a superficie do eletrodo a partir da integração da área sob o pico de oxidação ou redução, obtido em um voltamograma registrado com o sensor modificado (em eletrólito suporte), de acordo com [54].

A concentração superficial $\left(\Gamma=\mathrm{mol} \mathrm{cm}^{-2}\right)$ é dado por:

$$
\Gamma=\mathrm{Q} / \mathrm{nFA}=\int \mathrm{jid} / \mathrm{nFA}
$$

sendo, $Q$ a carga, $n$ o número de elétrons envolvidos no processo, $F$ a constante de Faraday e A, a área do eletrodo $\mathrm{em}^{\mathrm{cm}^{2}}$.

\subsection{Considerações sobre sistema de análise de injeção em fluxo} (FIA)

A análise química por injeção em fluxo contínuo pode ser definida como um processo de automatização de procedimentos analíticos, no qual a amostra em solução é injetada em um fluxo transportador, sendo transportada até o detector. Este último registra o sinal de corrente, absorbância ou outro parâmetro de interesse, devido a passagem da amostra pelo detector.

O registro é um pico cuja área ou altura é proporcional à concentração da amostra. Geralmente, por questão de facilidade trabalha-se com a altura dos picos.

A propulsão dos fluídos pode ser efetuada à vazão ou pressão constantes. Quando o sistema de análise trabalha à vazão constante, o meio 
mais empregado para movimentar o fluido transportador e as soluções dos reagentes é a bomba peristáltica. Esta deve possuir torque suficiente para manter a vazão constante, mesmo que ocorram variações na impedância hidrodinâmica do sistema. A impedância hidrodinâmica aumenta com o comprimento do percurso analítico, com a viscosidade das soluções e com a diminuição do diâmetro interno da tubulação. Define-se percurso analítico, como o espaço percorrido pela amostra desde o ponto de injeção até a célula de deteç̧ão [68].

Durante o transporte, a amostra se dispersa continuamente no fluído transportador, gerando um gradiente de concentração no percurso analítico. A eficiência de um sistema FIA pode ser acompanhada por meio do coeficiente de dispersão. O coeficiente de dispersão fornece a informação de quanto a solução amostra original é diluída no fluxo durante o percurso entre a injeção da amostra e a detecção, como ilustrado na figura 1.2.

Desta forma, o coeficiente de dispersão (D) refere-se à razão entre a concentração original da amostra $\left(C^{\circ}\right)$ e concentração após o processo de dispersão $\left(C^{\text {máx }}\right)$.

$$
D=C^{\circ} / C^{\text {máx }}
$$

Considera-se que valores de coeficiente de dispersão abaixo de 3 indicam sistemas com baixas dispersões, de 3 a 10 com dispersão média e maiores de 10 com dispersão elevadas [69].

Os fatores que influenciam a dispersão da zona de amostra em sistema em fluxo incluem as dimensões e configurações dos canais condutores do 
sistema (percurso analítico), as vazões dos carregadores, volume de amostra injetado, a temperatura e viscosidade [70]. Sob condições normais, os dois últimos fatores têm efeito bastante limitado na dispersão e na maioria dos casos, podem ser negligenciados.

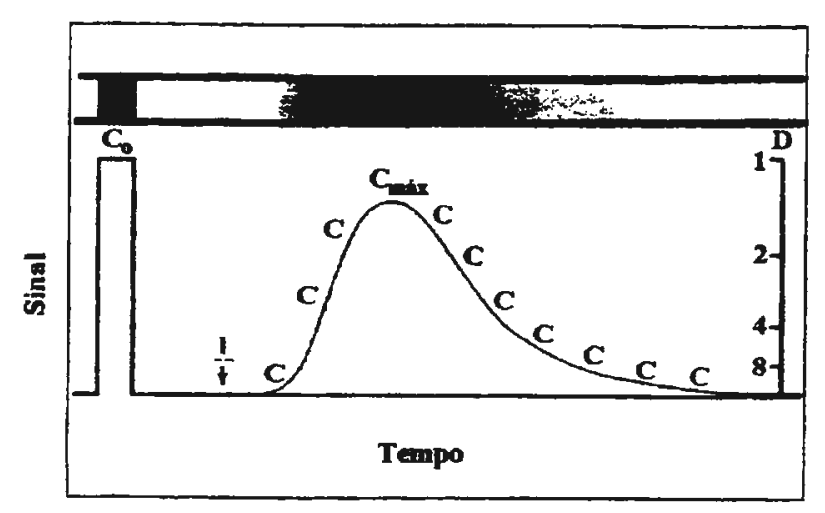

Figura 1.2: Representação esquemática do coeficiente de dispersão (D) de um sistema FIA. A zona de amostra original se dispersa durante o movimento em um reator tubular (no topo da figura), originando o perfil da curva (no centro da figura), no qual a concentração original, $C^{\circ}$, evolui para um gradiente de concentração com valor máximo, $\mathrm{C}^{\text {máx }}$, no ápice do pico [69].

O efeito da geometria dos canais condutores dos sistemas em fluxo sobre o coeficiente de dispersão é mais complexo. A geometria dos reatores comumente utilizadas em sistemas FIA são apresentadas na figura a seguir. 


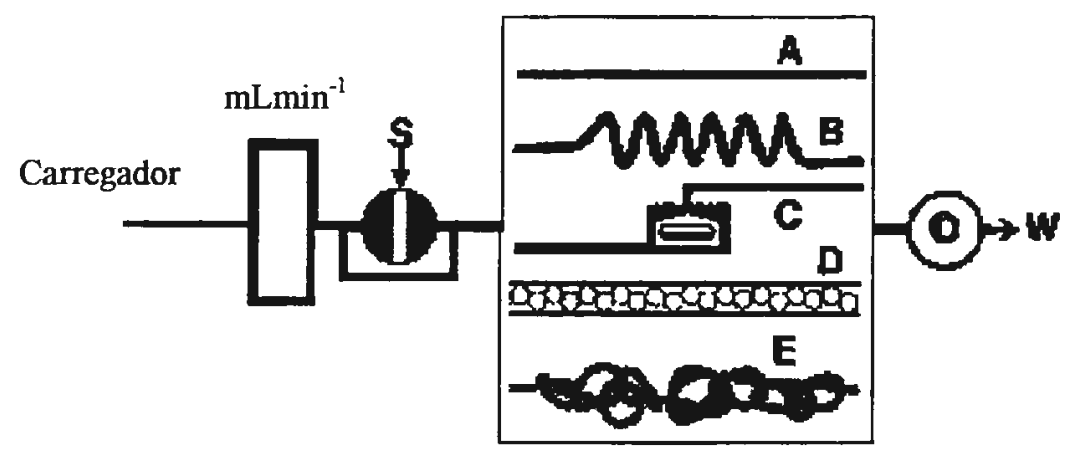

Figura 1.3: Geometria dos reatores de misturas mais freqüentemente utilizados em sistemas FIA: (A) tubo linear, (B) tubo em espiral, (C) câmara de mistura, (D) reator contendo uma fileira de esferas e $(E)$ reator em formato de malha. $O$ detector é indicado por (O) [69].

Segundo Ruzicka e Hansen [69] a dispersão da zona da amostra aumenta com a raiz quadrada da distância percorrida através do conduto tubular. Contudo, isto é válido quando o conduto é linear $(A)$, no caso de configurações espirais (B), este efeito é menos pronunciado devido ao desenvolvimento de um fluxo secundário que promove uma dispersão radial e limita a dispersão axial. Um tubo em espiral é a geometria de reator mais freqüentemente utilizada em FIA, pois além de promover uma mistura na direção radial, permite que um tubo longo possa ser convenientemente acomodado no sistema. Neste caso, os resultados são picos mais simétricos e maiores do que os obtidos com reator tubular linear com mesmas dimensões.

As câmaras de mistura (C) aumentam significantemente a dispersão do sistema, diminuindo a altura do pico (sinal de resposta), alargando-o. Este tipo 
de módulo de mistura é desaconselhável para sistemas em que a elevada freqüência de amostragem é prioritária ou pretende-se determinar baixas concentrações do analito. O reator cujo tubo é preenchido por pequenas esferas (D) é bastante útil, pois promove uma mistura radial no reator tubular, além de possuir maior relação superfície / líquido do que a observada no reator linear. Isto é vantajoso quando uma elevada interação superfície/líquido é desejada, como quando utilizam-se reagentes e enzimas imobilizadas, reatores empacotados, etc. Uma desvantagem é que bolhas de ar e partículas sólidas podem se acumular no reator.

O reator em configuração de malha $(E)$ também promove uma dispersão radial, resultante do movimento caótico do fluxo através do conduto desordenado. Na figura 1.4 o efeito das configurações dos reatores $A, B, C$ e D sobre a dispersão da amostra foi ilustrada.

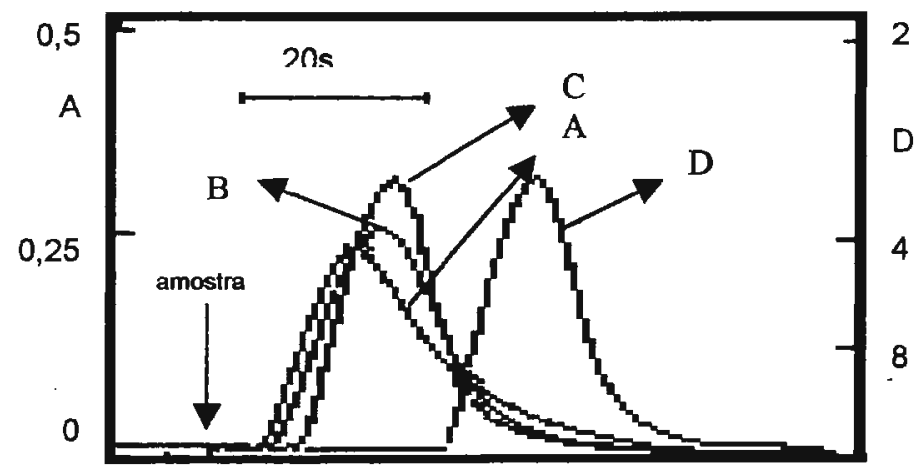

Tempo

Figura 1.4: Efeito de reatores de mistura sobre a dispersão da amostra em sistema FIA: (A) tubo linear; (B) tubo espiral, (D) reator contendo uma fileira de esferas, (C) reator em formato de malha. Nos eixos: $A=$ Absorbância $e$ $D=$ coeficiente de dispersão [69] 
Estudos sobre a influência do diâmetro interno do tubo sobre a dispersão indicaram que em faixa entre 0,35 a $0,9 \mathrm{~mm}$, este parâmetro não é crítico, levando a variações no valor do coeficiente de dispersão entre 3,0 e 3,8 [69]. Já em relação a vazão, pode-se afirmar que a dispersão diminui com o aumento da vazão do sistema em fluxo. Porém esta afirmação somente é correta para vazões baixas, em que a velocidade de difusão aproxima-se a velocidade de convecção gerada pelo fluxo.

A variação do volume da amostra injetado é um caminho muito conveniente para manipular a dispersão da amostra no sistema e é um dos fatores estudados freqüentemente. $O$ volume da amostra empregado na determinação do analito, é definido pelo comprimento de alça de amostragem. Aumentando-se o comprimento da alça aumenta-se o sinal gerado no detetor [68]. No entanto, o aumento do sinal com o aumento do volume da alça de amostragem tende a um limite máximo. O valor máximo do pico corresponde à situação de dispersão mínima obtida quando o fluído transportador é substituído pela amostra. Diz-se, então, que a amostra está em volume infinito [68]. O limite superior de volume de amostra injetada que é utilizado para manipulação, em geral, encontra-se na faixa de 100 a $200 \mu \mathrm{L}$. Volumes de amostras maiores podem ser utilizados, com algum sacrifício da freqüência de amostragem, quando pequenas dispersões ou elevadas sensibilidades são desejadas. O limite inferior de volume de amostra injetado é determinado pelo tipo de injetor utilizado, mas geralmente situa-se na faixa de 10 a $30 \mu \mathrm{L}$ [69].

Dentre as diversas técnicas eletroquímicas, a amperometria associada a processo FIA é bastante atraente. Baseia-se na medida de corrente produzida 
no eletrodo a um potencial aplicado constante. Os resultados obtidos são picos de corrente em função do tempo. Realiza-se uma medida diferencial entre o sinal (corrente) de fundo produzida pelo transportador (geralmente baixa, oriunda de pequenas quantidade de impurezas) e os picos produzidos pela passagem do analito no detector. Nesta modalidade de análise, estudos voltamétricos prévios são imprescindiveis para selecionar o potencial de oxidação ou redução adequado ao trabalho.

Uma grande vantagem da técnica amperométrica é obtenção de um baixo sinal de corrente residual, pois mantendo o potencial do eletrodo fixo em um mesmo valor, a corrente capacitiva (resultante do carregamento da dupla camada elétrica do eletrodo) torna-se constante. Via de regra, é recomendável que se utilize uma concentração relativamente elevada de eletrólito inerte, que deverá ser igual no transportador e na amostra a ser analisada, de forma que esta última, ao ser injetada, provoque variações pouco significativas na carga da dupla camada elétrica, garantindo que o sinal transiente registrado possa ser atribuído ao sinal faradaico. 


\subsection{Objetivos}

Como a faixa de potencial aplicado para formação dos filmes é relativamente baixa, a possibilidade de incorporar enzimas ou ainda co-fatores, durante o processo de eletropolimerização seria uma alternativa altamente interessante para construção de biossensores. No entanto, se o processo de formação dos filmes envolver formação de radicais livres, esta possibilidade deve ser descartada, uma vez que o centro ativo das enzimas não seria preservado. Além disto, os co-fatores como NADH e NADPH poderiam atuar como agentes seqüestrantes de radicais livres, inibindo a formação dos filmes.

O objetivo deste trabalho foi então estudar o mecanismo de eletropolimerização do 3,4-DHB com vista à preparação futura de biossensores. 


\section{PARTE EXPERIMENTAL}

\subsection{Equipamentos utilizados}

As medidas experimentais foram realizadas utilizando-se 0 potenciostato/galvonostato da Eco Chemie, Autolab, modelo PGSTAT 20, acoplado ao software GPES 3, versão 4.3.

As leituras de $\mathrm{pH}$ foram efetuadas utilizando-se o pHmetro modelo $654 \mathrm{e}$ um eletrodo de vidro combinado 6.0205.100 ( OE ), ambos da Metrohm.

A bomba peristáltica Gilson modelo Minipuls 3 foi utilizada no sistema de análise por injeção em fluxo ( FIA ).

\subsection{Reagentes e soluções}

$\mathrm{NADHNa}_{2}$ (124644); $\mathrm{NADPHNa}_{4}$ (CAS 2646-71-1); NaOH (106498); $\mathrm{NaNO}_{3}(106537) ; \mathrm{Na}_{2} \mathrm{HPO}_{4}$ (106586) e ácido cítrico (100241) foram adquiridos da Merck; PIPES (5625-37-6) da Alfa AESAR; 3,4-diidroxibenzaldeído (3,4DHB) $(\mathrm{D} 10,840-5)$ e óleo mineral nujol (16140-3) da Aldrich Chemical Co e grafite Acheson 38 da Fisher.

Todos os reagentes foram utilizados sem nenhuma purificação prévia. 
A solução tampão PIPES $0,1 \mathrm{~mol} \mathrm{~L}^{-1}$ foi preparada adicionando se solução de hidróxido de sódio $0,5 \mathrm{~mol} \mathrm{~L}^{-1}$ ao sal previamente pesado até obtenção de $\mathrm{pH}$ 6,8. A força iônica foi então ajustada para $0,3 \mathrm{~mol} \mathrm{~L}^{-1} \mathrm{com}$ a adição de nitrato de sódio e a seguir completou-se o volume da solução com água deionizada.

Todas as soluções foram preparadas por dissolução de quantidade apropriada dos sais em água deionizada proveniente de um purificador Nanopure, da Barnstead. As soluções de NADH e NADPH foram preparadas em solução tampão PIPES, enquanto a solução de 3,4-DHB utilizada para modificação dos eletrodos, foi preparada em solução de tampão fosfato à temperatura de $12^{\circ} \mathrm{C}$.

As demais soluções tampão foram preparadas como descrito na referência [71].

\subsection{Sistema de eletrodos}

Utilizou-se um sistema de três eletrodos, sendo o eletrodo de referência $\mathrm{Ag} / \mathrm{AgCl}(\mathrm{KCl}$ sat.) e Pt o auxiliar. O eletrodo de trabalho utilizado foi pasta de carbono modificado com 3,4-DHB. A pasta de carbono foi preparada misturando-se grafite (previamente aquecido a $150^{\circ} \mathrm{C}$ por pelo menos 2 horas) com óleo nujol na razão de 2:1 (grafite : nujol). 


\subsection{Preparação do eletrodo auxiliar de Pt}

O eletrodo auxiliar foi construído pela soldagem de um fio de platina a um fio de $\mathrm{Ni}-\mathrm{Cr}$, utilizando-se um suporte de vidro como corpo para o eletrodo (Figura 2.1).

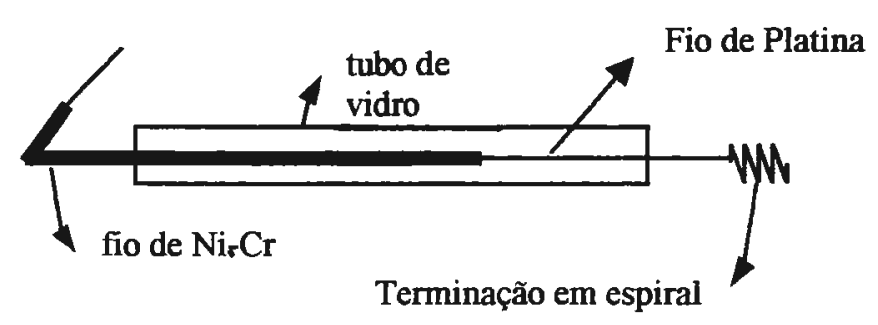

Figura 2.1 - Eletrodo auxiliar.

\subsection{Preparação do eletrodo de referência $(\mathrm{Ag} / \mathrm{AgCl})$}

O eletrodo de referência foi preparado por um dos procedimentos descritos abaixo:

A) O fio de prata foi lixado para a remoção de óxidos, lavado com etanol para a retirada de gordura e imerso com demais eletrodos (referência e auxiliar) em solução de ácido clorídrico $10^{-3} \mathrm{mmol} \mathrm{L}^{-1}$. O AgCl foi precipitado na superfície do eletrodo por oxidação do fio de prata a $8 \mathrm{mV}$ vs. $\mathrm{Ag} / \mathrm{AgCl}, \mathrm{KCl}$ sat. por $700 s$.

B ) O fio de prata, previamente lixado e lavado foi mergulhado em sal de cloreto de prata fundido. 
A montagem do eletrodo (Figura 2.2) foi efetuada como descrito por Pedrotti et al. [72].

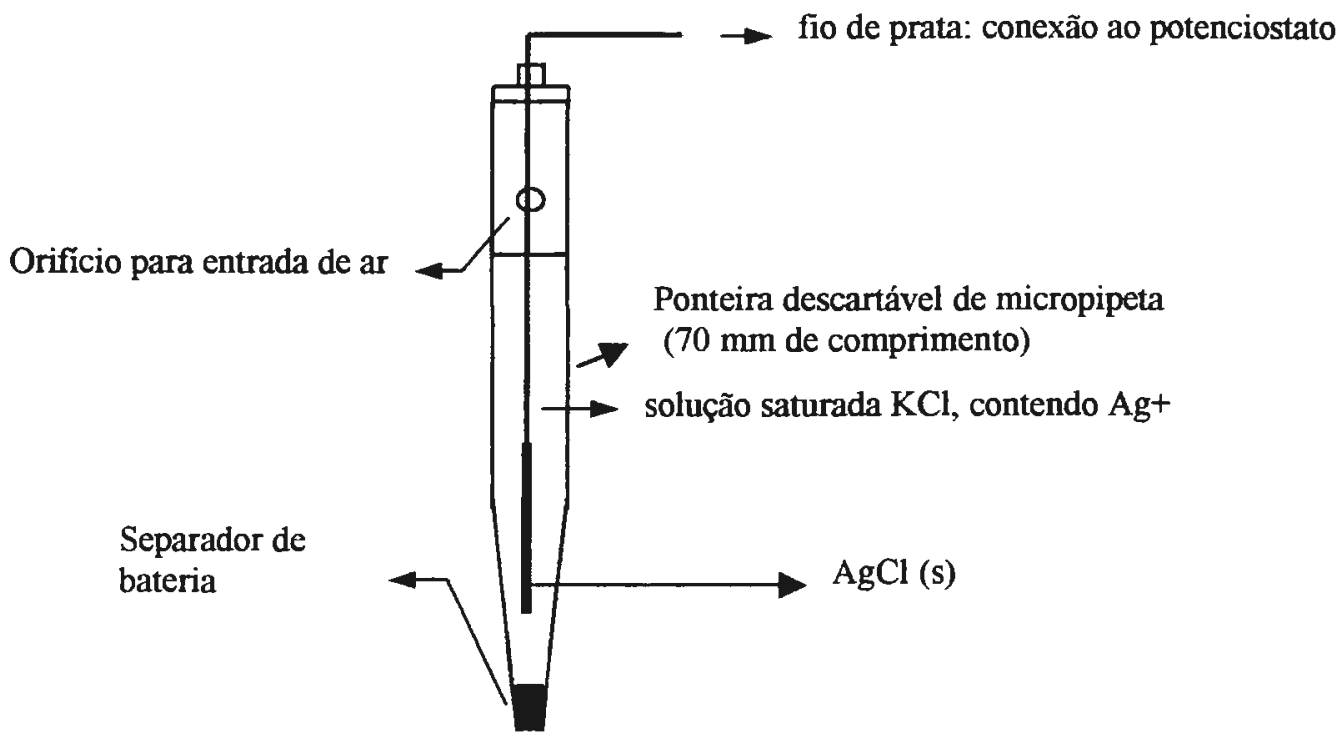

Figura 2.2 - Esquema representativo do eletrodo de referência utilizado (Ag/AgCl).

\subsubsection{Verificação da reversibilidade do eletrodo de referência}

$\mathrm{Na}$ célula eletroquímica contendo solução $3 \mathrm{mmol} \mathrm{L}^{-1}$ de $\mathrm{KCl}$, foram imersos três eletrodos: eletrodo de calomelano saturado; $\mathrm{Ag} / \mathrm{AgCl}, \mathrm{KCl}$ sat. (eletrodo a ser testado) e Pt (contra eletrodo). Efetuaram-se voltamogramas cíclicos na faixa de $-1,0 \mathrm{~V}$ a $1,0 \mathrm{~V}$, com velocidade de varredura $50 \mathrm{mVs}^{-1}$. Obteve-se variação linear sobreposta de corrente como função do potencial no sentido direto e inverso da varredura, o que indicou a reversibilidade do 
eletrodo, demonstrando o bom funcionamento do mesmo na faixa de trabalho testada [73].

\subsection{Preparação dos eletrodos de pasta de carbono}

O eletrodo de trabalho foi construído no próprio laboratório constituindose de um cilindro de cobre de $90 \mathrm{~mm}$ de comprimento por $3 \mathrm{~mm}$ de diâmetro (que tem a função de contato elétrico), envolto por um tubo de PVC de $75 \mathrm{~mm}$ de comprimento por $6 \mathrm{~mm}$ de diâmetro externo e $4 \mathrm{~mm}$ de diâmetro interno, com uma parede de $1 \mathrm{~mm}$ de espessura. A fio de cobre foi introduzida no interior do tubo de PVC por uma das extremidades até cerca de $1 \mathrm{~mm}$ da outra extremidade do tubo. Para vedação e fixação do fio de cobre ao tubo de PVC preencheu-se o espaço entre os mesmos com uma camada de cola Araldite. Após a secagem da cola, a pasta de carbono foi introduzida na cavidade formada entre a extremidade do fio de cobre e o tubo de PVC (Figura 2.3). 


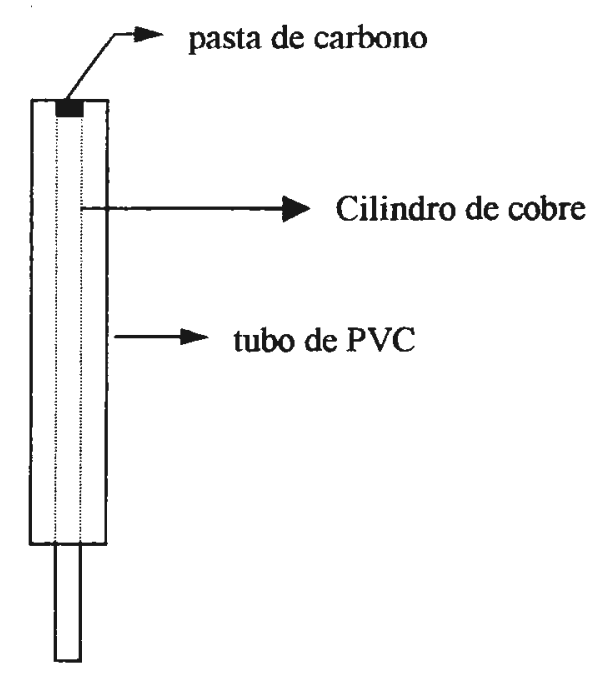

Figura 2.3 - Eletrodo de trabalho de pasta de carbono (área $=0,070 \mathrm{~cm}^{2}$ ).

2.7 Preparação dos eletrodos de trabalho modificados com filmes eletropolimerizados de 3,4-diidroxibenzaldeído (3,4-DHB) obtidos por voltametria cíclica e deposição a potencial controlado.

2.7.1 Pré tratamento e ativação da superfície do eletrodo de pasta de carbono em solução de $\mathrm{NaOH}$

Antes da modificação em solução de 3,4-DHB, efetuou-se pré tratamento eletroquímico do eletrodo de trabalho em solução de $1,0 \mathrm{~mol} \mathrm{~L}^{-1}$ de $\mathrm{NaOH}$ por aplicação de $+1,2 \vee$ por 5 min. Em seguida, efetuaram-se 6 
voltamogramas cíclicos em tampão fosfato (no pH em estudo) como descrito por Pariente et al. [20,62].

2.7.2 Escolha da faixa de potencial de ciclagem para formação de filmes por voltametria cíclica

Voltamogramas cíclicos foram registrados em solução $0,5 \mathrm{mmol} \mathrm{L}^{-1}$ de 3,4-DHB no intervalo de $-0,2 \leq \mathrm{E}_{\text {aplicado }} \leq 1,0 \mathrm{~V}$ e velocidade de varredura $50 \mathrm{mVs}^{-1}$ para os seguintes valores de $\mathrm{pH} 2,6 ; 3,6 ; 4,6 ; 6,6 ; 7,8$ e 10,2 Neste intervalo foram observados dois picos de oxidação $\left(E p_{a, 1}\right.$ e $\left.E p_{a, 2}\right)$ e dois picos de redução $\left(E p_{c, 1}\right.$ e $\left.E p_{c, 2}\right)$, os quais foram utilizados para fixar o intervalo de varredura e fixar o potencial de deposição para filmes formados a potencial controlado.

Independentemente do método empregado para preparação dos eletrodos modificados, estes foram lavados com água deionizada e a estabilidade dos filmes foi avaliada em eletrólito suporte (tampão fosfato, no mesmo $\mathrm{pH}$ em que o filme foi formado). Para tanto, efetuaram-se 10 ou 20 voltamogramas cíclicos, acompanhando-se a percentagem de perda de filme ativo durante ciclagens consecutivas empregando velocidade de varredura de $50 \mathrm{mVs}^{-1}$

Para filmes formados no intervalo de varredura descrito na tabela 2.1 ou potenciais aplicados descritos na tabela 2.2, a estabilidade dos filmes foi 
avaliada em tampão PIPES, $\mathrm{pH} 6,8$, no intervalo de $0 \leq E_{\text {aplicado }} \leq 0,32 \mathrm{~V}$, efetuando-se 20 ou 100 voltamogramas cíclicos com velocidade de varredura de $50 \mathrm{mVs}^{-1}$.

2.7.3 Avaliação da influência do potencial anódico de inversão de varredura, velocidade de varredura, número de ciclos e concentração da solução de 3,4-DHB na estabilidade de filmes formados por voltametria cíclica

2.7.3.1 Modificação dos eletrodos de pasta de carbono em solução de 3,4-DHB utilizando voltametria cíclica em diversos valores de $\mathrm{pH}$

Os filmes foram formados por ciclagem em solução $0,5 \mathrm{mmol} \mathrm{L}^{-1}$ de 3,4-DHB nos seguintes valores de $\mathrm{pH}: 2,6 ; 3,6 ; 4,6 ; 6,6 ; 7,8$ e 10,2, no intervalo de potencial de $\left(E p_{c, 1}-150 \mathrm{mV}\right) \leq E_{\text {aplicado }} \leq\left(E p_{\mathrm{a}, 2}+150 \mathrm{mV}\right)$. O número de ciclos registrados foi inicialmente estipulado em 10, que corresponde ao tempo de 3 minutos de formação com velocidade de varredura de $50 \mathrm{mVs}^{-1}$. 
2.7.3.2 Avaliação da influência do potencial anódico de inversão de varredura na estabilidade dos filmes eletropolimerizados

Diferentemente do procedimento adotado inicialmente no ítem 2.8.1, fixou-se o potencial aplicado no intervalo de $\left(E p_{c, 1}-150 \mathrm{mV}\right) \leq E_{\text {aplicado }} \leq\left(E p_{a, 1}\right.$ $+70 \mathrm{mV}$ ), utilizando-se soluções $0,5 \mathrm{mmol} \mathrm{L}^{-1}$ de 3,4-DHB em pH 7,8. Foram efetuados 10 voltamogramas cíclicos utilizando-se a velocidade de varredura $50 \mathrm{mV} \mathrm{s}^{-1}$. Avaliou-se deste modo, a influência do segundo pico de oxidação na estabilidade dos filmes formados.

Avaliou-se também, se a inversão do potencial de varredura deveria ser efetuada logo após o término do primeiro processo de oxidação (Tabela 2.1 B) ou no início do segundo processo de oxidação (Tabela 2.1 A).

Tabela 2.1: Intervalos de varredura utilizados para obtenção de filmes por ciclagem.

\begin{tabular}{ccc}
$\mathrm{pH}$ & Intervalo de varredura & Intervalo de varredura \\
& ( V ) & ( V ) \\
& A & B \\
\hline 3,6 & $0,20 \leq \mathrm{E} \leq 0,48$ & $0,23 \leq \mathrm{E} \leq 0,42$ \\
4,6 & $0,17 \leq \mathrm{E} \leq 0,44$ & $0,20 \leq \mathrm{E} \leq 0,38$ \\
6,6 & $0,050 \leq \mathrm{E} \leq 0,32$ & $0,070 \leq \mathrm{E} \leq 0,26$ \\
7,8 & $0,0 \leq \mathrm{E} \leq 0,25$ & $0,020 \leq \mathrm{E} \leq 0,20$
\end{tabular}


Com este procedimento estipulou-se a faixa de potencial aplicado que produzia filmes com maior estabilidade.

\subsubsection{Influência da velocidade de varredura}

Os filmes foram formados em diferentes velocidades de varredura: $5 ; 10$; 25; $50 ; 75$ e $100 \mathrm{mV} \mathrm{s}^{-1}$ em soluçōes $0,5 \mathrm{mmol} \mathrm{L}^{-1}$ de 3,4-DHB, pH 7,8 e intervalo de varredura de $0,0 \leq E_{\text {aplicado }} \leq 0,25 \mathrm{~V}$, efetuando-se 10 voltamogramas cíclicos.

\subsubsection{Influência do número de ciclos}

Os filmes foram formados com $5 ; 10 ; 15$ ou 20 voltamogramas cíclicos registrados em soluções $0,5 \mathrm{mmol}^{-1}$ de $3,4-\mathrm{DHB}, \mathrm{pH} 7,8$, intervalo de varredura de $0,0 \leq E_{\text {aplicado }} \leq 0,25 \vee$ e velocidade de varredura de $10 \mathrm{mV} \mathrm{s}^{-1}$.

\subsubsection{Influência da concentração da solução de 3,4-DHB}

Os filmes foram formados em soluções com diferentes concentrações de 3,4-DHB: 0,$25 ; 0,56 ; 0,90 \mathrm{mmol} \mathrm{L}^{-1} \mathrm{em} \mathrm{pH} 7,8$, intervalo de varredura de 
$0,0 \leq E_{\text {aplicado }} \leq 0,25 V$ e velocidade de varredura $10 \mathrm{mV} \mathrm{s}^{-1}$, efetuando-se 10 voltamogramas cíclicos.

\subsubsection{Eletrodos de pasta de carbono modificados em solução de}

\section{3,4-DHB por deposição a potencial controlado}

Os filmes de 3,4-DHB, obtidos a potencial controlado, foram formados a partir de soluções de $0,25 \mathrm{mmol} \mathrm{L}^{-1}$ de 3,4-DHB, em diferentes valores de $\mathrm{pH}$. O potencial foi fixado em um dos dois valores ( A ) ou ( B ) apresentados na tabela 2.2. O tempo para aplicação do potencial foi de 3 minutos, quando o potencial foi fixado no início do segundo processo eletródico (Tabela 2.2 A). No caso em que o potencial foi fixado no término do primeiro processo eletródico, o tempo de aplicação do potencial foi de 3 elou 6 minutos (Tabela 2.2 B).

Tabela 2.2 : Valores dos potenciais fixados para a formação do filme de 3,4DHB.

\begin{tabular}{ccc}
$\mathrm{pH}$ & $\begin{array}{c}\text { Potencial fixado ( V ) } \\
3 \text { minutos }\end{array}$ & $\begin{array}{c}\text { Potencial fixado ( V ) } \\
3 \text { minutos / 6 minutos }\end{array}$ \\
& ( A) & ( B ) \\
\hline 3,6 & 0,46 & 0,42 \\
6,6 & 0,42 & 0,38 \\
7,6 & 0,30 & 0,26 \\
\hline
\end{tabular}


2.8 Influência da forma de armazenamento no desempenho analítico dos sensores

Os eletrodos, preparados nas condições otimizadas de formação dos filmes, foram utilizados na determinação de NADH durante 3 dias (no dia em que foram preparados, no dia seguinte e após 3 dias do preparo), tendo sido armazenados em solução de tampão fosfato $\mathrm{pH} 7,8$; solução $0,25 \mathrm{mmoL}^{-1}$ 3,4-DHB e a temperatura ambiente.

\subsection{Metodologia experimental para a determinação de NADH}

Após a modificação dos eletrodos de pasta de carbono com 3,4-DHB foram realizados 20 ciclos no intervalo de $0,0 \leq E_{\text {aplicado }} \leq E 0,25 \mathrm{~V}$ e velocidade de varredura $50 \mathrm{mV} \mathrm{s}^{-1} \mathrm{em}$ tampão fosfato $\mathrm{pH} \mathrm{7,8}$. Estes foram utilizados na determinação amperométrica de NADH. O sistema de três eletrodos foi imerso na célula de eletroquímica contendo 10,0 mL de tampão PIPES pH 6,8. Em seguida, aplicou-se ao eletrodo de trabalho o potencial fixo de $+0,23 \mathrm{~V}$. Adicionaram-se volumes exatamente conhecidos de solução $3,0 \mathrm{mmol} \mathrm{L}^{-1}$ de $\mathrm{NADH}$, preparada em tampão PIPES na faixa de $0,015 \mathrm{mmol} \mathrm{L}^{-1} \leq[\mathrm{NADH}] \leq 0,93 \mathrm{mmol} \mathrm{L}^{-1}$ 
Foram efetuadas três curvas analíticas para cada uma das faixas de concentração acima citadas. Entre uma curva analítica e outra o eletrodo foi lavado com água deionizada, evitando-se a secagem superficial dos eletrodos.

2.10 Determinação de NADH e NADPH empregando sistema de análise por injeção em fluxo (FIA)

\subsubsection{Sistema de remoção de bolhas}

As micro bolhas de ar foram removidas com a introdução de um reator de polipropileno microporoso (Oxyphan $\circledast$ ), de $0,28 \mathrm{~mm}$ de diâmetro interno e $50 \mathrm{~cm}$ de comprimento (volume de $30 \mu \mathrm{L}$ ) entre o injetor de amostra e o detector eletroquímico. $O$ tubo microporoso (parede de $\sim 100 \mu \mathrm{m}$ ) foi montado concentricamente no interior de um tubo protetor de polietileno, de diâmetro interno de $0,8 \mathrm{~mm}$. Os dois tubos foram fixados entre si, nas extremidades, com cola epóxi. 


\subsubsection{Influência da vazão}

Empregaram-se vazões de 0,$2 ; 0,4 ; 0,6 ; 0,8 ; 1,0 ; 1,4$ e $1,9 \mathrm{~mL} \mathrm{~min}^{-1}$, avaliando-se a influência da alteração deste parâmetro na intensidade do sinal do analito. Para este estudo utilizaram-se eletrodos de pasta de carbono modificados por ciclagem em solução de 3,4-DHB.

\subsubsection{Influência do volume da alça de amostragem}

Alças de amostragem com volumes de 50,100, 150, 200 e $250 \mu \mathrm{L}$ foram utilizadas, avaliando-se a influência da alteração deste parâmetro na intensidade do sinal do analito. Para este estudo utilizaram-se eletrodos de pasta de carbono modificados por ciclagem em solução de 3,4-DHB.

\subsubsection{Metodologia experimental para a determinação de}

\section{NADH E NADPH}

Após a modificação dos eletrodos de pasta de carbono com 3,4-DHB por ciclagem e/ou a potencial controlado, em condições otimizadas, os mesmos foram utilizados para determinação de NADH e NADPH empregando sistema de análise por injeção em fluxo (FIA). O potencial do eletrodo de trabalho foi fixado em 0,23 V vs $\mathrm{Ag} / \mathrm{AgCl}$ ( $\mathrm{KCl}$ saturado ). 
O sistema FIA consistiu de uma bomba peristáltica Gilson modelo Minipuls 3, injetor de amostras manual provido de uma alça de amostragem com volume de $100 \mu \mathrm{L}$, sistema de remoção de bolhas e detector amperométrico (eletrodo de pasta de carbono modificado com filme eletropolimerizado de 3,4-DHB). A célula de camada delgada foi construída no laboratório com blocos usinados em acrílico e volume interno da ordem de $13 \mu \mathrm{L}$. Os dois blocos foram unidos por quatro parafusos com um separador de silicone entre os mesmos. A célula de camada delgada é apresentada na figura 2.4 

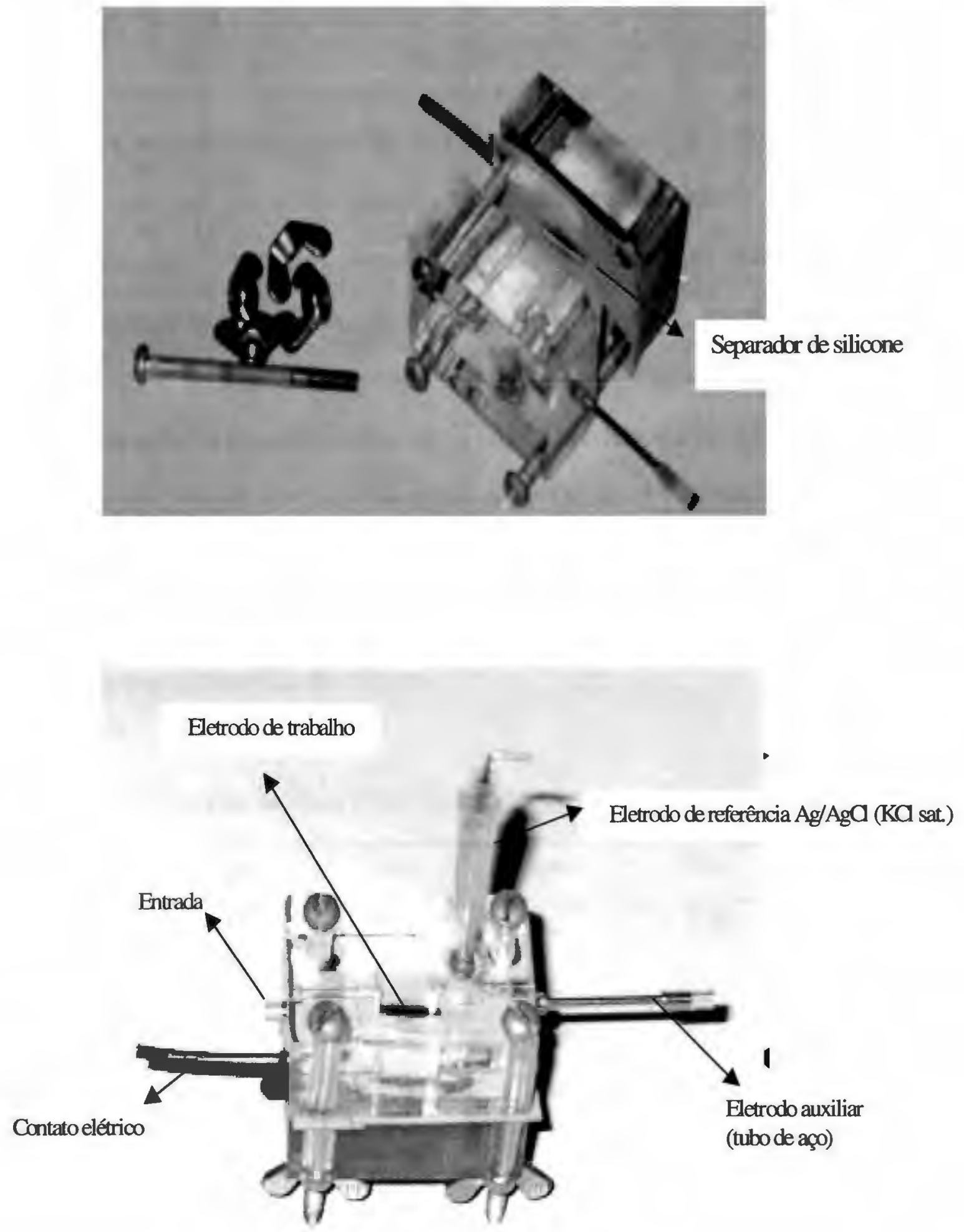

Figura 24: Célula de camada delgada e separador de silioone 


\section{RESULTADOS E DISCUSSÕES}

Os eletrodos de pasta de carbono modificados por eletropolimerização em solução de 3,4-DHB foram preparados por ciclagem e a potencial controlado. As condições experimentais para obtenção dos filmes foram otimizadas, com o objetivo de maximizar a atividade eletrocatalítica para determinação de NADH e aumentar a vida útil dos sensores.

Os valores de potencial anódico e catódico (Ep, a e Ep,c), são fortemente dependentes do pH conforme se observa na Tabela 3.1 e Figura 3.1. Tem-se 2 ou 3 picos anódicos e 1 ou 2 picos catódicos no intervalo de $-0,2 \mathrm{~V}$ a 1,0 V em solução de $0,5 \mathrm{mmol} \mathrm{L}^{-1}$ de 3,4-DHB, de modo que foi necessário avaliar qual o pH ótimo para obtenção dos filmes.

Tabela 3.1: Valores de Ep,a e Ep,c como função do pH.

\begin{tabular}{cccccc}
\hline $\mathrm{pH}$ & $\mathrm{E}_{\mathrm{pa}, 1}$ & $\mathrm{E}_{\mathrm{pa}, 2}$ & $\mathrm{E}_{\mathrm{pa}, 3}$ & $\mathrm{E}_{\mathrm{pc}, 1}$ & $\mathrm{E}_{\mathrm{pc}, 2}$ \\
\hline 2,6 & 0,47 & 0,62 & - & 0,39 & 0,53 \\
3,6 & 0,41 & 0,55 & - & 0,33 & 0,47 \\
4,6 & 0,37 & 0,50 & 0,76 & 0,30 & - \\
6,6 & 0,25 & 0,39 & 0,82 & 0,18 & - \\
7,8 & 0,18 & 0,31 & 0,76 & 0,13 & - \\
10,2 & - & 0,21 & 0,61 & - & - \\
\hline
\end{tabular}

Para facilitar a leitura do trabalho os resultados obtidos pelos dois métodos serão discutidos separadamente. 

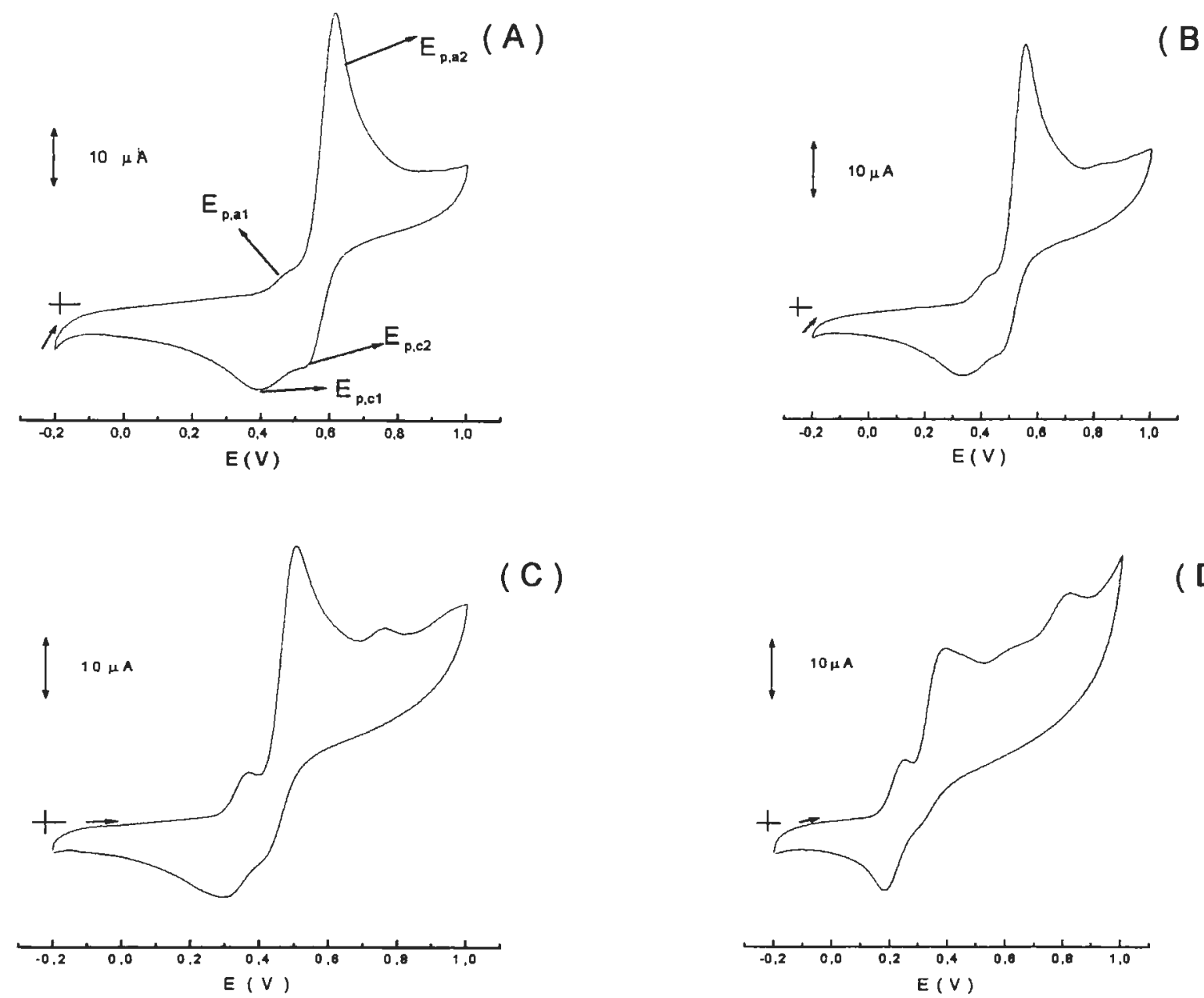

(D)

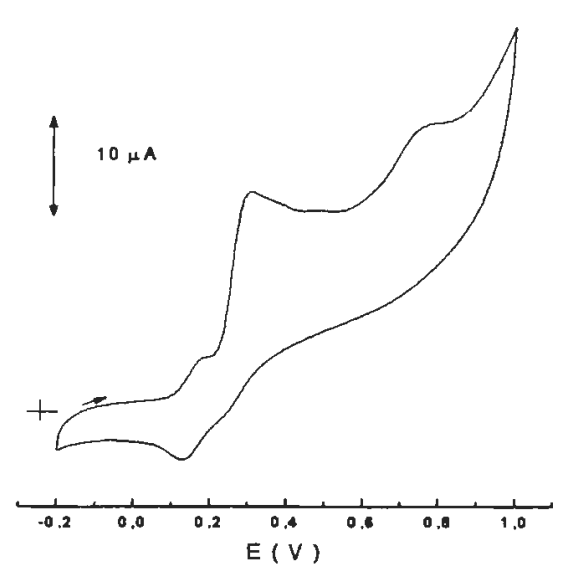

( $E$ )

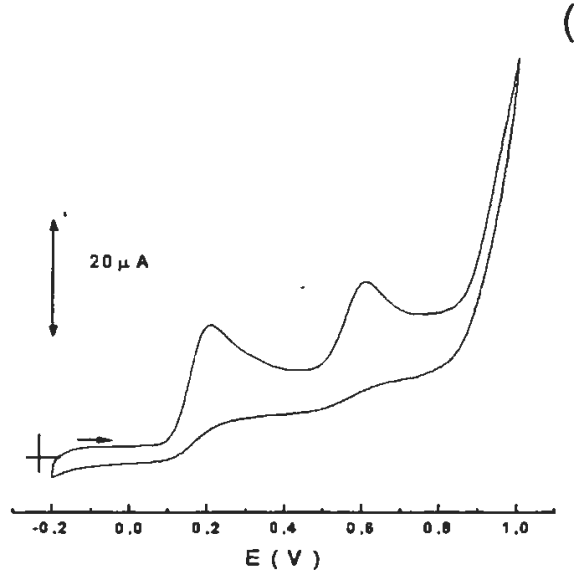

( F )

Figura. 3.1: Voltamogramas cíclicos registrados em solução $0,5 \mathrm{mmol} \mathrm{L}^{-1}$ de 3,4-DHB, no intervalo de $-0,2 \mathrm{~V} \leq \mathrm{E}_{\text {aplicado }} \leq 1,0 \mathrm{~V}$, velocidade de varredura $50 \mathrm{mVs}^{-1}$, em diversos valores de pH. ( A ) pH 2,6; ( B ) pH 3,6; (C ) pH 4,6; (D ) $\mathrm{pH} 6,6$; ( $\mathrm{E}$ ) $\mathrm{pH} 7,8$; ( F ) pH 10,2. 


\subsection{Eletrodos de pasta de carbono modificados com filmes} eletropolimerizados de 3,4-DHB obtidos por voltametria cíclica

Inicialmente os filmes foram preparados no intervalo de potencial $\left(E_{p c, 1}-150 \mathrm{mV}\right) \leq E_{\text {aplicado }} \leq\left(E_{p a, 2}+150 \mathrm{mV}\right)$

O par reversível $\left(E_{p a, 1}\right.$ e $\left.E_{p c, 1}\right)$ tornou-se cada vez mais definido com o aumento do $\mathrm{pH}$ até que em pH 10,2 observaram-se apenas dois picos de oxidação irreversíveis. No decorrer das discussões, será demonstrado que a espécie responsável pela oxidação catalítica do NADH é o par reversível $E_{p a, 1} / E_{p c, 1}$

Inicialmente avaliou-se a influência do $\mathrm{pH}$ na eletropolimerização e estabilidade dos filmes de 3,4-DHB formados por voltametria cíclica nos seguintes valores de $\mathrm{pH}: 2,6 ; 3,6 ; 4,6 ; 6,6 ; 7,8$ e 10,2 em solução de $0,5 \mathrm{mmol} \mathrm{L}^{-1}$ de 3,4-DHB, utilizando-se velocidade varredura de $50 \mathrm{mVs}^{-1}$ e 8 a 10 ciclos, o que corresponde à um tempo de modificação de 3 minutos.

A ciclagem para a formação dos filmes e a avaliação da estabilidade dos mesmos, em eletrólito suporte, em diversos valores de $\mathrm{pH}$ foi efetuada no intervalo $\left(E_{p c, 1}-150 m V\right) \leq E_{\text {aplicado }} \leq\left(E_{p a, 1}+150 m V\right)$

Conforme figura 3.2 em pH 2,6 existe um pré-pico anódico, $E_{p a, 1}$ com correntes praticamente não detectáveis, um segundo pico anódico, $E_{\mathrm{pa,2},}$ com altos valores de corrente e dois ombros catódicos, $E_{p c, 1}$ e $E_{p c, 2}$ com correntes muito inferiores àquelas observadas no processo anódico. Com o aumento do $\mathrm{pH}$, observou-se a definição do par reversivel ( $E_{p a, 1}$ e $E_{p c, 1}$ ), desaparecimento 
do ombro catódico $E_{p c, 2}$ e uma melhor definição do ombro catódico $E_{p c, 1}$, cujo valor de corrente aumentou progressivamente com o aumento do $\mathrm{pH}$.

À medida que os voltamogramas foram sendo efetuados (máximo 10 ciclos), observou-se aumento dos níveis de corrente do par reversível, ou seja, o crescimento do filme e, simultaneamente, uma queda na corrente de pico do segundo processo de oxidação $\left(E_{p a, 2}\right)$.

No entanto, em valores de pH tão altos quanto 10,2 , observaram-se os dois picos de oxidação, sem os respectivos componentes catódicos, ou seja, picos irreversíveis (Figura 3.2 e 3.3). Segundo Pariente et al. [74] em pH maior que 8,0 , a alta concentração de $\mathrm{OH}^{-}$(nucleófilo forte) minimiza a reação de 3,4-DHB com o grupo funcional ativo na superficie do eletrodo, impossibilitando a formação do filme.

Ao registrar voltamogramas cíclicos consecutivos em eletrólito suporte, no mesmo pH da formação do filme, observou-se que em $\mathrm{pH} 10,2$, os sinais de oxidação e redução do par reversivel não foram detectados (Figura 3.3), portanto não houve a formação do filme. Para os demais valores de pH estudados detectou-se o segundo pico anódico durante formação do filme, porém em eletrólito suporte, somente o par reversivel, responsável pela oxidação do NADH foi registrado, com exceção dos filmes formados em pH 3,6 e 6,6. No entanto, esse segundo pico de oxidação provavelmente foi registrado devido a perda das moléculas que estavam fracamente adsorvidas ao filme. 
( A )
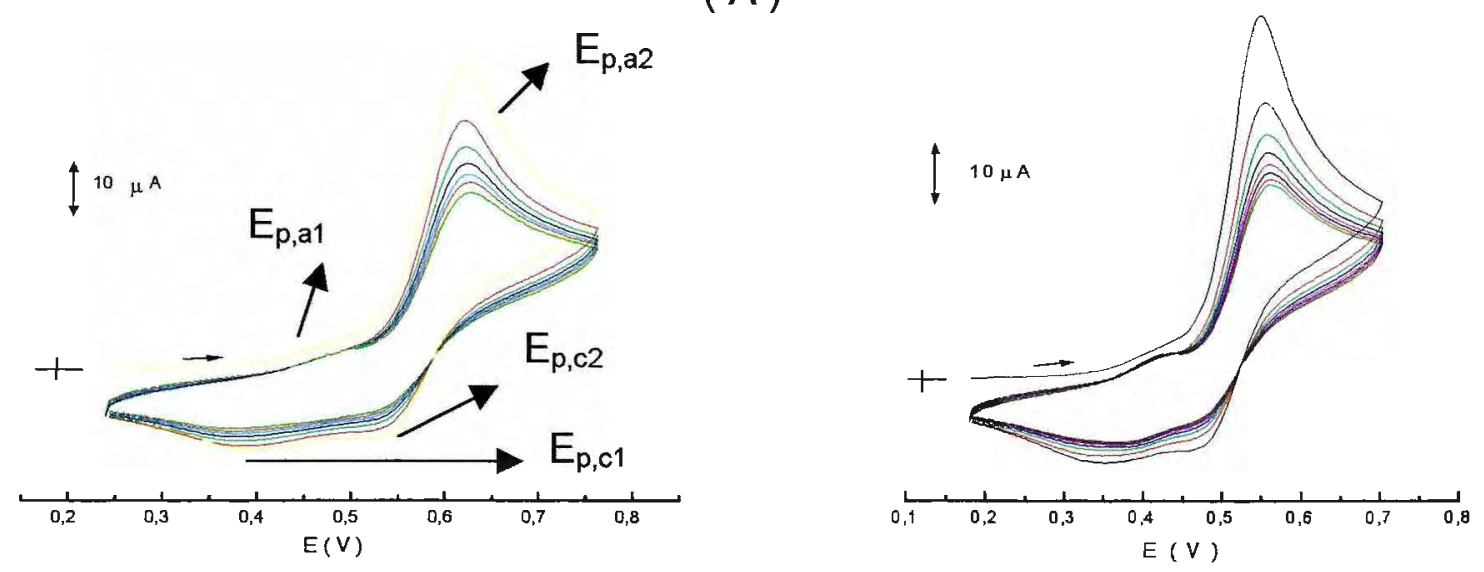

( B )

(C)
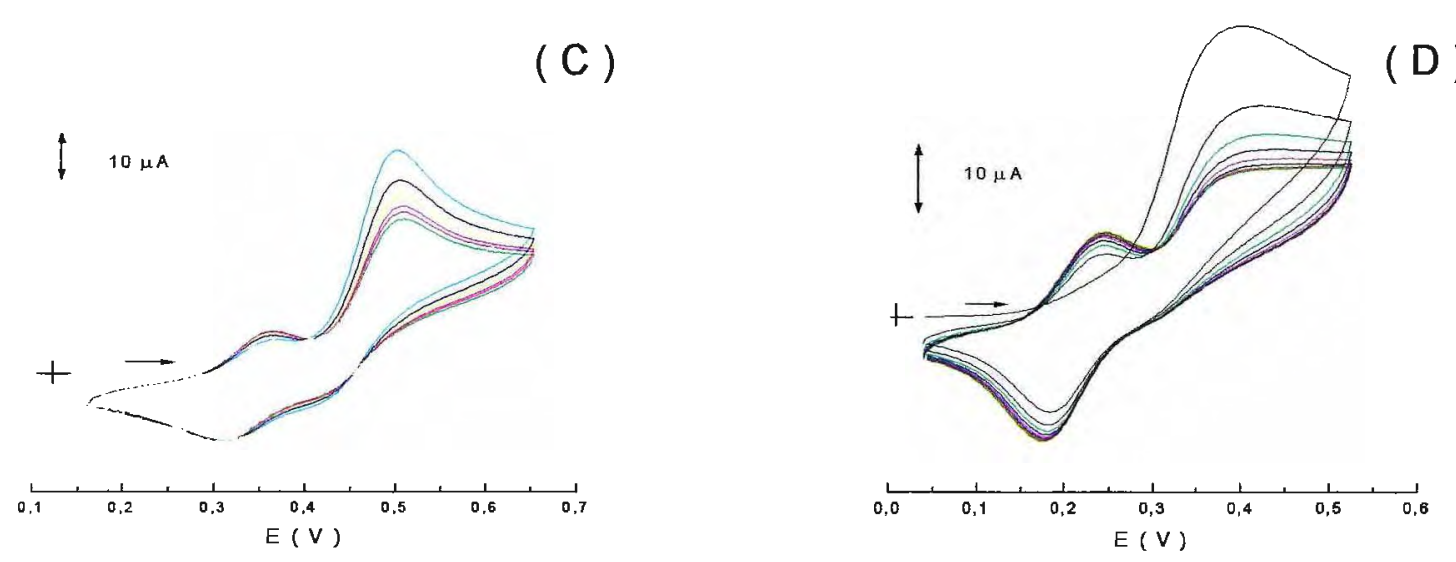

( $E$ )
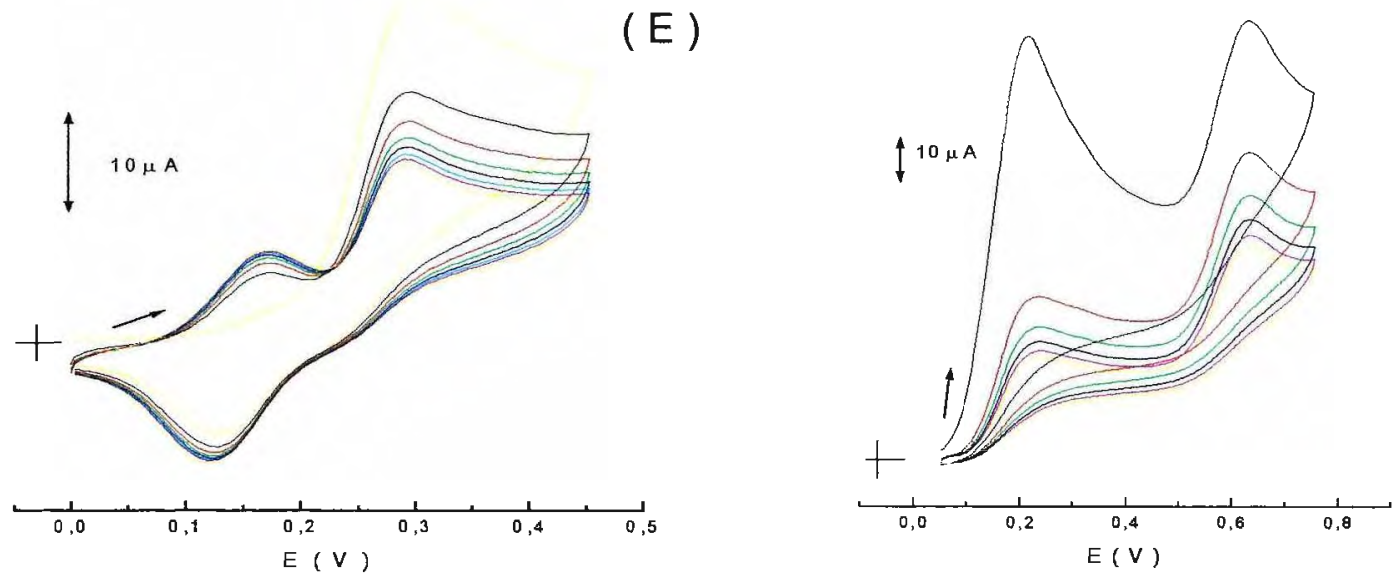

( $F)$

Figura 3.2: Formação do filme de 3,4-DHB em diversos valores de $\mathrm{pH}$ por ciclagem. ( A ) pH 2,6; ( B ) pH 3,6; ( C ) pH 4,6; ( D ) pH 6,6; ( E ) pH 7,8 e $(\mathrm{F}) \mathrm{pH} 10,2$. Condições experimentais para formação do filme: $0,5 \mathrm{mmol}^{-1} \mathrm{de}$ 3,4-DHB; intervalo de varredura: $\left(E_{p c, 1}-150 \mathrm{mV}\right) \leq E_{\text {aplicado }} \leq\left(E_{p a, 2}+150 \mathrm{mV}\right)$; velocidade de varredura:50 $\mathrm{mV} \mathrm{s}^{-1}$; número de ciclos: $(A)$ e ( $B$ ) 8 ciclos; ( C) e (D) 9 ciclos; ( E ) 10 ciclos e ( F ) 6 ciclos. 

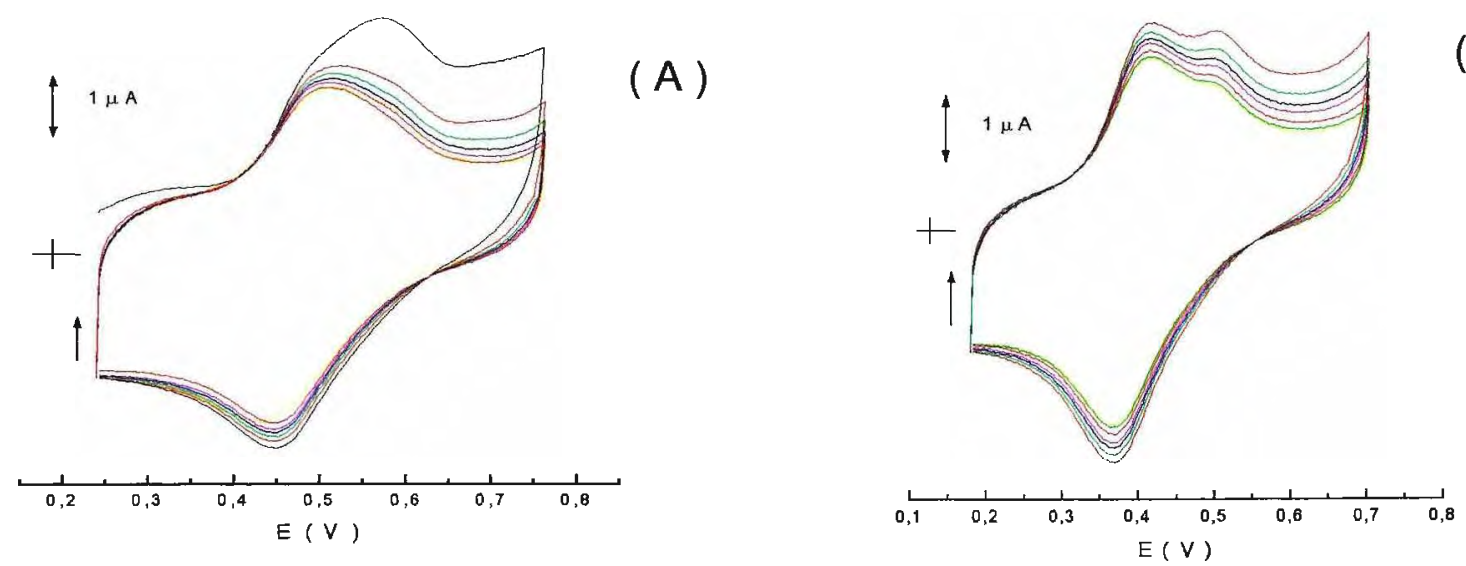

(B)
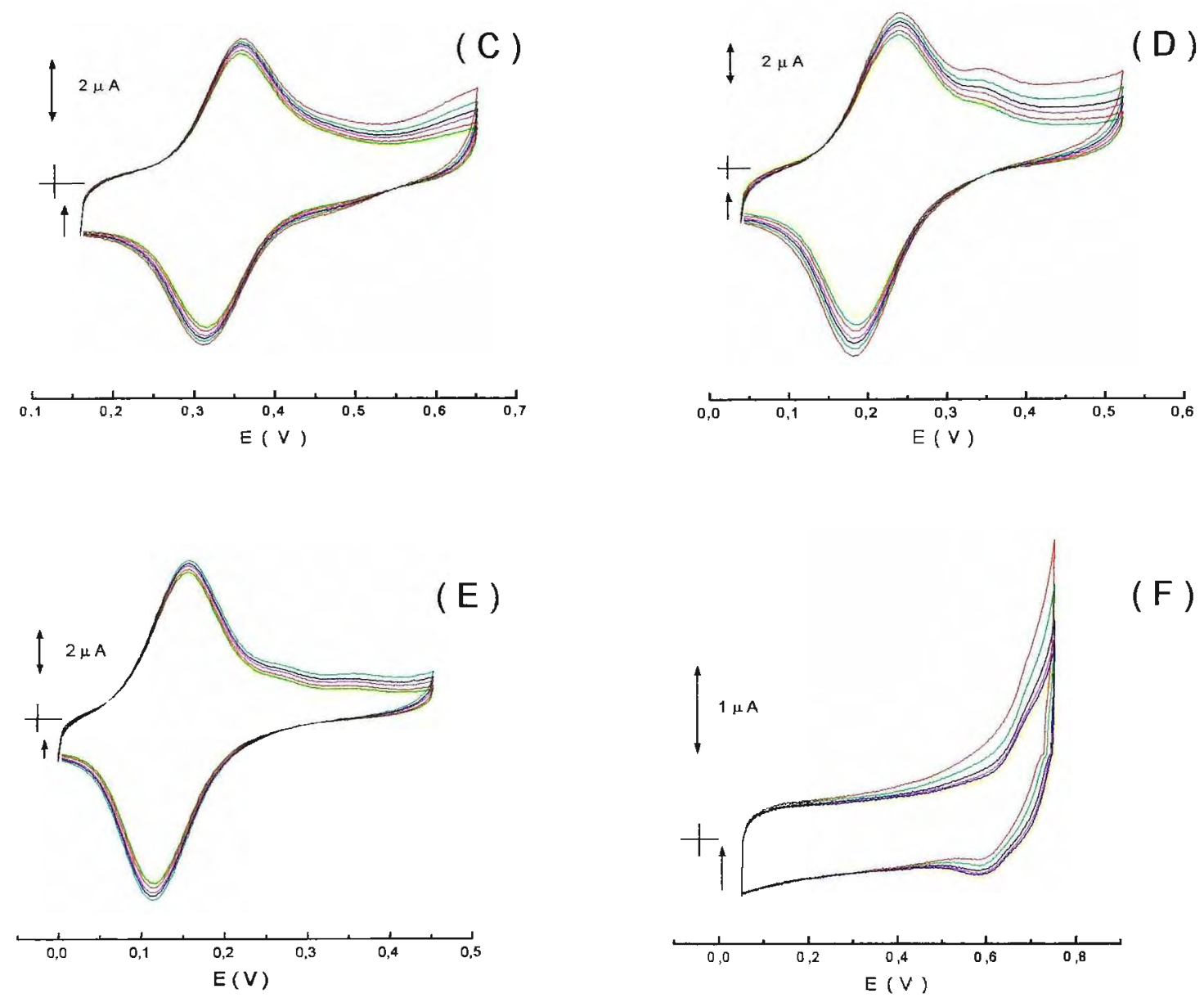

( F )

Figura: 3.3: Influência do $\mathrm{pH}$ no perfil dos voltamogramas registrados em eletrólito suporte cujo valor do $\mathrm{pH}$ foi o mesmo utilizado na formação dos filmes preparados por ciclagem: ( $\mathrm{A}$ ) $\mathrm{pH} 2,6$; (B) $\mathrm{pH} 3,6$; (C) $\mathrm{pH} \mathrm{4,6;} \mathrm{(D)} \mathrm{pH} 6,6$; (E) $\mathrm{pH} 7,8$; (F) pH 10,2. Condições experimentais: $\left(E_{p c, 1}-150 \mathrm{mV}\right) \leq \mathrm{E}_{\text {aplicado }} \leq$ $\left(\mathrm{E}_{\mathrm{pa}, 2}+150 \mathrm{mV}\right)$; velocidade de varredura: $50 \mathrm{mVs}^{-1}$ e 10 ciclos. 
A dependência dos potenciais de pico anódico e catódico do par redox reversivel em solução de eletrólito suporte com $\circ \mathrm{pH}$, é demonstrada claramente através da figura 3.4 , na qual observa-se uma diminuição dos valores de Ep,a e Ep,c com o aumento do $\mathrm{pH}$ no intervalo de $2,6 \leq \mathrm{pH} \leq 7,8$. Esta variação é descrita pelas seguintes equações: $E_{p, a}=0,65-0,064 p H$ e $E_{p, c}=0,61-0,064 p H$. Os resultados são similares aos obtidos por Zuman [66] para 2-hidroxibenzaldeído, 3-hidroxibenzaldeído e 4-hidroxibenzaldeído e por Pariente et al. [62] para 3,4-diidroxibenzaldeído.

Desde que a oxidação de compostos contendo grupos fenólicos envolve etapas de desprotonação e provável formação de quinonas, era esperado que os potenciais de pico variassem com o $\mathrm{pH}$. 

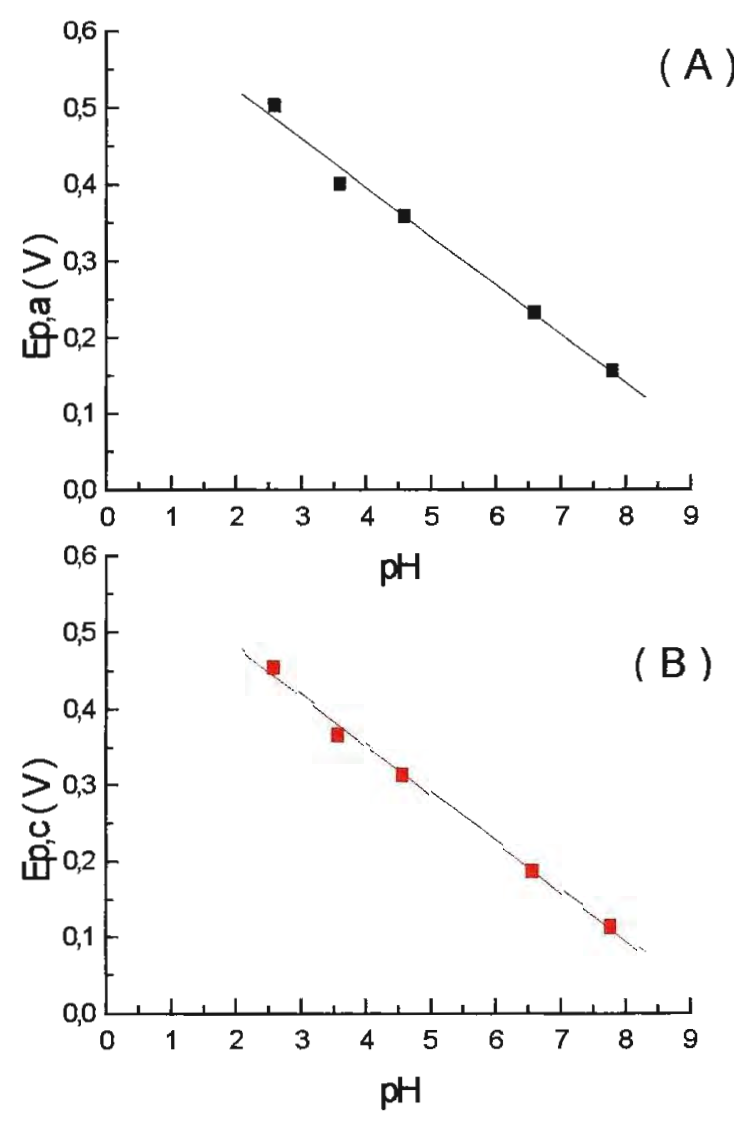
(A) Ep,a $=0,65-0,064 \mathrm{pH}$
(B) $E p, c=0,61-0,064 p H$

Figura 3.4: Variação dos potenciais de pico anódico (Ep,a) e catódico (Ep,c), registrados em eletrólito suporte (no mesmo valor de $\mathrm{pH}$ em que os filmes foram formados) com eletrodo modificado por ciclagem.

As percentagens de perda de filme ativo durante as ciclagens consecutivas, em eletrólito suporte nos mesmos valores de $\mathrm{pH}$ de formação do filme, podem ser avaliadas através da Tabela 3.2, na qual verifica-se que o filme formado a $\mathrm{pH} \mathrm{7,8} \mathrm{foi} \mathrm{o} \mathrm{que} \mathrm{apresentou} \mathrm{a} \mathrm{menor} \mathrm{percentagem} \mathrm{de} \mathrm{perda} \mathrm{de}$ filme ativo. 
O cálculo foi realizado comparando-se os niveis de corrente obtidos no décimo voltamograma cíclico com aqueles obtidos no segundo voltamograma cíclico, considerado como 100\%, ambos registrados em eletrólito suporte.

Conforme tabela 3.2 e figura 3.5 , os maiores niveis de corrente para o par reversivel, bem como as menores perdas de filme ativo foram obtidos para os filmes formados em $\mathrm{pH} 7,8$.

Tabela 3.2: Percentagens de perda de filme ativo, registradas em eletrólito suporte, para o décimo voltamograma cíclico.

\begin{tabular}{ccc}
\hline $\mathrm{pH}$ & $\begin{array}{c}\text { \% de perda de filme } \\
\text { ativo } \\
(\mathrm{Ip}, \mathrm{a})\end{array}$ & $\begin{array}{c}\text { \% de perda de filme } \\
\text { ativo }\end{array}$ \\
\hline 2,6 & 12 & $(\mathrm{Ip}, \mathrm{c})$ \\
3,6 & 18 & 14 \\
4,6 & 11 & 16 \\
6,6 & 19 & 12 \\
7,8 & 10 & 21 \\
\hline
\end{tabular}




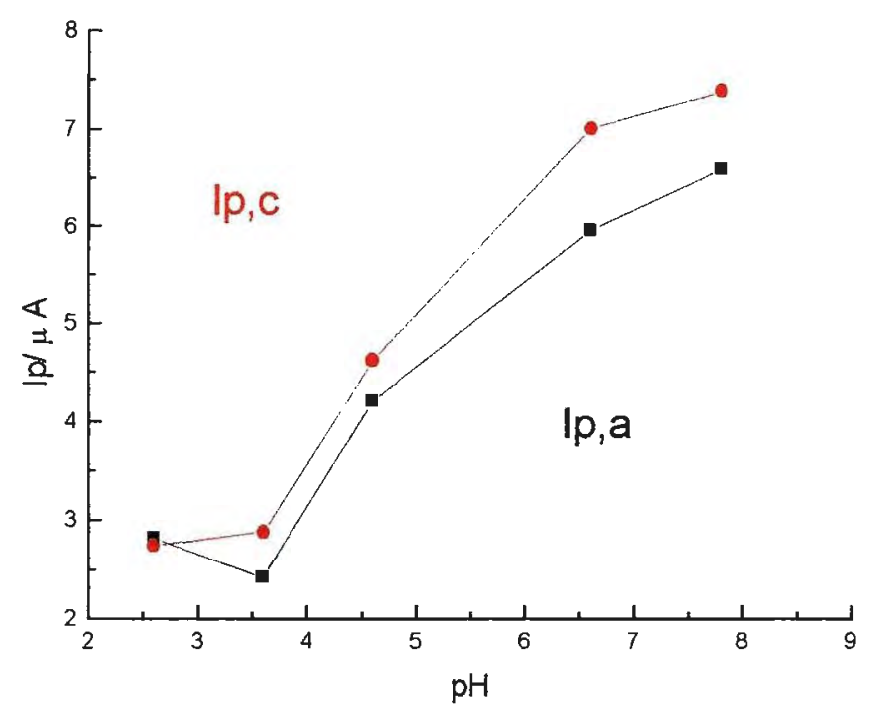

Figura 3.5: Variação das correntes de pico anódica ( Ip,a ) e catódica ( Ip,c ) com $\circ \mathrm{pH}$ para filmes preparados por ciclagem. Os níveis de corrente correspondem ao décimo voltamograma cíclico, registrado em eletrólito suporte (tampão fosfato). 


\subsubsection{Influência do potencial anódico de inversão de varredura na formação e estabilidade dos filmes de 3,4-DHB}

Otimizado o valor de $\mathrm{pH}$ 7,8 para a formação de filme por ciclagem, o intervalo de potencial foi reavaliado a fim de se analisar a influência do segundo pico de oxidação na formação do filme, uma vez que em eletrólito suporte apenas o par reversivel está presente. A velocidade varredura foi fixada em $50 \mathrm{mVs}^{-1}$ e o filme formado efetuando-se 10 voltamogramas cíclicos em solução $0,5 \mathrm{mmol} \mathrm{L}^{-1}$ de 3,4-DHB.

Os voltamogramas registrados durante a formação do filme no intervalo de $0,0 \leq E \leq 0,45 \mathrm{~V}$ e $0,0 \leq E \leq 0,25 \mathrm{~V}$, bem como aqueles registrados para verificação da estabilidade do filme são apresentados na Figura 3.6.

Quando o filme foi eletropolimerizado no intervalo de $0,0 \leq E \leq 0,45 \vee$ e o teste de estabilidade foi efetuado na mesma faixa de potencial verificou-se após 20 ciclos, uma maior percentagem de perda de filme ativo do que aquela observada quando a ciclagem em eletrólito suporte foi efetuada na faixa Dela 3.3). No entanto, as percentagens de perda de filme n.. in cumes formados na faixa de 0,0 a $0,45 \mathrm{~V}$ e 0,0 a $0,25 \mathrm{~V}$, foram similares para ciclagens efetuadas em eletrólito suporte na faixa de 0,0 a $0,25 \mathrm{~V}$, porém somente para filmes formados no intervalo de $0,0 \mathrm{~V}$ a $0,25 \mathrm{~V}$ a superfície se manteve estável após mais do que 20 ciclagens consecutivas em eletrólito suporte no intervalo de 0,0 a $0,25 \mathrm{~V}$ (Tabelas 3.3 e 3.4 ).

Estes resultados demonstraram, que para obtenção de filmes estáveis, é essencial que durante a eletropolimerização e posterior teste de estabilidade 
em eletrólito suporte, o potencial de varredura não atinja o segundo pico de oxidação, $E_{p, a 2}$.

Resultados semelhantes foram observados por Pariente et al. [62], os quais verificaram que registrar voltamogramas cíclicos até potenciais acima de $0,4 \vee(p H=7,0)$ consistia numa maneira de limpar a superfície do eletrodo. Como visto no estudo desenvolvido no presente trabalho, este potencial é dependente do $\mathrm{pH}$ e refere-se ao segundo pico de oxidação, nunca mencionado por aqueles pesquisadores.

Tabela 3.3 : Percentagens de perda de filme ativo para filmes formados no intervalo de $\mathrm{Ei}=0,0 \mathrm{~V}$ e $\mathrm{Ef}=0,45 \mathrm{~V}$.

\begin{tabular}{ccc}
\hline $\begin{array}{c}\text { Intervalo de varredura } \\
\text { em eletrólito suporte }\end{array}$ & $\begin{array}{c}\% \text { de perda de filme } \\
\text { ativo } \\
(I p, a)\end{array}$ & $\begin{array}{c}\% \text { de perda de filme } \\
\text { ativo } \\
(I p, c)\end{array}$ \\
\hline $\mathrm{Ei}=0,0 ; \mathrm{Ef}=0,45$ & 15 & 18 \\
$\mathrm{Ei}=0,0 ; \mathrm{Ef}=0,25$ & 9 & 12
\end{tabular}

Percentagens calculadas comparando-se os niveis de corrente do vigésimo voltamograma cíclico com o segundo voltamograma cíclico(100\%), registrados em eletrólito suporte, tampão fosfato $\mathrm{pH} 7,8$.

Tabela 3.4 : Percentagens de perda de filme ativo para filmes formados no intervalo de $\mathrm{Ei}=0,0 \mathrm{~V}$ e $\mathrm{Ef}=0,25 \mathrm{~V}$.

\begin{tabular}{ccc}
\hline $\begin{array}{c}\text { Intervalo de varredura } \\
\text { em eletrólito suporte }\end{array}$ & $\begin{array}{c}\text { \% de perda de filme } \\
\text { ativo } \\
(\mathrm{Ip}, \mathrm{a})\end{array}$ & $\begin{array}{c}\text { \% de perda de filme } \\
\text { ativo } \\
(\mathrm{Ip}, \mathrm{C})\end{array}$ \\
\hline $\mathrm{Ei}=0,0 ; \mathrm{Ef}=0,45$ & 34 & 35 \\
$\mathrm{Ei}=0,0 ; \mathrm{Ef}=0,25$ & 9 & 8
\end{tabular}

Percentagem de perda foi calculada comparando-se os níveis de corrente do vigésimo com o segundo voltamograma cíclico, ambos registrados em eletrólito suporte. 

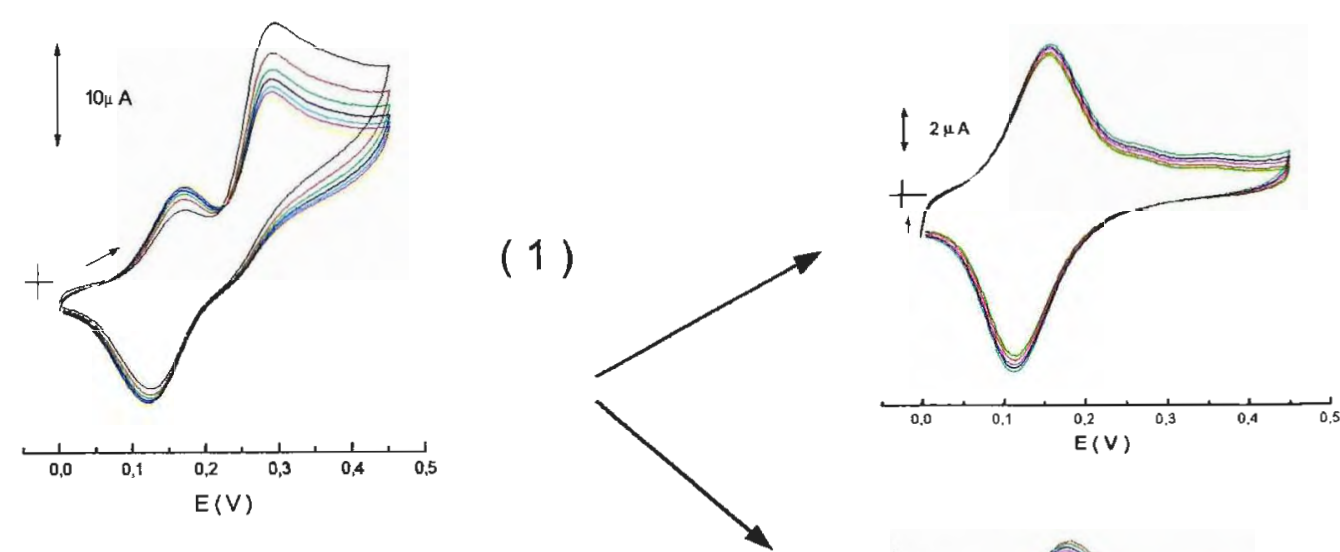

(1a)
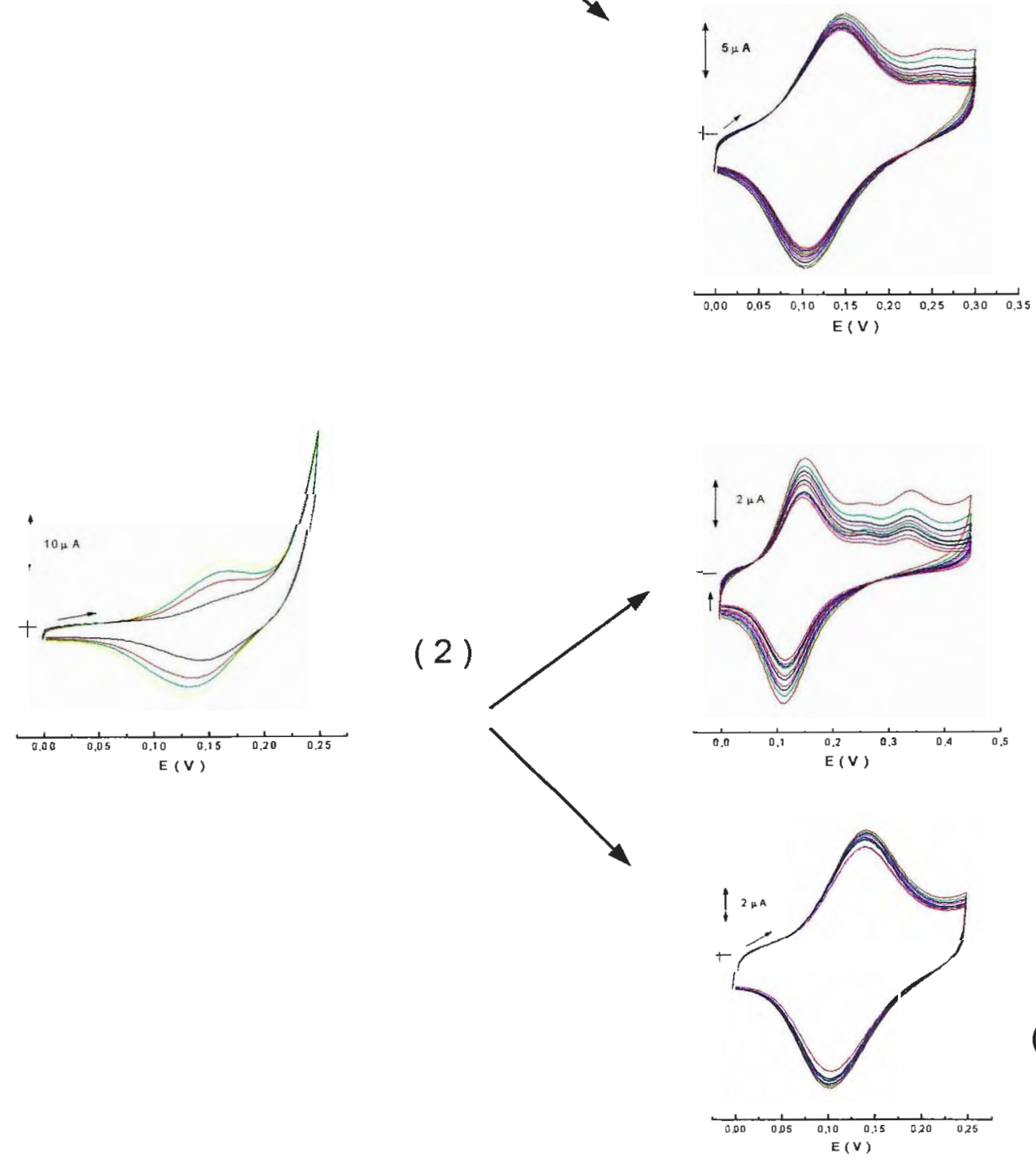

Figura 3.6: Influência do intervalo de varredura na estabilidade dos filmes: ( 1 ) Filme formado no intervalo de $0 \leq E_{\text {aplicado }} \leq 0,45 \mathrm{~V}$. Estabilidade em eletrólito suporte na faixa de (1a) $0 \leq E_{\text {aplicado }} \leq 0,45 \mathrm{Ve}$ (1b) $0 \leq \mathrm{E}_{\text {aplicado }} \leq 0,30 \mathrm{~V}$.

( 2 ) Filme formado no intervalo de $0 \leq E_{\text {aplicado }} \leq 0,25 \mathrm{~V}$. Estabilidade em eletrólito suporte na faixa de ( 2a ) $0 \leq E_{\text {aplicado }} \leq 0,45 \mathrm{~V}$ e (2b) de $0 \leq E_{\text {aplicado }} \leq 0,25 \mathrm{~V}$.

Condições experimentais para formação do filme: $\mathrm{pH} 7,8 ; 0,5 \mathrm{mmol} \mathrm{L}^{-1}$ de 3,4-DHB; velocidade de varredura: $50 \mathrm{mVs}^{-1}$ e 10 ciclos. Estabilidade dos filmes: eletrólito suporte com $\mathrm{pH} 7,8$; velocidade de varredura: $50 \mathrm{mVs}^{-1}$ e 20 ciclos. 


\subsubsection{Influência da velocidade de varredura e estabilidade do}

\section{filme de 3,4-DHB}

Após concluir que a formação dos filmes, bem como os testes de estabilidade deveriam ser efetuados em $\mathrm{pH} 7,8$, no intervalo $0,0 \leq \mathrm{E}_{\text {aplicado }} \leq 0,25 \mathrm{~V}$, fixou-se o número de ciclos em 10 e a concentração de 3,4-DHB em 0,5 mmol L-1, avaliando-se o efeito da velocidade de varredura na estabilidade dos filmes formados nestas condições. As velocidades de varredura utilizadas foram: 5, 10, 25, 50, 75 e $100 \mathrm{mVs}^{-1}$. Para testar a estabilidade do filme em eletrólito suporte fixou-se a velocidade em $50 \mathrm{mV} \mathrm{s}^{-1}$.

Com o aumento da velocidade de varredura, tem-se aparentemente a formação de filmes mais espessos ou com multicamadas, fato este verificado pelo aumento dos níveis de corrente anódica e catódica (Figura 3.7). Por outro lado, quando efetuaram-se voltamogramas cíclicos consecutivos em eletrólito suporte na velocidade fixa de $50 \mathrm{mVs}^{-1}$, observou-se que quanto maior a velocidade de varredura utilizada para formação do filme, menores eram os níveis de corrente anódica e catódica (Figura 3.8). Provavelmente, não houve tempo suficiente para formação dos filmes e o material encontra-se menos fortemente adsorvido na superfície dos eletrodos, sendo facilmente perdido, Tabela 3.5

Decorre destes dados, que a melhor velocidade para a formação do filme situa-se entre 10 e $50 \mathrm{mVs}^{-1}$, porém a percentagem de perda de filme ativo em eletrólito suporte foi menor para velocidade de $10 \mathrm{mVs}^{-1}$, de modo que em todos os demais experimentos utilizou-se esta velocidade durante a formação do filme. 
Tabela 3.5: Percentagens de perda de filme ativo como função da velocidade de formação em solução $0,5 \mathrm{mmol}^{-1}$ de 3,4-DHB.

\begin{tabular}{ccc}
\hline $\begin{array}{c}\text { Velocidade de varredura } \\
\left(\mathrm{mVs}^{-1}\right)\end{array}$ & $\begin{array}{c}\text { \% de perda de filme } \\
\text { ativo }(\mid \mathrm{p}, \mathrm{a})\end{array}$ & $\begin{array}{c}\text { \% de perda de filme } \\
\text { ativo }(\mathrm{Ip}, \mathrm{c})\end{array}$ \\
\hline 5 & 15 & 12 \\
10 & 8 & 7 \\
25 & 9 & 8 \\
50 & 9 & 8 \\
75 & 12 & 13 \\
100 & 17 & 16 \\
\hline
\end{tabular}

Percentagens calculadas comparando os níveis de corrente do vigésimo voltamograma cíclico com o segundo voltamograma, ambos registrados em eletrólito suporte, tampão fosfato $\mathrm{pH} 7,8$.

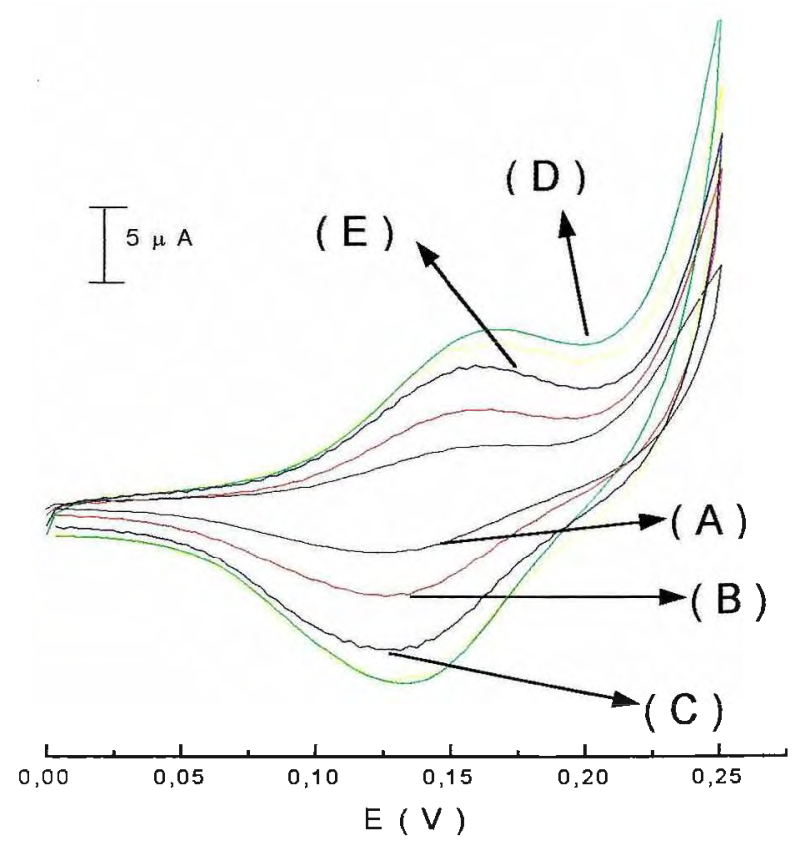

Figura 3.7: Formação dos filmes de 3,4-DHB em diferentes velocidades de varredura.(A) $10 \mathrm{mVs}^{-1}$;(B) $25 \mathrm{mVs}^{-1}$; (C) $50 \mathrm{mVs}^{-1}$; (D) $75 \mathrm{mVs}^{-1}$; (E) $100 \mathrm{mVs}^{-1}$. Os voltamogramas apresentados correspondem ao décimo voltamograma cíclico para cada uma das velocidades. Condições experimentais para formação do filme: $\mathrm{pH} 7,8 ; 0,5 \mathrm{mmol} \mathrm{L}^{-1}$ de 3,4-DHB; intervalo de varredura $0,0 \leq E_{\text {aplicado }} \leq 0,25 \vee$ e 10 ciclos. 


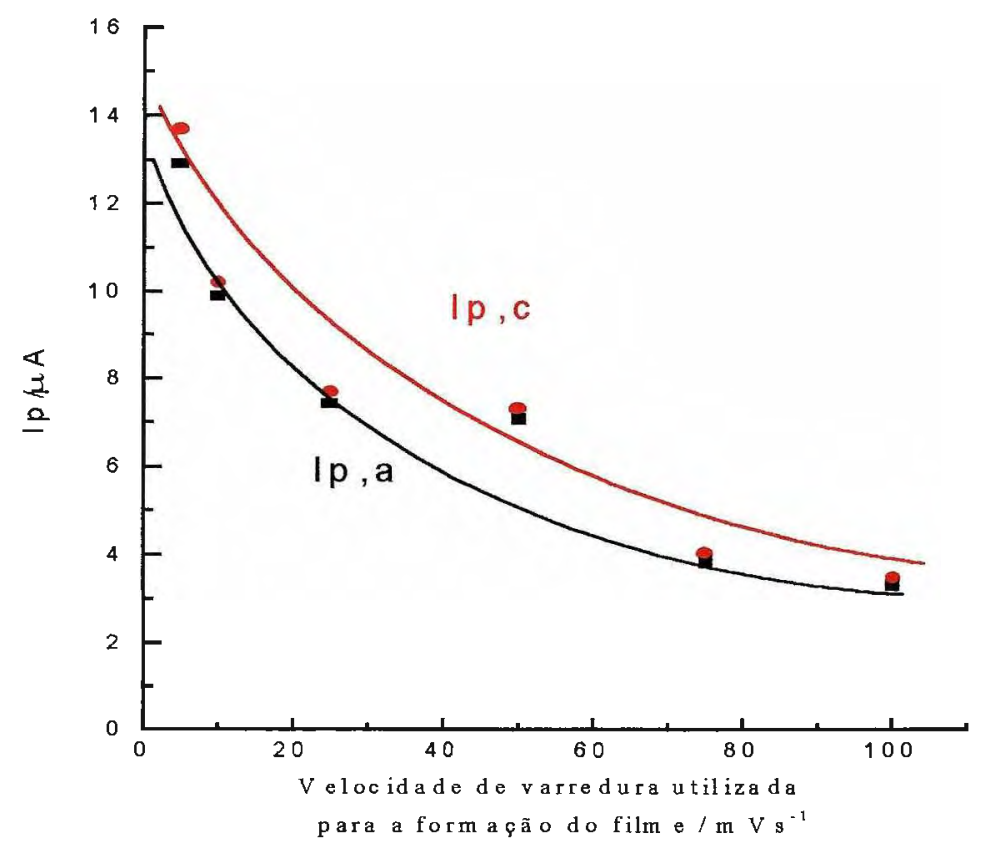

Figura 3.8: Variação dos níveis de corrente de pico anódica e catódica em solução de eletrólito suporte tampão fosfato $\mathrm{pH}=7,8$ em função da velocidade de formação do filme em solução de $0,5 \mathrm{mmol} \mathrm{L}^{-1} 3,4$-DHB. Niveis de corrente correspondentes ao vigésimo voltamograma cíclico registrado em eletrólito suporte.

\subsubsection{Influência do número de ciclos utilizados para formação}

\section{do filme}

O número de ciclos efetuados para a formação do filme $(5 ; 10 ; 15$ e 20 ciclos) foi outro parâmetro estudado. Após estabelecer as melhores condições experimentais para a formação do filme como sendo $\mathrm{pH} 7,8$, intervalo de varredura $0,00 \leq E_{\text {aplicado }} \leq 0,25 \mathrm{~V}$ e velocidade de varredura a $10 \mathrm{mVs}^{-1}$, 
manteve-se a concentração de $0,5 \mathrm{mmol} \mathrm{L}^{-1}$ de $3,4-\mathrm{DHB}$ e avaliou-se a influência do número de ciclos utilizados na formação do filme, na posterior estabilidade e niveis de corrente registrados em eletrólito suporte.

Os filmes formados com 10 ciclos apresentaram os maiores niveis de corrente anódica e catódica (Figura 3.9). Para um número de ciclos inferior ou superior a 10, obtiveram-se maiores percentagens de perda de filme ativo em eletrólito suporte (Tabela 3.6). Com o aumento do número de ciclos, parece ocorrer a formação de várias camadas pouco adsorvidas de material, nas quais apenas uma fração é eletroquimicamente ativa [62].

Tabela 3.6: Percentagens de perda de filme ativo como função do número de ciclos utilizados durante o processo de formação do filme.

\begin{tabular}{ccc}
\hline $\begin{array}{c}\text { Número de ciclos } \\
\text { ativo } \\
(\mathrm{Ip}, \mathrm{a})\end{array}$ & $\begin{array}{c}\text { \% de perda de filme } \\
\text { ativo } \\
(\mathrm{Ip}, \mathrm{C})\end{array}$ \\
\hline 5 & 13 & 12 \\
10 & 8 & 7 \\
15 & 11 & 11 \\
20 & 9 & 13 \\
\hline Percentagens calculadas comparando os níveis de corrente do vigésimo voltamograma \\
$\mathrm{pH} 7,8$.
\end{tabular}




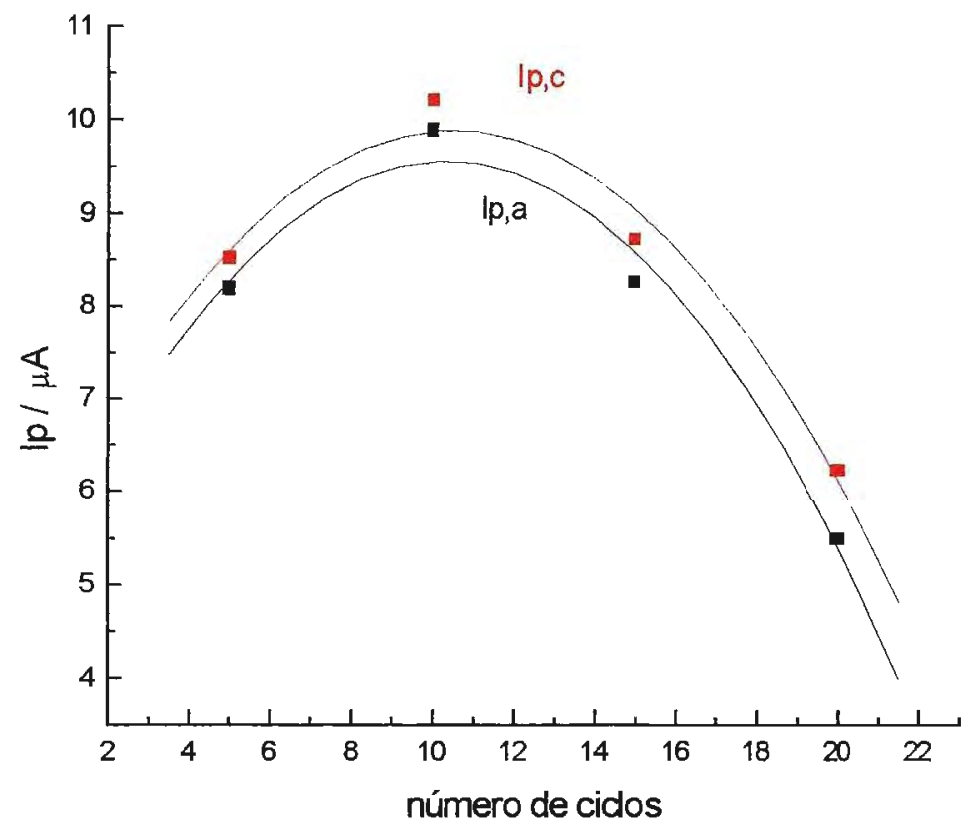

Figura 3.9: Variação dos níveis de corrente anódica e catódica como função do número de voltamogramas cíclicos utilizados para a formação do filme de 3,4-DHB. Os niveis de corrente correspondem ao vigésimo voltamograma cíclico registrado em eletrólito suporte, tampão fosfato $\mathrm{pH} 7,8$. 


\subsubsection{Influência da concentração da solução de 3,4-DHB na} estabilidade dos filmes de 3,4-DHB em eletrólito suporte

Utilizando-se $\mathrm{pH} 7,8$, intervalo de varredura $0,0 \leq \mathrm{E}_{\text {aplicado }} \leq 0,25 \mathrm{~V}$, velocidade de varredura de $10 \mathrm{mV} \mathrm{s}^{-1}$ e 10 ciclos como condições otimizadas para formação do filme, avaliou-se o efeito da concentração de 3,4-DHB nas características de formação e estabilidade dos filmes obtidos. As concentrações de 3,4-DHB utilizadas foram : 0,25; 0,56; 0,90 e 1,8 $\mathrm{mmol} \mathrm{L}^{-1}$.

Com o aumento da concentração da solução de 3,4-DHB tem-se, aparentemente, a formação de filmes mais espessos, indicada pelo aumento dos níveis de corrente anódico e catódico. Os picos tornaram-se progressivamente mal definidos (Figura 3.10), pois a grande concentração de 3,4-DHB próxima ao eletrodo deve provocar a formação do filme não muito uniforme ou muito espesso, no qual apenas uma fração é eletroativa [62,75].

Durante os testes de estabilidade, efetuados em eletrólito suporte, foram obtidos, para 20 voltamogramas cíclicos consecutivos, boa definição de picos correspondentes ao par reversivel em todos as concentrações utilizadas. 0 filme formado em concentração de 0,25 mmol L $\mathrm{m}^{-1}$ apresentou níveis de corrente menores, porém neste, a perda do filme ativo também foi menor (Figura 3.11). 


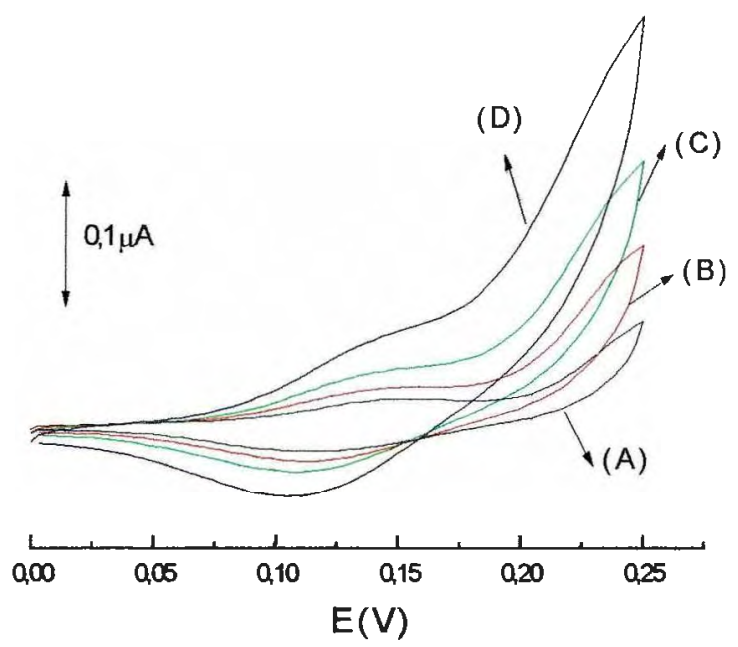

Figura 3.10: Influência da concentração da solução de 3,4-DHB na formação dos filmes eletropolimerizados de 3,4-DHB. ( A ) 0,25 $\mathrm{mmol} \mathrm{L}^{-1}$; ( B ) 0,56 mmol $\mathrm{L}^{-1}$, ( C ) $0,90 \mathrm{mmol} \mathrm{L}^{-1}$; ( D ) $1,8 \mathrm{mmol} \mathrm{L}^{-1}$. Os voltamogramas correspondem ao do décimo ciclo. Condições experimentais de formação dos filmes: $\mathrm{pH} 7,8$; intervalo de varredura: $0 \leq \mathrm{E}_{\text {aplicado }} \leq 0,25 \mathrm{~V}$; velocidade de varredura: $50 \mathrm{mVs}^{-1} \mathrm{e}$ 10 ciclos.
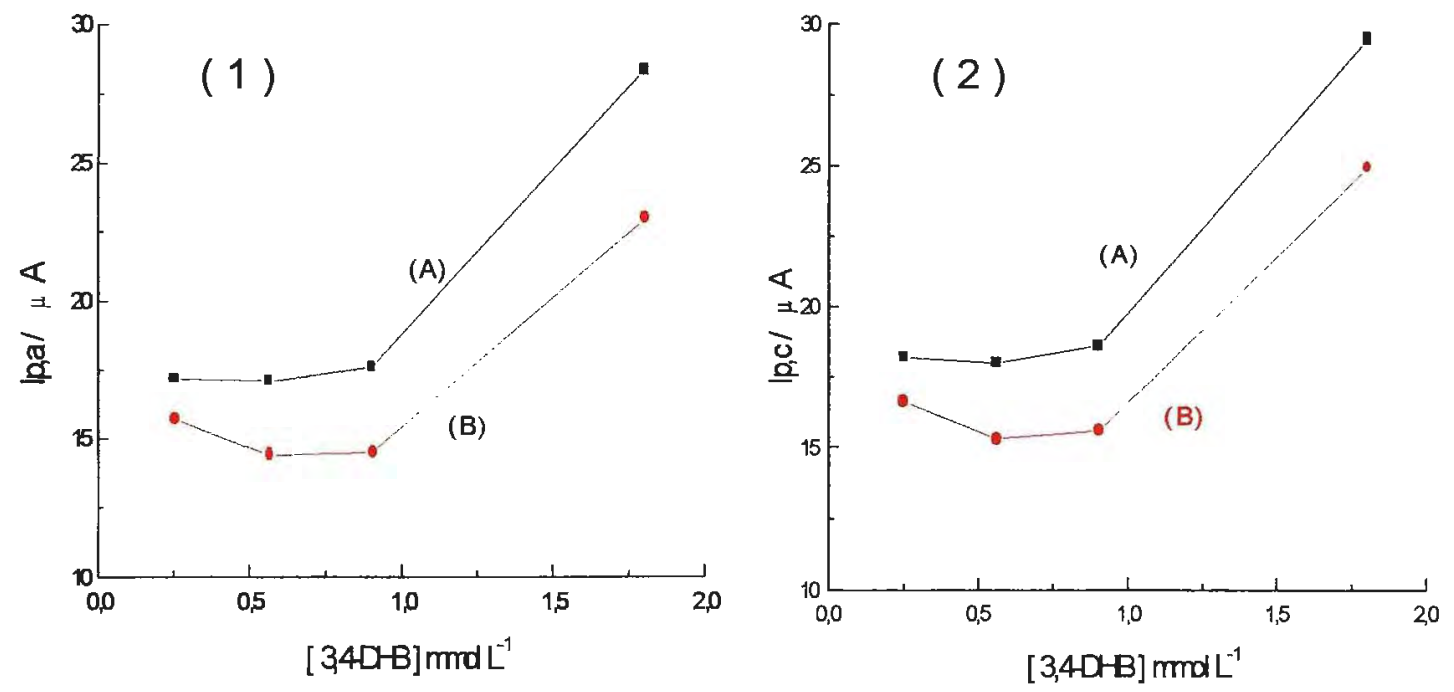

Figura 3.11: Variação das correntes de pico de anódica ( 1 ) e catódica ( 2 ) registradas em eletrólito suporte tampão fosfato $\mathrm{pH} \mathrm{7,8,} \mathrm{como} \mathrm{função} \mathrm{da}$ concentração da solução de 3,4-DHB $\left(0,25 ; 0,56 ; 0,90\right.$ e $\left.1,8 \mathrm{mmol} \mathrm{L}^{-1}\right)$ usada para a formação dos filmes. ( A ) Níveis de corrente do segundo voltamograma cíclico ( B ) Níveis de corrente do vigésimo voltamograma cíclico. 
Na Tabela 3.7 são apresentadas as variações entre os potenciais de pico anódico e catódico para as diversas concentrações de 3,4-DHB estudadas.

Tabela 3.7: Variações entre os potenciais de pico anódico e catódico $(\Delta \mathrm{Ep})$ como função da concentração 3,4-DHB utilizada para formação dos filmes.

\begin{tabular}{cccc}
\hline$[3,4-\mathrm{DHB}] \mathrm{mmol} \mathrm{L}$ & -1 & $\mathrm{Ep}, \mathrm{a}(\mathrm{mV})$ & $\Delta \mathrm{Ep}(\mathrm{mV})$ \\
\hline 0,25 & 137 & 98 & 39 \\
0,56 & 140 & 98 & 42 \\
0,90 & 143 & 98 & 45 \\
1,8 & 150 & 98 & 52 \\
\hline
\end{tabular}

Ao variar a concentração de $3,4 \mathrm{DHB}$ até $1 \mathrm{mmol} \mathrm{L}^{-1}$ para eletrodo modificado a potencial controlado, Gao et al [75] observaram um acentuado aumento no valores de $\Delta E p$. Para concentrações maiores ou iguais a $1 \mathrm{mmol} \mathrm{L}{ }^{-1}, \Delta$ Ep assumiu valor constante de $59 \mathrm{mV}$. A variação de 8 a $59 \mathrm{mV}$ para $\triangle E p$ foi interpretada pelos autores como indicativo de que o 3,4-DHB pode variar de monômero para polímero na superfície do eletrodo. Nossos dados são muitos discrepantes daqueles obtidos por Gao et al, uma vez que durante todo o estudo realizado, os valores de $\Delta \mathrm{Ep}$ variaram de no máximo $10 \mathrm{mV}$, o que sugere que a estrutura intrínseca do filme permanece constante ao longo de todo o processo. 
3.1.5 Reavaliação da influência do potencial anódico de inversão de varredura na formação e estabilidade dos filmes de 3,4-DHB

Os dados apresentados no item 3.1.1 deixaram evidente que para a obtenção de filmes estáveis, era essencial que durante o processo de preparação dos mesmos e posterior teste de estabilidade em eletrólito suporte, o potencial de varredura não atingisse o valor de potencial correspondente ao segundo pico de oxidação. No entanto, não se havia avaliado se a inversão do potencial deveria ser feita logo após o término do primeiro processo de oxidação ou no início do segundo.

Os filmes de 3,4-DHB foram então formados por ciclagem em diferentes valores de $\mathrm{pH}$. O potencial de inversão de varredura foi fixado no fim do primeiro processo de oxidação ou no início do segundo processo.

As figuras 3.12 e 3.13 correspondem ao décimo voltamograma cíclico registrado durante a formação do filme de 3,4-DHB. Na figura 3.12 os potenciais de inversão de varredura foram fixados no final do primeiro processo de oxidação enquanto na figura 3.13 no início do segundo processo. 


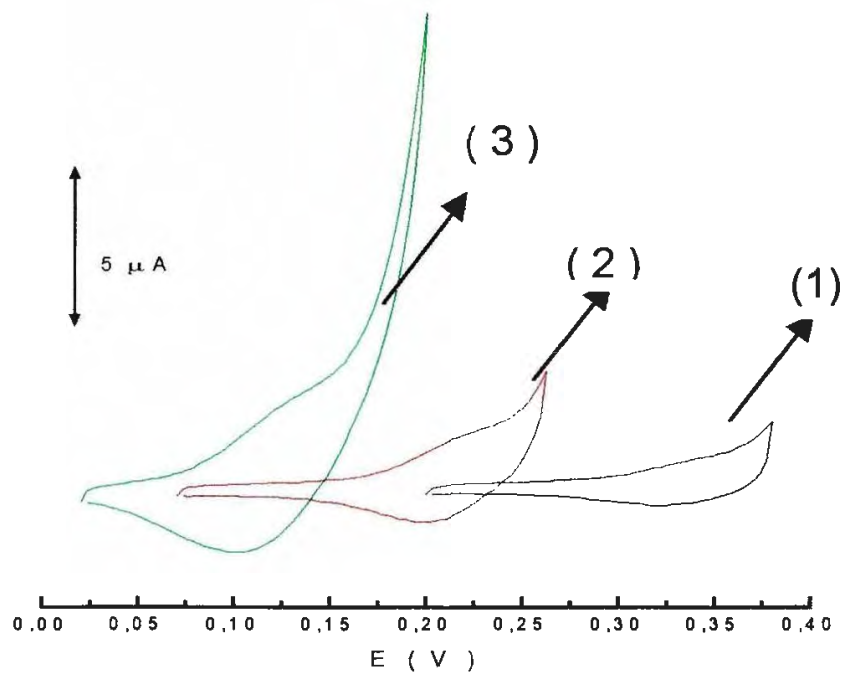

Figura 3.12: Voltamogramas cíclicos correspondentes ao décimo ciclo de formação dos filmes de 3,4-DHB em diferentes valores de pH: ( 1 ) pH 4,6 e $0,20 \leq \mathrm{E}_{\text {aplicado }} \leq 0,38 \mathrm{~V}$; ( 2 ) pH 6,8 e $0,07 \leq \mathrm{E}_{\text {aplicado }} \leq 0,26 \mathrm{~V}$; ( 3 ) pH 7,8 e $0,02 \leq \mathrm{E}_{\text {aplicado }} \leq 0,20 \mathrm{~V}$.

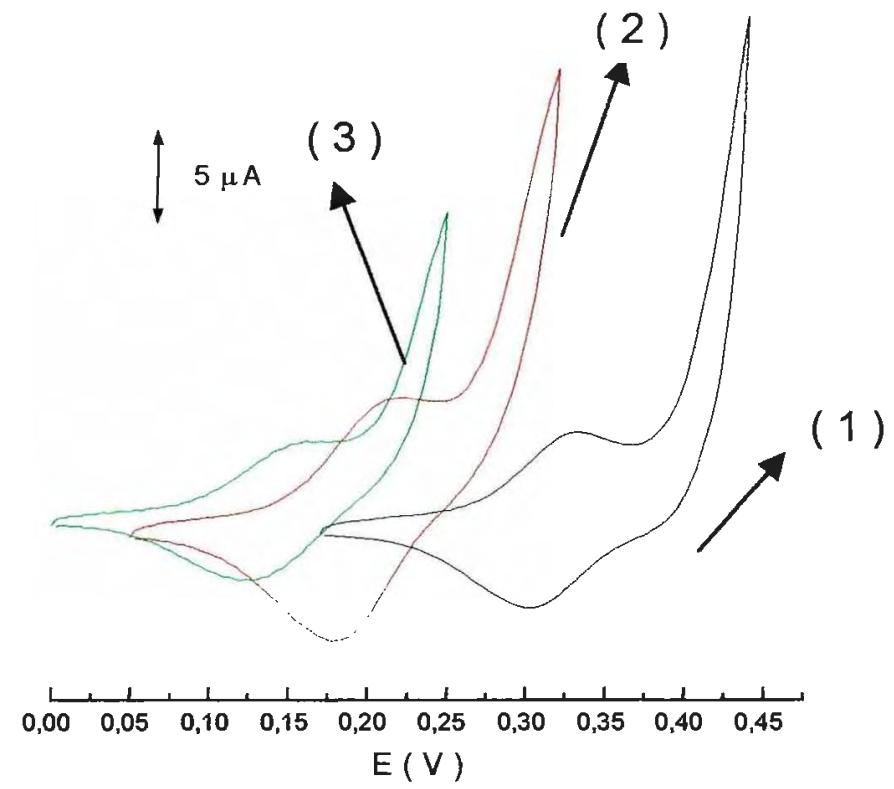

Figura 3.13: Voltamogramas cíclicos correspondentes ao décimo ciclo de formação dos filmes de 3,4-DHB em diferentes valores de $\mathrm{pH}$ : (1) pH 4,6 e $0,17 \leq \mathrm{E}_{\text {aplicado }} \leq 0,44 \mathrm{~V}$; ( 2 ) pH 6,8 e 0,05 $\leq \mathrm{E}_{\text {aplicado }} \leq 0,32 \mathrm{~V}$; ( 3 ) pH 7,8 e $0,0 \leq \mathrm{E}_{\text {aplicado }} \leq 0,25 \mathrm{~V}$. 
Após a formação dos filmes, os eletrodos modificados foram lavados com água deionizada e transportados para eletrólito suporte, tampão PIPES $\mathrm{pH} 6,8$, independentemente do $\mathrm{pH}$ de formação do filme. Os dados apresentados na tabela 3.8 indicam que as menores percentagens de perda de filme ativo foram obtidas para filmes formados em $\mathrm{pH} 7,8$. No entanto, os valores numéricos das perdas são ligeiramente menores para filmes formados, sob condições em que o potencial de inversão de varredura foi fixado no início do segundo processo eletródico .

Tabela 3.8: Percentagens de perda de filme ativo para eletrodos modificados por ciclagem como função do potencial de inversão anódico: (1) Potencial de inversão de varredura fixado no início do segundo processo de oxidação ( 2 ) Potencial de inversão de varredura fixado no fim do primeiro processo de oxidação.

\begin{tabular}{|c|c|c|c|c|}
\hline $\begin{array}{c}\mathrm{pH} \text { de } \\
\text { formação do } \\
\text { filme }\end{array}$ & $\begin{array}{l}\text { \% de perda } \\
\text { de filme ativo } \\
(\mid p, a) \\
\text { (1) }\end{array}$ & $\begin{array}{l}\text { \% de perda } \\
\text { de filme ativo } \\
(\mid p, c) \\
\text { (1) }\end{array}$ & $\begin{array}{c}\text { \% de perda } \\
\text { de filme ativo } \\
(I p, a) \\
\text { (2) }\end{array}$ & $\begin{array}{c}\text { \% de perda } \\
\text { de filme ativo } \\
(I p, C) \\
\text { (2) }\end{array}$ \\
\hline 3,6 & * & * & * & * \\
\hline 4,6 & 13 & 14 & * & * \\
\hline 6,6 & 16 & 16 & 21 & 21 \\
\hline 7,8 & 11 & 12 & 13 & 10 \\
\hline
\end{tabular}

Os voltamogramas cíclicos foram mal definidos, impossibilitando o cálculo de \% de perda de filme ativo.

Cálculos efetuados comparando-se os níveis de corrente (registrados em eletrólito suporte, tampão PIPES $\mathrm{pH}=6,8)$ do vigésimo voltamograma cíclico com aqueles do segundo voltamograma cíclico (considerado como $100 \%$ ). 
Os voltamogramas cíclicos registrados com filmes formados em ambos potenciais de inversão de varredura apresentaram boa definição em eletrólito suporte. No entanto, os níveis de corrente anódico e catódico, foram maiores quando o potencial foi fixado no início do segundo processo eletródico (Tabela 3.9). Assim, é necessário que o potencial anódico de inversão de varredura seja fixado no início do segundo processo anódico.

Tabela 3.9: Níveis de corrente anódica e catódica para filmes formados em diferentes valores de $\mathrm{pH}$ : ( 1 ) Potencial de inversão de varredura fixado no início do segundo processo de oxidação. ( 2 ) o potencial de inversão de varredura fixado ao término do primeiro processo de oxidação.

\begin{tabular}{ccccc}
\hline pH de & Ip,a & Ip,c & Ip,a & Ip,c \\
formação do & $(\mu \mathrm{A})$ & $(\mu \mathrm{A})$ & $(\mu \mathrm{A})$ & $(\mu \mathrm{A})$ \\
filme & $(1)$ & $(1)$ & $(2)$ & $(2)$ \\
\hline 4,6 & 10,4 & 10,2 & $*$ & $*$ \\
6,6 & 11,2 & 11,9 & 4,24 & 4,49 \\
7,8 & 10,2 & 10,5 & 8,45 & 9,16
\end{tabular}

Os voltamogramas cíclicos foram mal definidos, impossibilitando a determinação dos níveis de corrente.

Os valores dos níveis de corrente correspondem ao vigésimo voltamograma cíclico, registrado em eletrólito suporte tampão PIPES pH 6,8. 
3.2 Eletrodos de pasta de carbono modificados com filmes de

\section{3,4-DHB obtidos por deposição a potencial controlado}

Eletrodos de pasta de carbono modificados com filmes de 3,4-DHB também foram preparados por deposição a potencial controlado em diferentes valores de $\mathrm{pH}$. O potencial foi fixado em um dos dois valores de acordo com a tabela 2.2. O tempo de aplicação de potencial foi de 3 ou 6 minutos, para potenciais fixados no início do segundo processo oxidação, ou potenciais fixados logo após o término do primeiro processo oxidação.

\subsubsection{Eletrodos de pasta de carbono modificados com filmes de}

3,4-DHB preparados por deposição com potencial fixado no início do segundo processo de oxidação

O potencial de deposição foi fixado em um valor correspondente ao início de segundo processo de oxidação. O tempo de deposição para a formação do filme foi de 3 ou 6 minutos. Para analisar a estabilidade dos eletrodos modificados os voltamogramas cíclicos foram registrados em tampão PIPES, pH 6,8.

O eletrodo modificado com filme de 3,4-DHB formado em $\mathrm{pH} 3,6$ apresentou voltamogramas cíclicos mal definidos em tampão, PIPES pH 6,8. Este fato impossibilitou a determinação dos níveis de corrente. O mesmo não foi observado para filmes formados em $\mathrm{pH} 4,6 ; 6,6$ e 7,8. 
As percentagens de perda de filme ativo, bem como valores de corrente, anódica e catódica, obtidas são apresentados na tabela 3.10 e 3.11 , respectivamente.

Tabela 3.10: Percentagens de perda de filme ativo em tampão PIPES pH=6,8 para eletrodos modificados a potencial controlado como função do $\mathrm{pH}$ de formação.

\begin{tabular}{ccccc}
\hline $\begin{array}{c}\text { Tempo de } \\
\text { deposição } \\
\text { ( } \min )\end{array}$ & $\begin{array}{c}\text { Potencial de } \\
\text { deposição } \\
\text { ( V })\end{array}$ & $\begin{array}{c}\mathrm{pH} \text { de } \\
\text { formação do } \\
\text { filme }\end{array}$ & $\begin{array}{c}\text { \% de perda } \\
\text { de filme ativo } \\
(\text { Ip,a })\end{array}$ & $\begin{array}{c}\text { \% de perda } \\
\text { de filme ativo } \\
(\text { Ip,c })\end{array}$ \\
\hline 3 & 0,42 & 4,6 & 44 & 20 \\
3 & 0,30 & 6,6 & 14 & 12 \\
6 & 0,30 & 6,6 & 9 & 8 \\
3 & 0,25 & 7,8 & 16 & 9 \\
6 & 0,25 & 7,8 & 7 & 5
\end{tabular}

Potenciais de deposição correspondentes ao início do segundo processo de oxidação do 3,4DHB. Cálculos efetuados comparando-se os níveis de corrente do vigésimo voltamograma cíclico com aqueles do segundo voltamograma cíclico (considerado como 100\%).

Tabela 3.11: Valores de corrente anódico e catódico obtidos com eletrodos modificados com filmes de 3,4-DHB preparados a potencial controlado como função do $\mathrm{pH}$ de formação.

\begin{tabular}{ccccc}
$\begin{array}{c}\text { Tempo de } \\
\text { deposição } \\
(\min )\end{array}$ & $\begin{array}{c}\text { Potencial de } \\
\text { deposição } \\
(\mathrm{V})\end{array}$ & $\begin{array}{c}\mathrm{pH} \text { de } \\
\text { formação do } \\
\text { filme }\end{array}$ & $\begin{array}{c}\mathrm{Ip}, \mathrm{a} \\
(\mu \mathrm{A})\end{array}$ & $\begin{array}{c}\mathrm{lp}, \mathrm{c} \\
(\mu \mathrm{A})\end{array}$ \\
\hline 3 & 0,42 & 4,6 & 4,09 & 5,38 \\
3 & 0,30 & 6,6 & 23,3 & 24,3 \\
6 & 0,30 & 6,6 & 11,8 & 12,0 \\
3 & 0,25 & 7,8 & 7,64 & 8,48 \\
6 & 0,25 & 7,8 & 8,18 & 8,76
\end{tabular}

Potenciais de deposição correspondentes ao início do segundo processo de oxidação do 3,4DHB. Correntes correspondentes ao vigésimo voltamograma cíclico registrado em tampão PIPES, $\mathrm{pH}=6,8$. 
Os niveis de corrente, bem como, as percentagens de perda de filme ativo diminuíram com o aumento do tempo de deposição para 6 minutos em pH 6,6 (Tabelas 3.10 e 3.11), demonstrando eventual formação de um filme mais espesso, porém com menor número de sítios ativos (níveis inferiores de corrente). Por outro lado, a percentagem de perda de filme ativo diminuiu, demonstrando que estes eram mais estáveis.

Deste modo, os eletrodos preparados em pH 6,6 e 7,8 com tempo de deposição de 6 minutos foram escolhidos para utilização em sistema FIA e os resultados utilizados para concluir qual seria o melhor $\mathrm{pH}$ de formação.

\subsubsection{Eletrodos de pasta de carbono modificados com filmes de}

3,4-DHB preparados por deposição com potencial fixado após o término do primeiro processo de oxidação

Fixou-se também, o potencial de deposição ao término do primeiro processo de oxidação, com a finalidade de comparar os resultados com aqueles obtidos no item anterior. Os tempos de deposição para a formação do filme foram de 3 ou 6 minutos. Os testes de estabilidade foram efetuados em tampão PIPES, pH 6,8.

Quando o potencial foi fixado ao término do primeiro processo de oxidação, obtiveram-se niveis mais elevados de corrente (Tabela 3.12) e menor percentagem de perda de filme ativo (Tabela 3.13) para os eletrodos modificados em pH 7,8, com tempo de deposição de 6 minutos. 
Tabela 3.12: Valores de corrente anódica e catódica para filmes formados em diferentes valores de $\mathrm{pH}$, com o potencial fixado ao término do primeiro processo oxidação.

\begin{tabular}{cccccc}
\hline $\begin{array}{c}\text { Potencial } \\
\text { de } \\
\text { deposição } \\
(\mathrm{V})\end{array}$ & $\begin{array}{c}\mathrm{pH} \text { de } \\
\text { formação } \\
\text { do filme }\end{array}$ & $\begin{array}{c}\mathrm{Ip}, \mathrm{a} \\
(\mu \mathrm{A})\end{array}$ & $\begin{array}{c}\mathrm{lp}, \mathrm{c} \\
(\mu \mathrm{A})\end{array}$ & $\begin{array}{c}\mathrm{Ip}, \mathrm{a} \\
(\mu \mathrm{A})\end{array}$ & $\begin{array}{c}\mathrm{lp}, \mathrm{c} \\
(\mu \mathrm{A})\end{array}$ \\
\hline 0,38 & 4,6 & $\star$ & $*$ & $*$ & $*$ \\
0,26 & 6,6 & 6,71 & 6,90 & 6,23 & 6,35 \\
0,20 & 7,8 & 6,38 & 6,62 & 11,6 & 12,0
\end{tabular}

Os voltamogramas cíclicos foram mal definidos, impossibilitando a determinação dos niveis de corrente.

Os níveis de corrente apresentados correspondem do vigésimo voltamograma cíclico registrado em eletrólito suporte, tampão PIPES pH 6,8.

Tabela 3.13: Percentagens de perda de filme ativo em tampão PIPES pH 6,8 para eletrodos modificados a potencial controlado como função do $\mathrm{pH}$ de formação.

\begin{tabular}{|c|c|c|c|c|c|}
\hline $\begin{array}{l}\text { Potencial } \\
\text { de } \\
\text { deposição } \\
\text { (V) }\end{array}$ & $\begin{array}{c}\mathrm{pH} \text { de } \\
\text { formação } \\
\text { do filme }\end{array}$ & $\begin{array}{c}\text { \% de perda } \\
\text { de filme } \\
\text { ativo } \\
(\text { Ip,a }) \\
3 \text { minutos }\end{array}$ & $\begin{array}{c}\text { \% de perda } \\
\text { de filme } \\
\text { ativo } \\
(I p, c) \\
3 \text { minutos }\end{array}$ & $\begin{array}{c}\% \text { de perda } \\
\text { de filme } \\
\text { ativo } \\
\text { (Ip,a) } \\
6 \text { minutos }\end{array}$ & $\begin{array}{c}\% \text { de perda } \\
\text { de filme } \\
\text { ativo } \\
(\mathrm{lp}, \mathrm{C}) \\
6 \text { minutos }\end{array}$ \\
\hline 0,38 & 4,6 & * & * & * & * \\
\hline 0,26 & 6,6 & 18 & 15 & 19 & 15 \\
\hline 0,20 & 7,8 & 13 & 11 & 9 & 8 \\
\hline
\end{tabular}

Os voltamogramas cíclicos foram mal definidos, impossibilitando o cálculo da percentagem de perda de filme ativo.

Potencial fixado ao término do primeiro processo oxidação. Cálculos efetuados comparando-se os niveis de corrente do vigésimo voltamograma cíclico com aqueles do segundo voltamograma (considerado como $100 \%$ ). 
Para filmes preparados a potencial controlado, o potencial aplicado (fim do primeiro processo anódico ou início do segundo processo anódico) não foi um fator limitante para obtenção de filmes mais estáveis. Neste caso o fator mais importante foi realmente o $\mathrm{pH}$.

3.3 Melhores condições de formação de filme obtidos por voltametria cíclica e a potencial controlado

As melhores condições para formação de filme foram: ( a ) filme formado por voltametria cíclica $\left(\mathrm{pH} \quad 7,8 ; 0,25 \mathrm{mmol}^{-1}\right.$ de 3,4-DHB; $0 \leq \mathrm{E}$ aplicado $\leq 0,25 \mathrm{~V}$; velocidade de varredura $10 \mathrm{mVs}^{-1}$ e 10 ciclos); (b ) filme formado a potencial controlado $\left(\mathrm{pH} \mathrm{6,6;0,25} \mathrm{mmol} \mathrm{L}^{-1}\right.$ de 3,4-DHB;

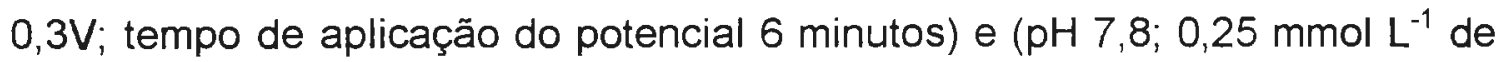
3,4-DHB; 0,25V; tempo de aplicação do potencial 6 minutos ).

A escolha do melhor método de modificação foi efetuada durante a determinação catalítica de NADH em sistema FIA e será discutida posteriormente. 


\subsection{Eletroquímica do filme de 3,4-DHB eletropolimerizado}

Como mencionado no item 1.2 , o parâmetro $\left|E_{p}-E_{p / 2}\right|$ pode ser utilizado para diagnosticar a reversibilidade de um sistema e permite avaliar o número de elétrons envolvidos no processo eletródico. Para filmes formados por ciclagem e nas condições otimizadas, o valor experimental obtido para este parâmetro foi $0,030 \mathrm{~V}$, calculado a partir de voltamogramas registrados em eletrólito suporte.

Substituindo-se este valor na equação 1 , verifica-se que o número de elétrons envolvido no processo eletródico é 2.

De acordo com as figuras $3.4 \mathrm{~A}$ e $3.4 \mathrm{~B}$, a variação de $\Delta \mathrm{Ep} / \Delta \mathrm{pH}$ para os processos anódico e catódico corresponde a $0,064 \mathrm{~V}$, indicativo de que 0 número de prótons e elétrons envolvidos no processo eletródico é o mesmo. Deste modo, substituindo-se o valor de $\Delta \mathrm{Ep} / \Delta \mathrm{pH}$ na equação 2 e considerando $n=2$, observa-se que $p$ também corresponde a 2 .

O voltamograma cíclico do eletrodo modificado, registrado em eletrólito suporte, foi utilizado para estimar o excesso superficial ou concentração superficial $(\Gamma)$ de 3,4-DHB imobilizada no eletrodo (Figura 3.14) 


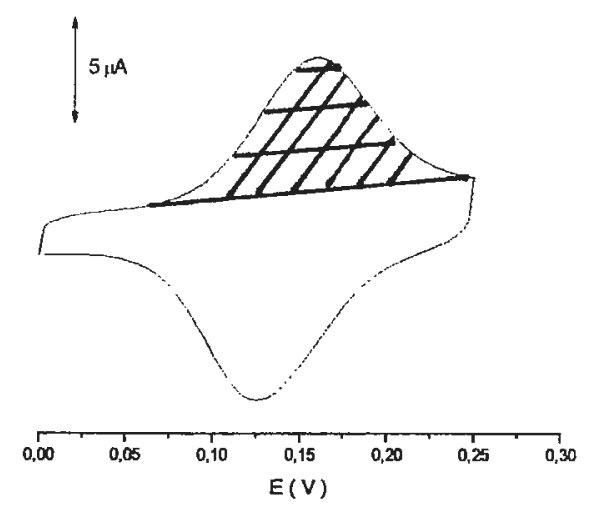

Figura 3.14: Voltamograma cíclico, registrado em eletrólito suporte, com o eletrodo modificado por ciclagem, utilizado para cálculo do excesso superficial do agente modificador.

Para tanto, determinou-se a carga do pico anódico, após descontar a contribuição da corrente capacitiva, encontrando-se o valor de $1,1 \times 10^{-5} \mathrm{C}$. Considerando-se que 2 elétrons estão envolvidos no processo eletródico e que o eletrodo possui área de $0,070 \mathrm{~cm}^{2}$, o valor estimado de $\Gamma$ (equação 4) foi de $8 \times 10^{-10} \mathrm{~mol} \mathrm{~cm}^{-2}$. 


\subsection{Mecanismo proposto para formação dos filmes} eletropolimerizados de 3,4-DHB

Pariente et al. [62] acreditam que o mecanismo de eletropolimerização em soluções de 3,4-DHB ocorre a partir da formação de radicais livres, citando como exemplo o trabalho efetuado por Hapiot et al [76]. Estes últimos estudaram o comportamento eletroquímico do cumaraldeido, coniferaldeído e sinapaldeído, demonstrando que filmes eletropolimerizados destes compostos são constituidos de dímeros formados a partir de radicais livres. Os gráficos Ep vs $\log v\left(0,05 \leq\right.$ velocidade $\left.\leq 20 \mathrm{Vs}^{-1}\right)$ apresentaram coeficientes angulares da ordem de $20 \mathrm{mV}$ com largura de pico de $\sim 41 \mathrm{mV}$, dados característicos da formação de dímeros: $\partial \mathrm{Ep} / \partial \log (\mathrm{v})=19,7 \mathrm{mV}$ e largura de pico $40 \mathrm{mV}$.

Esta relação não foi observada em nosso trabalho, pois o potencial de pico não variou com o aumento da velocidade de varredura.

Gao et al. [75] apresentaram uma proposta de eletropolimerização em que 0 processo se inicia através do grupamento aldeído, mas Pariente et al. [62] não observaram a formação de filmes poliméricos a partir de soluções de benzaldeído. Segundo eles, o bezaldeído apresentou um pico irreversível a $1,8 \mathrm{~V}$ e os picos redox no intervalo de $+0,5$ a $-0,2 \mathrm{~V}$ em eletrólito suporte não foram observados. Somente as correntes de fundo foram registradas.

Com base nos resultados obtidos neste trabalho, propôs-se o mecanismo apresentado na Figura 3.15 para a formação do filme eletropolimerizado de 3,4-DHB. 
1VOLTAMOGRAMA CÍCLICO

- Varredura Anódica

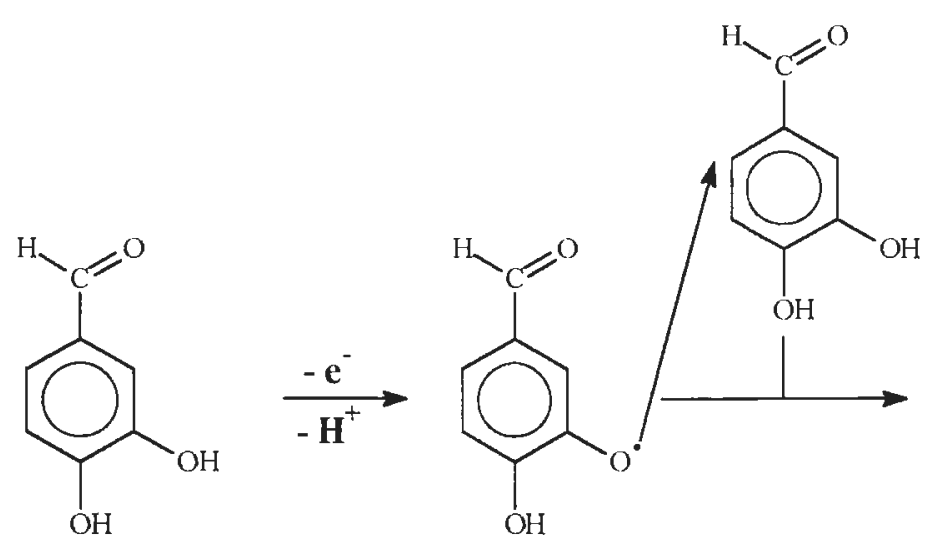

(I)

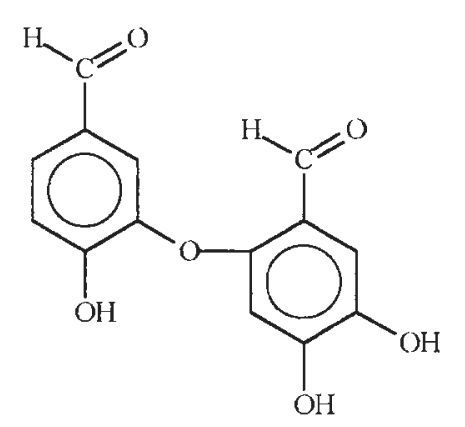

(III)<smiles>O=Cc1ccc(O)c(OC2C=C(O)C(O)=CC2=O)c1</smiles>

(II)

- Varredura Catódica<smiles>O=Cc1ccc(O)c(Oc2cc(O)c(O)cc2C=O)c1</smiles>

(III)<smiles>O=Cc1cc(O)c(O)cc1OC1CC=CC=C1O</smiles> 
$2^{\circ}$ VOLTAMOGRAMA CÍCLICO

- Varredura Anódica<smiles>CC1(Oc2cc(O)c(O)cc2C=O)C(O)=C(I)C=CC1C=O</smiles><smiles></smiles>

(V)

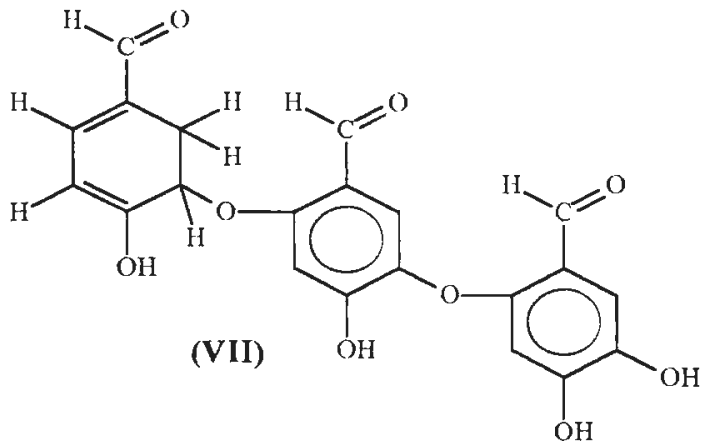

- Varredura Catódica<smiles>[12H]c1cc(C=O)c(Oc2cc(C=O)c(OC3CC(C=O)=CC([Tl])=C3O)cc2O)cc1O</smiles><smiles>O=Cc1cc(O)c(O)cc1O[C@H]1C(O)=CC=CC1C=O</smiles><smiles>CC(C)Oc1ccc(C=O)cc1O</smiles>

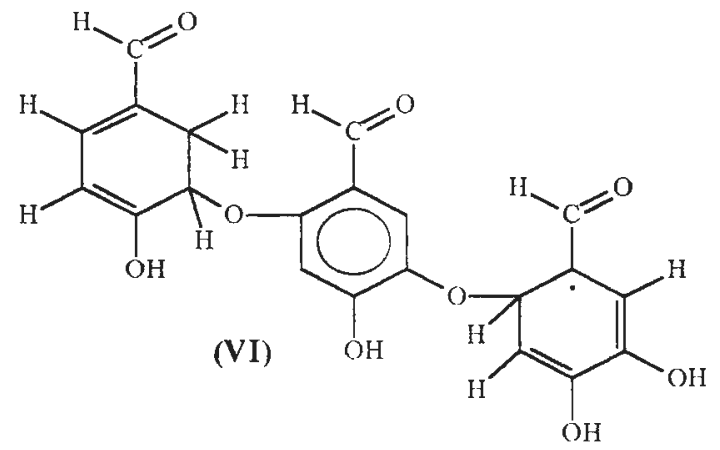

Figura 3.15: Mecanismo proposto para a formação do filme de 3,4-DHB em eletrodos de pasta de carbono. 
Durante a primeira varredura anódica, a molécula de 3,4-DHB perde 1 próton e 1 elétron produzindo o radical fenoxil (I). No mecanismo proposto, o radical é formado na hidroxila ligada ao carbono (3), porém o mesmo poderia ser igualmente formado na hidroxila ligada ao carbono (4) do anel aromático. É provável que o radical esteja sendo formado no início do segundo processo de oxidação do 3,4-DHB, de modo que nenhum pico de oxidação, correspondente a formação do radical foi registrado. O radical fenoxil (I) ataca outra molécula de 3,4-DHB produzindo um novo radical livre (II), posteriormente oxidado ao composto (III), em uma etapa envolvendo 1 próton e 1 elétron. Na varredura reversa, o composto (III) é reduzido ao composto (IV) em um processo envolvendo 2 elétrons e 2 prótons.

No segundo voltamograma cíclico o composto (IV) é então re-oxidado a um outro radical fenoxil, (V), em um potencial mais baixo do que àquele correspondente ao $2^{0}$ pico de oxidação da molécula de $3,4-\mathrm{DHB}(0,28 \mathrm{~V}$ vs $\mathrm{Ag} / \mathrm{AgCl}, \mathrm{KCl}$ sat, $\mathrm{pH} \mathrm{7,8).} \mathrm{Esta} \mathrm{possibilidade} \mathrm{é} \mathrm{viável,} \mathrm{porque} \mathrm{o} \mathrm{composto} \mathrm{(IV)}$ possui um oxigênio a mais ligado ao anel aromático, o qual deve favorecer a estabilização do radical fenoxil, (V). Este último ataca nova molécula de 3,4-DHB para produzir o composto (VI), posteriormente oxidado ao composto (VII) numa etapa envolvendo mais 1 elétron e 1 próton. Na varredura reversa o composto (VII) é reduzido ao composto (VIII) num processo envolvendo mais 2 prótons e 2 elétrons.

Em eletrólito suporte, os picos de oxidação e redução registrados devem envolver o par redox (VII)/(VIII), ou compostos com estruturas similares, cujo potencial médio $(\mathrm{Em})$ em $\mathrm{pH} 7,8$ corresponde a $0,12 \mathrm{~V}$ vs $\mathrm{Ag} / \mathrm{AgCl}, \mathrm{KCl}$ sat $(E p, a=0,14 \mathrm{~V}$ e $E p, c=0,098 \mathrm{~V})$. A oxidação catalítica do $\mathrm{NADH}$ pode ser 
promovida por reação química com os grupos aldeído, ou ainda com os radicais fenoxil, formados mediante o potencial aplicado. Em ambas as possibilidades aventadas, a espécie reduzida formada durante a reação química é re-oxidada na superfície do eletrodo com a corrente de oxidação sendo proporcional à concentração de NADH em solução.

Uma outra questão, é a maneira pela qual o filme é imobilizado na superfície do eletrodo. Uma das possibilidades é admitir que uma das formas tautoméricas do composto (IV), (IV a), (IV b) e (IV c) seja fisicamente imobilizada na superfície do eletrodo:<smiles>O=Cc1cc(O)c(O)cc1OC1CC(C=O)CC=C1O</smiles><smiles>[2H][C@H]1C(=O)C[C@H](C)C=C(C=O)[C@H]1Oc1cc(O)c(O)cc1C=O</smiles><smiles>O=Cc1cc(O)c(O)cc1OC1=CC(C=O)C(C=O)C(=O)C1</smiles><smiles>O=Cc1cc(O)c(O)cc1OC1CC(C=O)C=CC1=O</smiles>

Figura 3.15.1: Estruturas tautoméricas do composto (IV)

Segundo este mecanismo, baixas velocidades de varredura deveriam ser utilizadas durante o processo de eletropolimerização, de modo a permitir a 
formação do filme e imobilização física do mesmo na superfície do eletrodo. Quando o filme é formado a partir de soluções concentradas de 3,4 -DHB, maior concentração de radicais fenoxil é formada durante a etapa de oxidação - que, pelo menos em tese, facilitaria a formação de vários pontos de nucleação em detrimento da formação e crescimento de um filme homogêneo. Esta análise é perfeitamente compativel com os resultados experimentais obtidos.

Este modelo explica também porque os melhores resultados foram obtidos em $\mathrm{pH}$ 7,8: em meio ácido os grupos fenólicos encontram-se protonacos, dificultando a formação do radical fenoxil. Em valores de pH 10,2 o grupo aldeído pode ser transformado no respectivo hidrato (gendiol) oxidado irreversivelmente (Figura 3.16).

\section{(A)}<smiles>O=Cc1ccc(O)c(O)c1</smiles>

Figura 3.16: (A) 3,4 - DHB
(B)<smiles>Oc1ccc(C(O)O)cc1O</smiles> 
Quando o potencial de inversão de varredura para formação do filme foi fixado após o segundo processo de oxidação, à medida que os voltamogramas foram sendo efetuados (10 ciclos), observou-se aumento dos niveis de corrente correspondentes ao par reversível, ou seja, o crescimento do filme e simultaneamente uma queda na corrente do segundo pico de oxidação. (Figura 3.2). Este fato pode ser atribuído à formação de um filme não condutor. No potencial correspondente ao segundo processo eletródico de oxidação do 3,4-DHB, o radical derivado (II) pode ser oxidado, juntamente com o 3,4-DHB que chega por difusão para formar a respectiva quinona. Conseqüentemente dificulta-se a formação do filme, além de ser ter um crescimento desordenado.

Com o objetivo de obter subsídios experimentais que suportassem este mecanismo, eletrodos de pasta de carbono foram modificados em soluções de 3,4 $\mathrm{DHB}$ na presença do cofatores NADPH e NADH, que sabidamente reduzem radicais fenoxil em sistemas biológicos $[\mathbf{7 7 , 7 8 ]}$. A figura 3.17 mostra que na presença do cofator NADPH a formação do filme é totalmente inibida, enquanto na presença de NADH, esta é parcialmente inibida. 


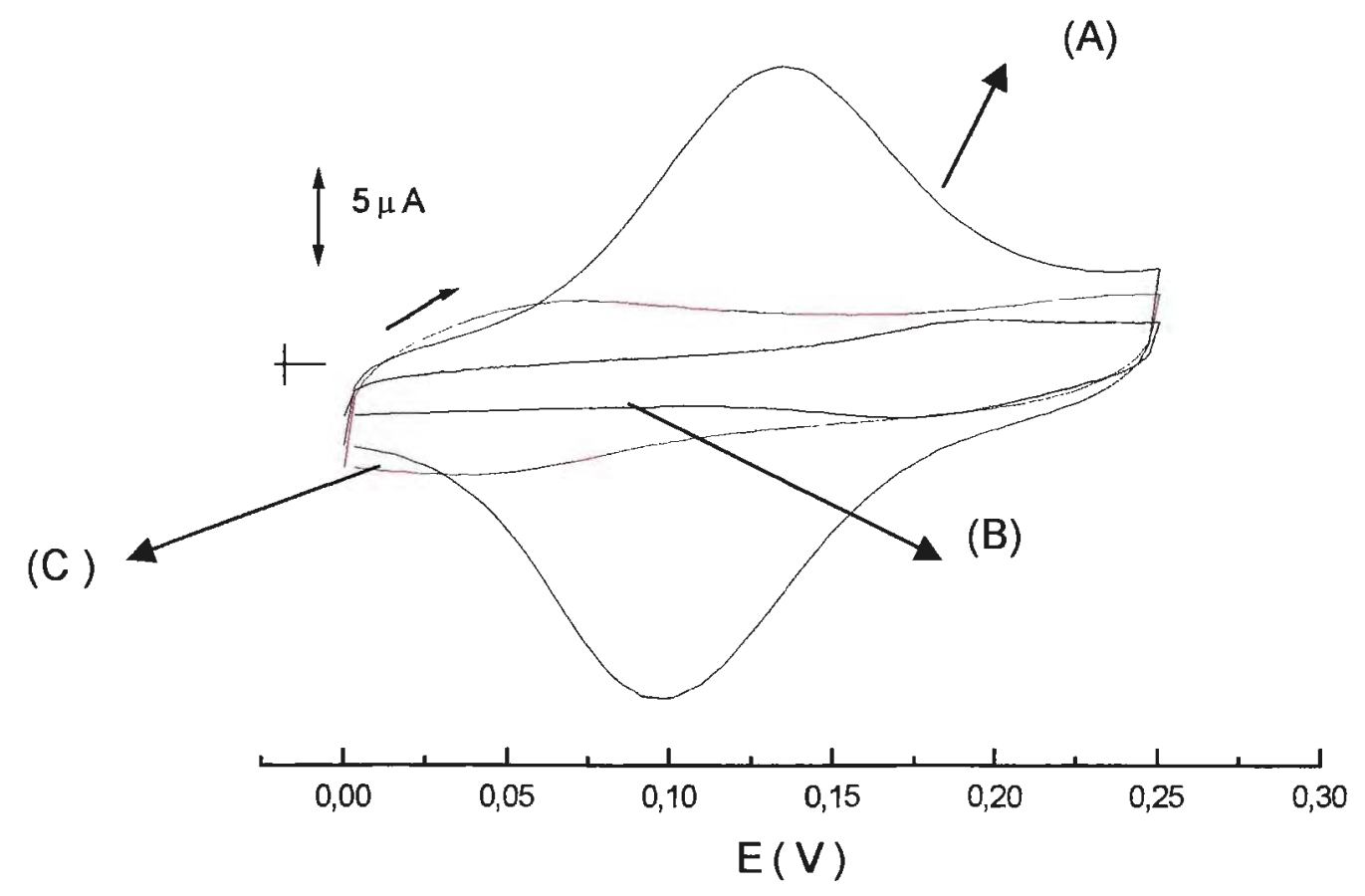

Figura 3.17: (A) voltamograma cíclico registrado em tampão fosfato, $\mathrm{pH} 7,8$ com o eletrodo modificado apenas em solução de 3,4 DHB. (B) Voltamograma ciclico registrado com o eletrodo modificado em solução de 3,4-DHB contendo $\mathrm{NADH}$; (C) Voltamograma ciclico registrado com o eletrodo modificado em solução de 3,4-DHB contendo NADPH;

Para certificar-se que a formação do filme não era inibida devido a adsorção de NADPH na superfície do eletrodo (Figura 3.17), este último foi ciclado em solução de $0,60 \mathrm{mmol} \mathrm{L}^{-1}$ de NADPH (10 ciclos, velocidade de varredura $10 \mathrm{mVs}^{-1}, 0,0 \leq E_{\text {aplicado }} \leq 0,25 \mathrm{~V}$ ), antes da formação do filme eletropolimerizado de 3,4-DHB (Figura 3.18 A). O eletrodo foi então transferido para solução de $0,25 \mathrm{mmol} \mathrm{L}^{-1}$ de 3,4-DHB, onde a formação normal do filme foi observada (Figura 3.18 B). Em seguida, registraram-se voltamogramas 
cíclicos, com o eletrodo modificado, em tampão fosfato, pH 7,8 (Figura 3.18 C). Portanto, a inibição da formação do filme na presença de NADPH (Figura 3.17) é um forte indicativo da formação do filme realmente envolve com a formação inicial de radicais fenoxil.

(A)

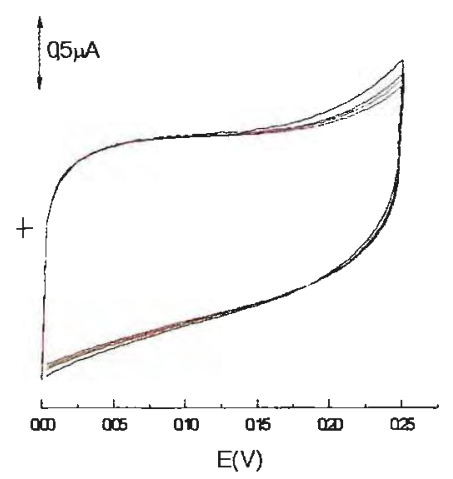

(B)

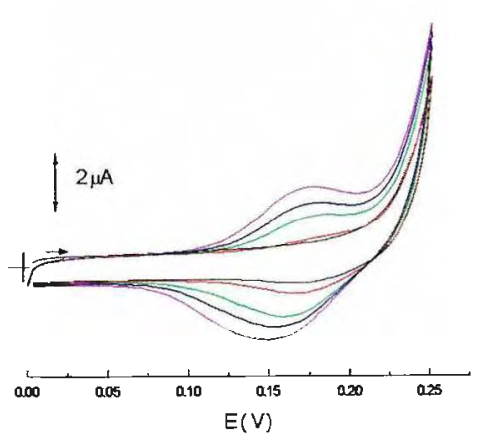

(C)

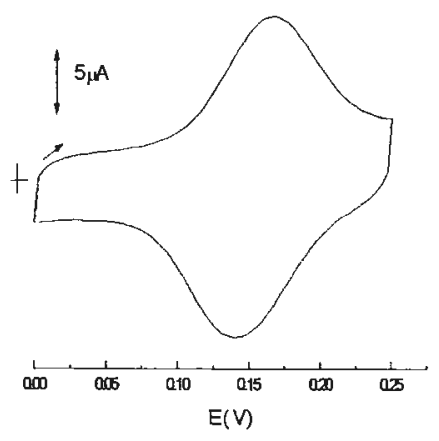

Figura 3.18: ( A ) Voltamogramas cíclicos registrados em soluções de $0,6 \mathrm{mmol} \mathrm{L}^{-1}$ de NADPH nas melhores condições de obtenção do filme de 3,4-DHB.( B ) Voltamogramas registrados em solução de $0,25 \mathrm{mmol} \mathrm{L}^{-1}$ de 3,4-DHB, após a ciclagem em solução de NADPH. ( C ) Voltamograma cíclico realizado em tampão fosfato $\mathrm{pH} 7,8$ após realização das etapas $(A)$ e $(B)$.

\subsection{Determinação catalítica de NADH com eletrodos de pasta de carbono modificados com filmes eletropolimerizados de 3,4-DHB}

Utilizando-se eletrodos de pasta de carbono modificados por ciclagem em solução de 3,4-DHB nas condições otimizadas: [3,4-DHB] $=0,25 \mathrm{mmol} \mathrm{L}^{-1}$; $\mathrm{pH}=7,8$; número de ciclos $=10$; intervalo de varredura $0,0 \leq \mathrm{E}_{\text {aplicado }} \leq 0,25 \mathrm{Ve}$ 
velocidade de varredura de $10 \mathrm{mVs}^{-1}$, estudou-se a oxidação catalítica de NADH.

O filme eletropolimerizado atua como mediador para a forma reduzida NADH (Figura 3.19 A) segundo o esquema:

$$
\mathrm{NADH}+\text { Filme }_{(\mathrm{ox})} \rightarrow \mathrm{NAD}^{+}+\text {Filme }_{(\text {red) }}
$$

Filme $_{(\text {red.) }} \rightarrow$ Filme $_{(\text {ox })}+2 e^{-}$[no eletrodo]

(A)

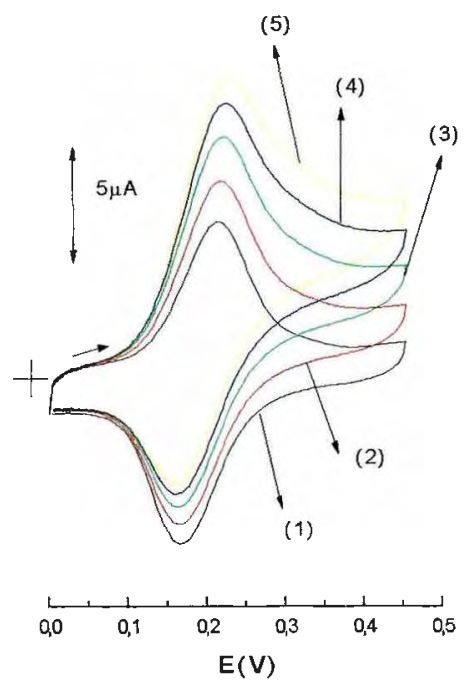

(B)

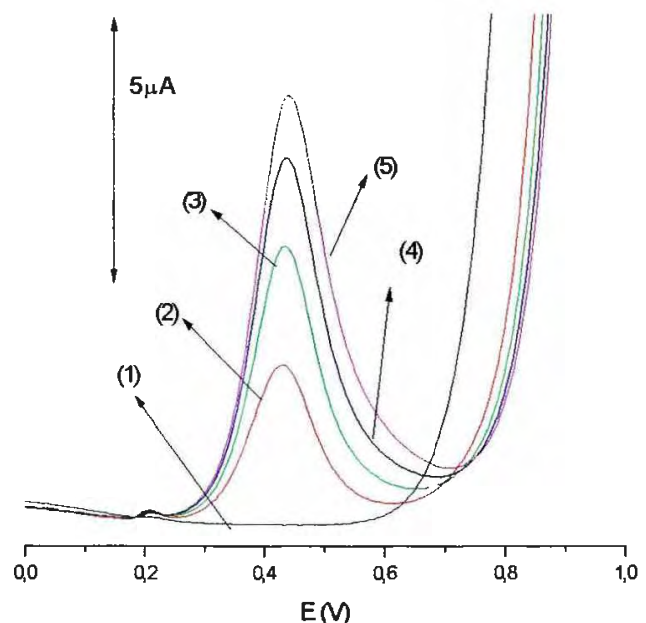

Figura 3.19: (A) Voltamogramas cíclicos registrados em soluções de NADH, $\mathrm{pH}$ 6,8, com eletrodo modificado com 3,4-DHB: (1) branco, (2) $0,16 \mathrm{mmol} \mathrm{L}^{-1}$; (3) $0,34 \mathrm{mmol} \mathrm{L}^{-1}$; (4) $0,51 \mathrm{mmol} \mathrm{L}^{-1}$; (5) $0,65 \mathrm{mmol} \mathrm{L}^{-1}$. (B) Voltamogramas de pulso diferencial, registrados em soluções de $\mathrm{NADH}, \mathrm{pH} 6,8$, com eletrodo de pasta de carbono (1) branco, (2) $0,19 \mathrm{mmol} \mathrm{L}^{-1}$; (3) $0,35 \mathrm{mmol} \mathrm{L}^{-1}$; (4) 0,49 $\mathrm{mmol} \mathrm{L}^{-1}$; (5) $0,62 \mathrm{mmol} \mathrm{L}^{-1}$.

A figura 3.20 refere-se ao amperograma e a curva analítica realizados em soluções de $\mathrm{NADH}$.

A faixa linear para o $\mathrm{NADH}$ foi de $0,015 \leq[\mathrm{NADH}] \leq 0,21 \mathrm{mmol} \mathrm{L}^{-1}$. 

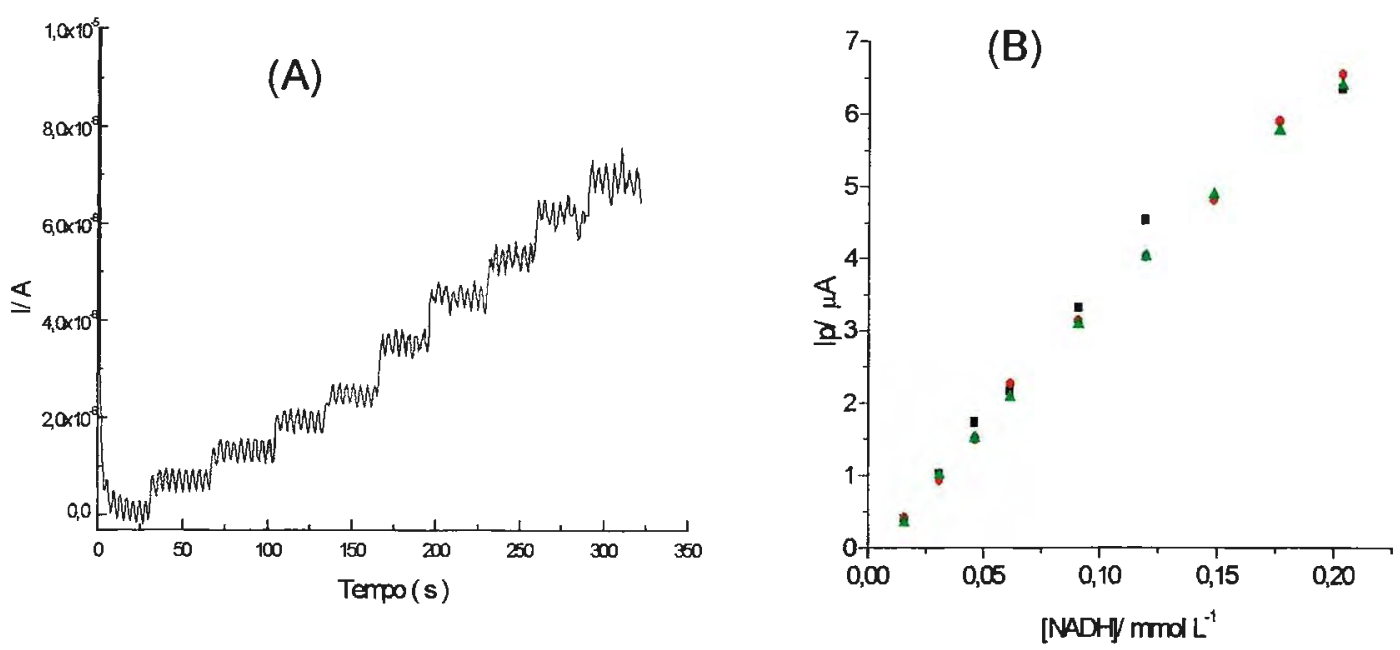

Figura 3.20: (A) Amperograma registrado em soluções de NADH (segunda curva analítica). (B) Curvas analíticas para determinação de NADH: (preto) $1^{\text {a }}$ curva analítica; (verde) $2^{\mathrm{a}}$ curva analítica; (vermelho) $3^{\mathrm{a}}$ curva analítica.

$$
\begin{array}{lc}
\mathrm{I}_{1}=0,187+32,2[\mathrm{NADH}] & r: 0,9893 \\
\mathrm{I}_{2}=0,0505+32,8[\mathrm{NADH}] & r: 0,9981 \\
\mathrm{I}_{3}=0,0504+32,4[\mathrm{NADH}] & r: 0,9984
\end{array}
$$

Sendo $r=$ coeficiente de correlação

3.7 Influência da forma de armazenamento do eletrodo na determinação catalítica do NADH

Avaliou-se o desempenho do eletrodo modificado para determinação catalítica de NADH como função da forma de armazenamento do mesmo (item 2.8). 
Conforme se analisa pela tabela 3.15 , os dados da primeira e segunda curvas analíticas (realizadas no mesmo dia) para os três eletrodos modificados foram praticamente idênticas.

O EPC modificado com 3,4-DHB manteve a superficie ativa quando guardado, por 24 horas em solução tampão fosfato pH 7,8 ou em solução de $0,025 \mathrm{mmol} \mathrm{L}^{-1}$ de 3,4-DHB (igualmente preparada em solução tampão fosfato, $\mathrm{pH}=7,8$ ). Por outro lado, mantendo-se o eletrodo a seco por 24 horas, observou-se uma diminuição brusca de sensibilidade.

Portanto a superfície deve estar sempre úmida, já que quando o eletrodo quando foi mantido a temperatura ambiente a sensibilidade aumentou com o passar do tempo de utilização em solução.

Comparando-se os dados obtidos para o eletrodo mantido em solução tampão com aqueles obtidos para o eletrodo mantido em solução de 3,4-DHB, concluiu-se que o eletrodo modificado guardado em tampão fosfato apresentou maior sensibilidade. 
Tabela 3.14: Avaliação do desempenho analítico do eletrodo como função do método de armazenamento. Estudo da faixa linear de 0,015 $\leq[\mathrm{NADH}] \leq$ $0,21 \mathrm{mmol} \mathrm{L}^{-1} \mathrm{com} \mathrm{Ip}=\mathrm{A}+\mathrm{B}[3,4 \mathrm{DHB}]$.

Eletrodo de pasta de carbono modificado mantido em solução tampão fosfato $\mathrm{pH} 7,8$.

\begin{tabular}{ccccc}
$\begin{array}{c}\text { Tempo de } \\
\text { armazenamento } \\
(\mathrm{h})\end{array}$ & Curva Analítica & $\begin{array}{c}\mathrm{A} \\
(\mu \mathrm{A})\end{array}$ & $\begin{array}{c}\mathrm{B} \\
\left(\mathrm{mA} / \mathrm{molL}^{-1}\right)\end{array}$ & $\begin{array}{c}\text { Coeficiente } \\
\text { de } \\
\text { Correlação }\end{array}$ \\
\hline $\begin{array}{c}\text { Curva realizada } \\
\text { no dia da }\end{array}$ & $1^{\mathrm{a}}$ & 0,51 & 16,3 & 0,9975 \\
$\begin{array}{c}\text { preparação do } \\
\text { eletrodo }\end{array}$ & $2^{\mathrm{a}}$ & 0,43 & 15,2 & 0,9992 \\
24 & & & & \\
24 & $3^{\mathrm{a}}$ & 0,43 & 14,1 & 0,9984 \\
24 & $4^{\mathrm{a}}$ & 0,41 & 14,6 & 0,9982 \\
72 & $5^{\mathrm{a}}$ & 0,41 & 14,6 & 0,9982 \\
72 & & & & \\
72 & $6^{\mathrm{a}}$ & 0,32 & 13,2 & 0,9988 \\
& $7^{\mathrm{a}}$ & 0,35 & 13,1 & 0,9985 \\
& $8^{\mathrm{a}}$ & 0,35 & 12,6 & 0,9984 \\
\hline
\end{tabular}

Eletrodo de pasta de carbono modificado mantido em solução de 3,4-DHB (tampão fosfato $\mathrm{pH} \mathrm{7,8).}$

\begin{tabular}{ccccc}
\hline $\begin{array}{c}\text { Tempo de } \\
\text { armazenamento } \\
(\mathrm{h})\end{array}$ & Curva Analítica & $\begin{array}{c}\mathrm{A} \\
(\mu \mathrm{A})\end{array}$ & $\begin{array}{c}\mathrm{B} \\
\left(\mathrm{mA} / \mathrm{molL}^{-1}\right)\end{array}$ & $\begin{array}{c}\text { Coeficiente } \\
\text { de } \\
\text { Correlação }\end{array}$ \\
\hline $\begin{array}{c}\text { Curva realizada } \\
\text { no dia da }\end{array}$ & $1^{\mathrm{a}}$ & 0,63 & 15,3 & 0,9979 \\
$\begin{array}{c}\text { preparação do } \\
\text { eletrodo }\end{array}$ & $2^{\mathrm{a}}$ & 0,59 & 16,4 & 0,9988 \\
24 & & & & \\
24 & $3^{\mathrm{a}}$ & 0,57 & 11,1 & 0,9925 \\
24 & $4^{\mathrm{a}}$ & 0,55 & 11,2 & 0,9963 \\
& $5^{\mathrm{a}}$ & 0,51 & 10,8 & 0,9982 \\
\hline
\end{tabular}

Eletrodo de pasta de carbono modificado mantido a temperatura ambiente.

\begin{tabular}{ccccc}
\hline $\begin{array}{c}\text { Tempo de } \\
\text { armazenamento } \\
(\mathrm{h})\end{array}$ & Curva Analítica & $\begin{array}{c}\mathrm{A} \\
(\mu \mathrm{A})\end{array}$ & $\begin{array}{c}\mathrm{B} \\
\left(\mathrm{mA} / \mathrm{molL}^{-1}\right)\end{array}$ & $\begin{array}{c}\text { Coeficiente } \\
\text { de } \\
\text { Correlação }\end{array}$ \\
\hline $\begin{array}{c}\text { Curva realizada } \\
\text { no dia da }\end{array}$ & $1^{\mathrm{a}}$ & 0,61 & 19,2 & 0,9979 \\
$\begin{array}{c}\text { preparação do } \\
\text { eletrodo }\end{array}$ & $2^{\mathrm{a}}$ & 0,60 & 19,5 & 0,9993 \\
24 & & & & \\
24 & $3^{\mathrm{a}}$ & 0,40 & 11,8 & 0,9981 \\
24 & $4^{\mathrm{a}}$ & 0,48 & 10,9 & 0,9989 \\
& $5^{\mathrm{a}}$ & 0,49 & 12,8 & 0,9988 \\
\hline
\end{tabular}


3.8 Influência do pré tratamento do eletrodo de pasta de carbono em soluções de $\mathrm{NaOH}$

Avaliou-se também a necessidade do pré-tratamento eletroquímico do eletrodo de pasta de carbono em soluções de $\mathrm{NaOH} 1,0 \mathrm{~mol} \mathrm{~L}^{-1}$ como descrito no item 2.7.1. Para tanto, eletrodos de pasta de carbono foram modificados na ausência deste pré tratamento e nas condições otimizadas, sendo em seguida utilizados para determinação de NADH.

Realizaram-se 3 curvas analíticas, observando-se diminuição da faixa linear de resposta. Para a primeira curva analítica observou-se resposta linear na faixa de $0,015 \leq[\mathrm{NADH}] \leq 0,21 \mathrm{mmol} \mathrm{L}^{-1}$, enquanto para a segunda e a terceira curvas, a faixa linear diminui para $0,015 \leq[\mathrm{NADH}] \leq 0,059 \mathrm{mmol} \mathrm{L}^{-1} \mathrm{e}$ $0,015 \leq[\mathrm{NADH}] \leq 0,044 \mathrm{mmol} \mathrm{L}^{-1}$, respectivamente.

Filmes formados em eletrodos de pasta de carbono pré tratados eletroquimicamente em $\mathrm{NaOH}$ possuem resposta linear constante de $0,015 \leq[\mathrm{NADH}] \leq 0,21 \mathrm{mmol} \mathrm{L}^{-1}$.

Estes dados confirmam a necessidade do pré-tratamento, da superfície do eletrodo de pasta de carbono em solução de $\mathrm{NaOH}$ ou seja, a modificação da superfície do eletrodo através da alteração dos grupos de oxigênio já presentes na superfície. Segundo Pariente et al. [62] o filme de 3,4-DHB não polimeriza em eletrodo de platina, mas a polimerização ocorre em eletrodo de $\mathrm{SnO}_{2}$, sugerindo que espécies contendo oxigênio atuam no processo de adsorção do filme na superfície do eletrodo.

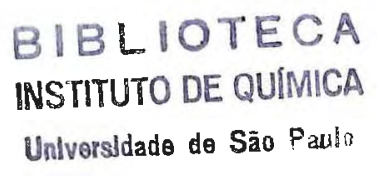




\subsection{Determinação de NADH e NADPH empregando sistema de análise por injeção em fluxo}

Utilizando-se eletrodos de pasta de carbono modificados por ciclagem em solução de 3,4-DHB nas condições otimizadas: $[3,4-\mathrm{DHB}]=0,25 \mathrm{mmol} \mathrm{L}^{-1}$; $\mathrm{pH}=7,8$; número de ciclos $=10$; intervalo de varredura $0,0 \leq \mathrm{E}_{\text {aplicado }} \leq 0,25 \mathrm{Ve}$ velocidade de varredura de $10 \mathrm{mVs}^{-1}$ e eletrodos modificados a potencial controlado nas condições otimizadas: [ 3,4-DHB ] $=0,25 \mathrm{mmol} \mathrm{L}^{-1}, \mathrm{pH}=6,6$, tempo de deposição de 6 minutos e potencial aplicado de 0,30V, avaliou-se a resposta dos sensores as espécies: NADH e NADPH.

\subsubsection{Sistema de remoção de bolhas}

As micro-bolhas de ar que se formam ao longo do percurso analítico, introduziam instabilidade no sinal da linha base e falta de repetibilidade na altura das correntes de picos. Alguns sistemas eficientes de remoção das mesmas foram testados como o de membrana porosa [79], porém não foram adequadas para o sistema em estudo. Desenvolveu-se um novo sistema, no qual foi introduzido um reator de polipropileno microporoso de $0,28 \mathrm{~mm}$ de diâmetro interno e $50 \mathrm{~cm}$ de comprimento (volume de $30 \mu \mathrm{L}$ ) entre o injetor de amostras e o detector eletroquímico. Este tubo microporoso, originaimente utilizado na área médica (Oxyphan®), mostrou-se eficiente para a remoção completa das micros bolhas. Devido à fragilidade mecânica do tubo microporoso (parede de $\sim 100 \mu \mathrm{m}$ ) este foi montado concentricamente no 
interior de um tubo protetor de polietileno, de diâmetro interno de 0,8 mm. Os dois tubos foram fixados entre si, nas extremidades, com cola epóxi.

\subsubsection{Estabilidade do filme de 3,4-DHB}

De acordo com estudos anteriormente realizados [18,19], comprovou-se que o tampão fosfato altera a integridade das soluções de NADH e NADPH, de modo que estas passaram a ser preparadas em tampão PIPES. Observou-se maior durabilidade do eletrodo modificado quando este foi exposto a tampão fosfato como fluido transportador do sistema FIA, ao invés do tampão PIPES. Assim, somente as amostras de NADH e NADPH a determinar foram injetadas em tampão PIPES.

No entanto, cabe salientar que o fato de se trabalhar com 2 soluções tampão com diferentes composições produziram alteração no sinal da linha base. Verificou-se assim, o efeito de um tampão sobre o outro pela injeção, na alça de amostragem, de tampão PIPES sem o analito (Figura 3.21). O sinal do tampão PIPES refere-se ao intervalo de tempo $0<t<600$ s, enquanto o intervalo $600<\mathrm{t}<900$ s, refere-se à injeções de solução $0,025 \mathrm{mmolL}^{-1}$ de NADH em tampão PIPES. 


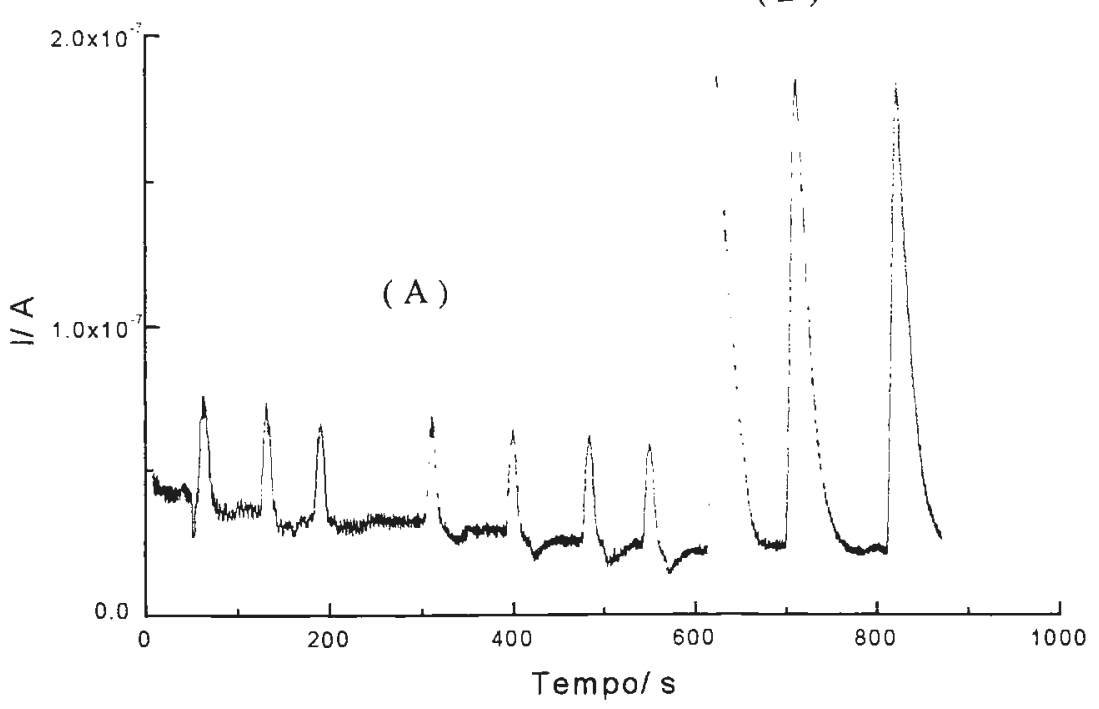

Figura 3.21: ( A ) Injeções da alça de amostragem contendo apenas o tampão PIPES (0 < tempo < 600s); ( B ) Injeções de NADH 0,025 mmol L ${ }^{-1}$ em tampão PIPES.

Observou-se que quando utiliza-se tampão fosfato $0,010 \mathrm{~mol} \mathrm{~L}^{-1}$ como fluido transportador e tampão PIPES $0,010 \mathrm{~mol} \mathrm{~L}^{-1}$ sem o analito na alça de amostragem, obtinha-se um sinal positivo de corrente. No entanto, ao injetar tampão PIPES $0,10 \mathrm{~mol} \mathrm{~L}^{-1}$, portanto 10 vezes mais concentrado que o fluido transportador o sinal de corrente foi negativo (Figura 3.22). Portanto, os sinais de corrente registrados correspondem ao tampão PIPES, devido à carga e descarga da dupla camada elétrica. 


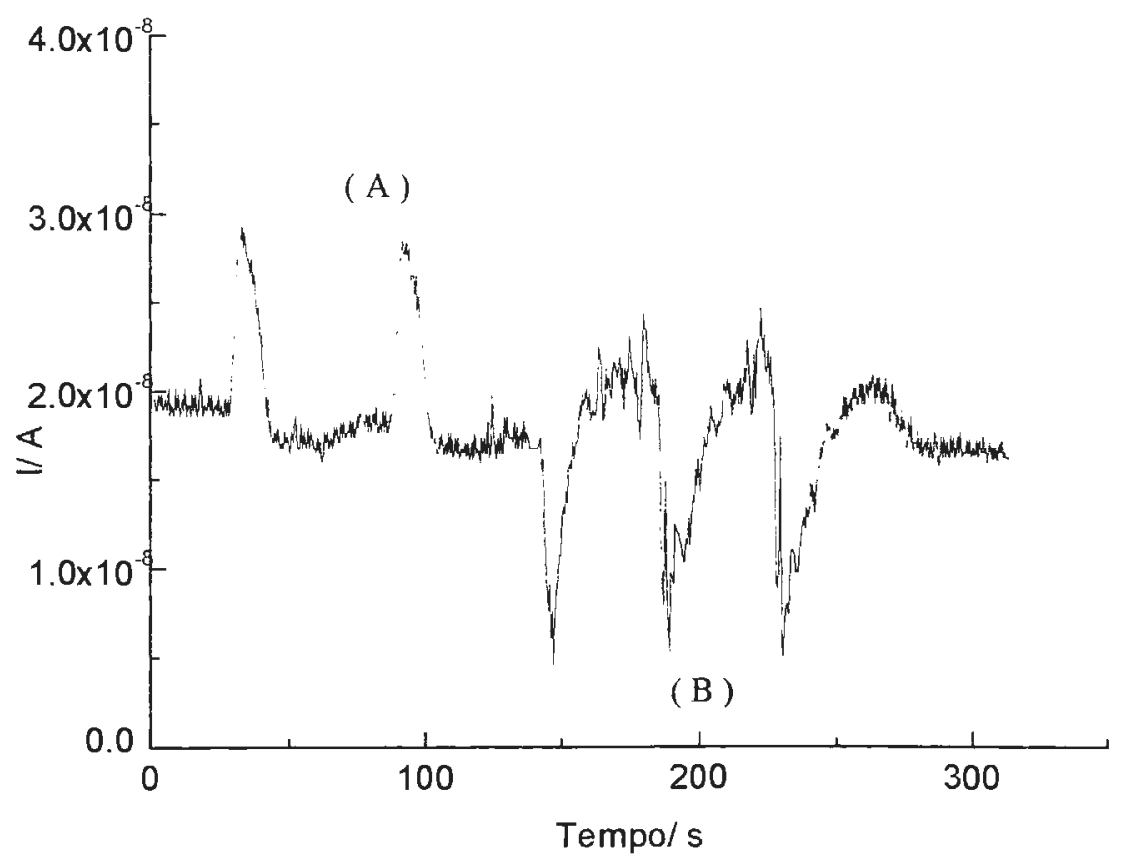

Figura 3.22: Fluido transportador tampão fosfato $0,010 \mathrm{~mol} \mathrm{~L}^{-1}$. ( A ) Tampão PIPES 0,010 mol L-1 ( B ) Tampão PIPES 0,10 $\mathrm{mol} \mathrm{L}^{-1}$.

3.9.3 Influência da vazão na determinação de NADH empregando sistema FIA

O estudo da vazão confirmou os dados obtidos no estudo da influência do número de ciclos no crescimento do filme, discutido no item 3.1.3. O filme não deve ser espesso, pois conforme figura 3.23 , observa-se aumento do sinal do analito com o aumento da vazão. Se o filme fosse espesso uma diminuição do sinal, devido a dificuldade de difusão do NADH, deveria ter sido observada.

O aumento da vazão diminuiu o tempo necessário para a determinação do analito, fato este verificado pela diminuição da largura dos picos. Adicionalmente as lavagens tornaram-se mais rápidas e eficientes. 
Dentre as vazões estudadas os melhores resultados foram obtidos para $0,6 \mathrm{~mL} \mathrm{~min}^{-1}$ e $0,8 \mathrm{~mL} \mathrm{~min}^{-1}$. No entanto ao traçar as curvas analíticas concluiuse que para vazões de $0,6 \mathrm{~mL} \mathrm{~min}^{-1}$, apesar do menor sinal do analito, compensa-se este fato com a maior repetibilidade dos picos e maior estabilidade do filme. Para vazões superiores a $0,8 \mathrm{~mL} \mathrm{~min}^{-1}$, observou-se perda do sinal do analito devido ao lixiviação do filme.

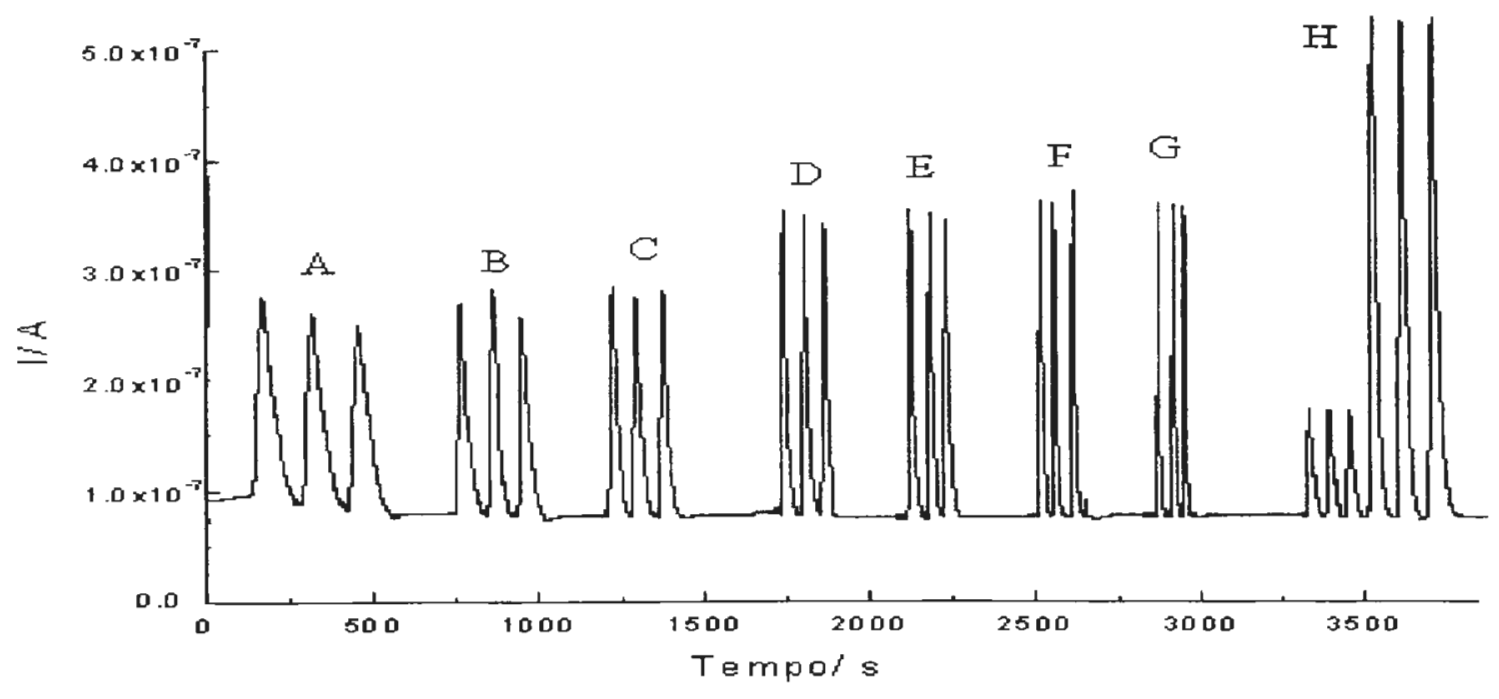

Figura 3.23: Influência da vazão nos sinais de corrente obtidos com injeções de 0,0024 mmol L-1 de NADH: ( A ) 0,2 $\mathrm{mL} \mathrm{min}^{-1}$; ( B ) 0,4 $\mathrm{mL} \mathrm{min}^{-1}$; ( C ) 0,6 mL $\mathrm{min}^{-1}$; ( D ) 0,8 $\mathrm{mL} \mathrm{min}^{-1}$; ( E ) $1,0 \mathrm{~mL} \mathrm{~min}^{-1}$; ( F ) 1,4 $\mathrm{mL} \mathrm{min}^{-1}$; ( G ) 1,9 $\mathrm{mLmin}^{-1}$. $(\mathrm{H})$ vazão $0,6 \mathrm{~mL} \mathrm{~min}^{-1}$, concentração de $\mathrm{NADH} 0,0067$ e $0,071 \mathrm{mmol} \mathrm{L}^{-1}$.

\subsubsection{Influência do volume da alça de amostragem nos sistemas} em fluxo

Para avaliar a influência do volume da alça de amostragem nos sistemas em fluxo utilizaram-se os seguintes volumes: $50 ; 100 ; 150 ; 200$ e $250 \mu \mathrm{L}$. 
Deste modo, conforme figura 3.24 para volumes $\geq 100 \mu \mathrm{L} \circ$ sinal do analito permaneceu constante, de modo que a alça de amostragem utilizada para a continuidade do trabalho foi de $100 \mu \mathrm{L}$, onde a dispersão mínima foi obtida.

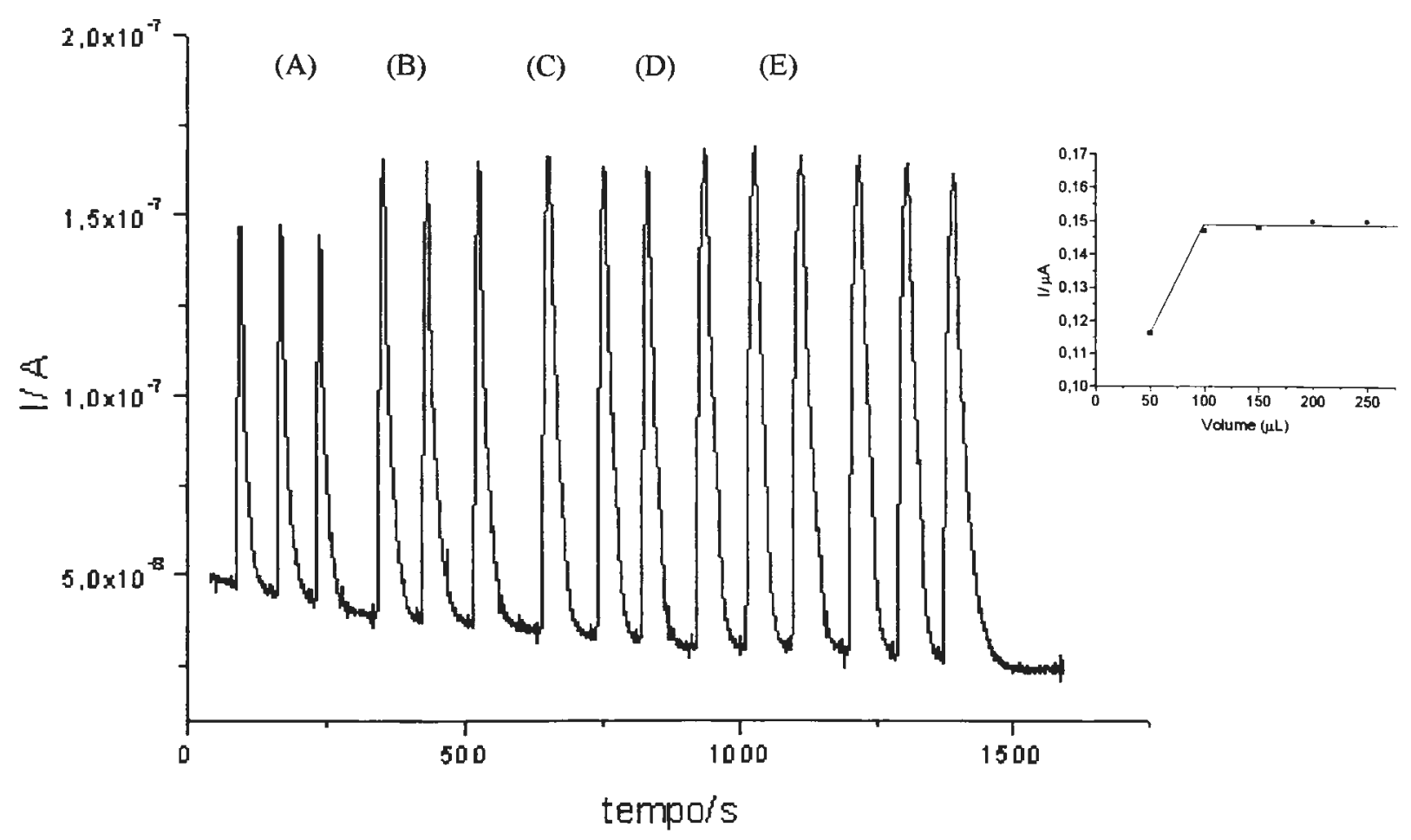

Figura 3.24: Influência da alça de amostragem nos sinais de corrente obtidos com injeções de $0,0024 \mathrm{mmol} \mathrm{L}^{-1}$ de $\mathrm{NADH}$, vazão de $0,6 \mathrm{~mL} \mathrm{~min}^{-1}$ : (A ) $50 \mu \mathrm{L}$; ( B ) $100 \mu \mathrm{L}$; ( C ) $150 \mu \mathrm{L}$; ( D ) $200 \mu \mathrm{L}$; ( E ) $250 \mu \mathrm{L}$.

\subsubsection{Determinação de NADH e NADPH}

O desempenho em sistema FIA, do eletrodo preparado por ciclagem foi avaliado da seguinte maneira: injetaram-se amostras com concentrações crescentes de $\mathrm{NADH}$, para em seguida proceder à injeção das amostras, 
porém em sentido decrescentes de concentração, obtendo-se boa reprodutibilidade do sinal analítico.

A figura 3.25 corresponde ao fiagrama e curva analítica para determinação de NADH com eletrodos modificados com 3,4-DHB preparados por ciclagem. 


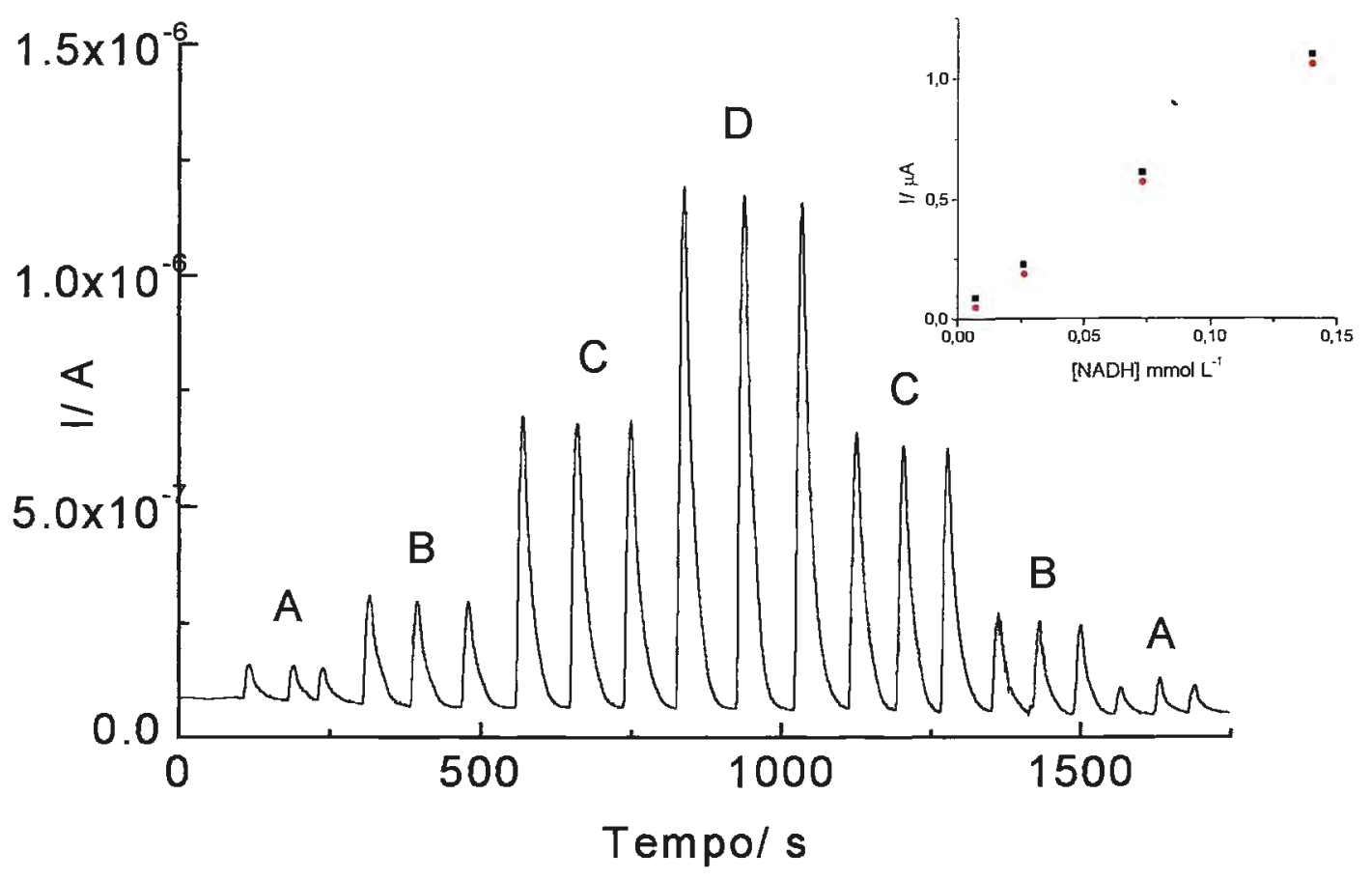

Figura 3.25: Sinais de corrente obtidos na determinação de NADH em tampão PIPES $0,10 \mathrm{~mol} \mathrm{~L}^{-1}$ e a respectiva curva analítica. Concentrações de NADH: (A) 0,0050 mmol L-1; (B) 0,025 $\mathrm{mmol} \mathrm{L}^{-1}$; (C) 0,072 $\mathrm{mmol} \mathrm{L}^{-1}$; (D) 0,15 $\mathrm{mmol} \mathrm{L}^{-1}$. (preta) curva analítica sem descontar o sinal do tampão PIPES e (vermelha) após descontar o sinal do tampão PIPES. Eletrodo de pasta de carbono modificado com 3,4-DHB por ciclagem. Potencial de trabalho $0,23 \mathrm{~V}$, volume de amostra $100 \mu \mathrm{L}$; vazão: $0,6 \mathrm{~mL} \mathrm{~min}{ }^{-1}$, eletrólito de suporte: tampão fosfato $0,010 \mathrm{molL}^{-1}$.

O desempenho, em sistemas FIA, de eletrodos preparados por deposição a potencial controlado foi avaliado de maneira similar ao procedimento adotado para avaliação de eletrodos preparados por ciclagem. No entanto, quando injetaram-se amostras em ordem crescente e decrescente de concentração obtiveram-se níveis de corrente inferiores aos obtidos com o 
eletrodo preparado por ciclagem. Além disto, não houve reprodutibilidade do sinal analítico (Figura 3.26). Além disto, as equações que descrevem os parâmetros das curvas analíticas mostraram que a resposta do eletrodo diminuiu rapidamente ao longo de 3 dias:

$$
\begin{array}{lll}
I_{1}=0,036+4,0[\mathrm{NADH}] & r=0,9974 & \left(1^{0} \mathrm{dia}\right) \\
I_{2}=0,082+0,77[\mathrm{NADH}] & r=0,9964 & \left(2^{0} \mathrm{dia}\right) \\
I_{3}=0,012+0,41[\mathrm{NADH}] & r=0,9969 & \left(3^{0} \mathrm{dia}\right)
\end{array}
$$

Resposta linear foi observada no intervalo de 0,005 $\leq[\mathrm{NADH}] \leq$ $0,15 \mathrm{molL}^{-1}$, sendo r o coeficiente de correlação. 


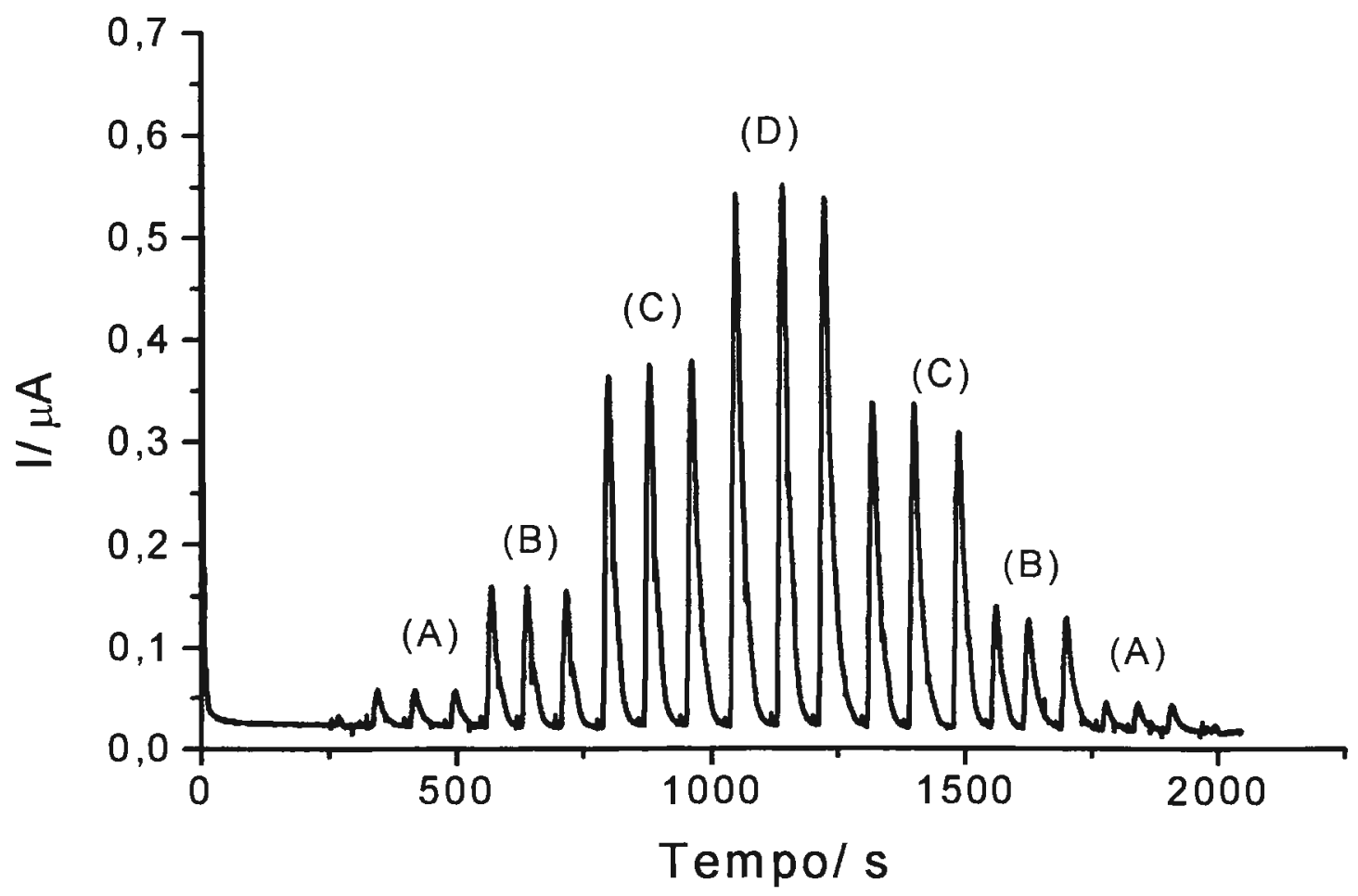

Figura 3.26: Sinais de corrente obtidos na determinação de NADH em tampão PIPES $0,10 \mathrm{~mol} \mathrm{~L}^{-1}$ e a respectiva curva analítica. Concentração de NADH (A) $0,0040 \mathrm{mmol} \mathrm{L}^{-1}$; (B) $0,024 \mathrm{mmol} \mathrm{L}^{-1}$; (C) $0,070 \mathrm{mmol} \mathrm{L}^{-1}$; (D) $0,13 \mathrm{mmol} \mathrm{L}^{-1}$. Eletrodo de pasta de carbono modificado com 3,4-DHB por deposição a potencial controlado. Potencial de trabalho $0,23 \mathrm{~V}$, volume de amostra $100 \mu \mathrm{L}$; vazão: $0,6 \mathrm{~mL} \mathrm{~min}^{-1}$, eletrólito de suporte: tampão fosfato $0,10 \mathrm{molL}^{-1}$. 
Por outro lado, eletrodos preparados por ciclagem apresentaram queda menos acentuada de sinal ao longo de 3 dias:

$$
\begin{array}{lll}
\mathrm{I}_{1}=0,036+7,7[\mathrm{NADH}] & \mathrm{r}=0,9997 & \left(1^{0} \cdot \mathrm{dia}\right) \\
\mathrm{I}_{2}=0,082+4,1[\mathrm{NADH}] & \mathrm{r}=0,9993 & \left(2^{0} \cdot \mathrm{dia}\right) \\
\mathrm{I}_{3}=0,012+2,6[\mathrm{NADH}] & \mathrm{r}=0,9999 & \left(3^{0} \mathrm{dia}\right)
\end{array}
$$

Resposta linear foi observada no intervalo de $0,005 \leq[\mathrm{NADH}] \leq 0,15$ mmolL $^{-1}$, sendo r o coeficiente de correlação.

Deste modo, concluiu-se que os filmes obtidos por ciclagem apresentam maior sensibilidade e durabilidade. Estes últimos também apresentaram atividade catalítica para oxidação de NADPH. Os resultados são apresentados na Figura 3.27. Embora estes resultados sejam similares àqueles obtidos em solução de NADH, cabe salientar que após a obtenção dos dados apresentados na Figura 3.27 a superfície ativa foi totalmente destruída. 


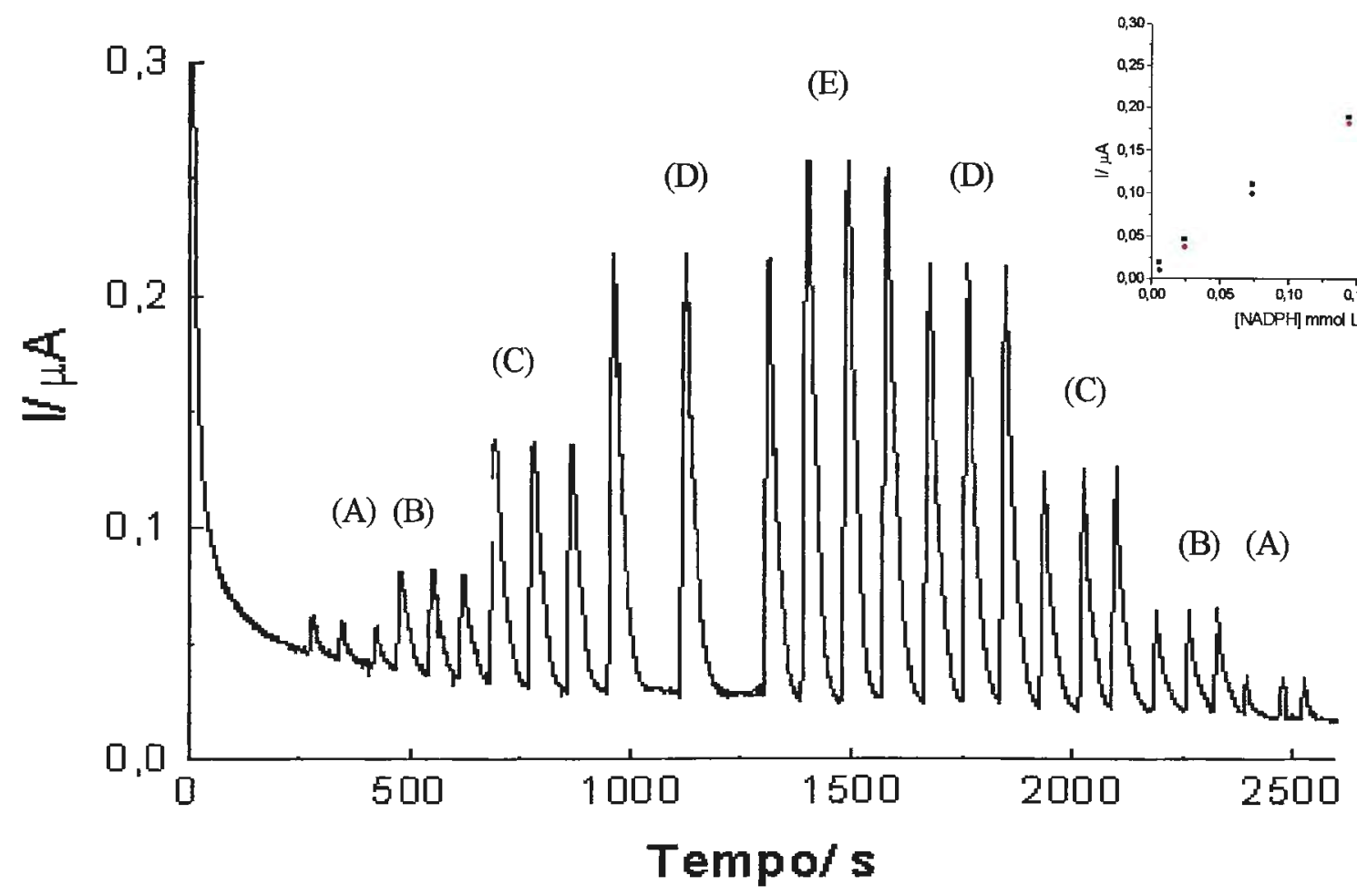

Figura 3.27: Sinais de corrente obtidos na determinação de NADPH em tampão PIPES $0,10 \mathrm{~mol} \mathrm{~L}^{-1} \mathrm{e}$ a respectiva curva analítica. Concentração de NADPH (A) 0,0054 $\mathrm{mmol} \mathrm{L}^{-1}$; (B) 0,024 $\mathrm{mmol} \mathrm{L}^{-1}$; (C) 0,073 $\mathrm{mmol} \mathrm{L}^{-1}$; (D) 0,14 $\mathrm{mmol} \mathrm{L}^{-1}$; (E) $0,19 \mathrm{mmol} \mathrm{L}^{-1}$. Eletrodo de pasta de carbono modificado com 3,4-DHB por ciclagem Potencial de trabalho $0,23 \mathrm{~V}$, volume de amostra $100 \mu \mathrm{L}$; vazão: $0,6 \mathrm{~mL} \mathrm{~min}^{-1}$, eletrólito de suporte: tampão fosfato $0,010 \mathrm{molL}^{-1}$.

A repetibilidade do método do método para injeções de solução de NADH $25 \mu \mathrm{mol} \mathrm{L}^{-1}$ foi de $1,6 \%$ ( 18 injeções de $160 \mu \mathrm{L}$ ) e o limite de deteç̧ão calculado em $0,4 \mu \mathrm{mol} \mathrm{L} \mathrm{L}^{-1}$ (3S/R). Sob a vazão de $0,6 \mathrm{~mL} \mathrm{~min}^{-1}$, a freqüência analítica foi de 55 determinações/hora.

O eletrodo modificado com filme eletropolimerizado de 3,4-DHB pode ser utilizado por 3 dias consecutivos, conservando resposta linear na faixa de $5 \times 10^{-6} \leq[\mathrm{NADH}] \leq 1,5 \times 10^{-4} \mathrm{~mol} \mathrm{~L}^{-1}$. Quando fora de uso o eletrodo modificado deve ser mantido em tampão fosfato, $\mathrm{pH} 7,8$. 


\subsection{Estabilidade da solução de NADH}

A solução de NADH preparada no primeiro dia de uso do eletrodo foi utilizada para a realização das 3 curvas analíticas. Houve uma diminuição nos níveis de corrente, que poderia ser atribuído à perda de filme ativo, ou decomposição do NADH durante o período em que a solução ficou armazenada. Novo filme de 3,4-DHB foi preparado e outra curva analítica foi efetuada utilizando-se a solução mantida em geladeira durante 7 dias. Os niveis de corrente obtidos para oxidação do analito foram os mesmos do primeiro dia de uso da solução de NADH. Portanto, a solução do cofator em tampão PIPES pode ser mantida em geladeira por 7 dias sem sofrer nenhum tipo de alteração. 


\section{CONCLUSÕES}

Concluiu-se com este trabalho que os eletrodos de pasta de carbono modificados com 3,4 DHB devem ser pré-tratados eletroquimicamente em solução de $\mathrm{NaOH}$ para posterior formação do filme eletropolimerizado de 3,4-DHB. Os resultados demonstraram que para obtenção de filmes estáveis, é essencial que durante a preparação do filme e posterior teste de estabilidade em eletrólito suporte, a janela de potencial de varredura não alcance o segundo pico de oxidação do 3,4-DHB, $E_{p, a 2}$.

Filmes mais estáveis e duráveis foram obtidos por ciclagem. As condições otimizadas foram: [ 3,4-DHB ] = 0,25 mmol L-1 $; \mathrm{pH}=7,8$; número de ciclos $=10$; intervalo de varredura $0,0 \leq \mathrm{E}_{\text {aplicado }} \leq 0,25 \mathrm{~V}$ e velocidade de varredura $=10 \mathrm{mVs}^{-1}$.

Os dados obtidos permitiram a proposição de um mecanismo para eletropolimerização deste composto na superfície do eletrodo, o qual consiste na formação do radical fenoxil, que inicia o processo de eletropolimerização do filme. Estes dados permitiram concluir que não há possibilidade de incorporação simultânea de enzimas, uma vez que o centro ativo das mesmas não seria preservado. Além disto, a imobilização de co-fatores enzimáticos também não pode ser efetuada, uma vez que estes atuam como agentes seqüestrantes de radicais livres, inibindo a formação do filme eletropolimerizado de 3,4-DHB.

Os eletrodos modificados com filmes eletropolimerizados de 3,4-DHB apresentaram estabilidade apenas em soluções do cofator NADH. Em soluções de NADPH o filme é desestabilizado, fato este que se encontra em 
concordância com o mecanismo proposto para a etapa de eletropolimerização e imobilização do filme na superfície do eletrodo.

Para determinação de NADH em sistema FIA desenvolveu-se um reator de polipropileno microporoso de $0,28 \mathrm{~mm}$ de d.i. e $50 \mathrm{~cm}$ de comprimento introduzido entre o injetor de amostras e o detector eletroquímico. Este sistema mostrou-se eficiente na remoção de micro bolhas de ar que se formam ao longo do percurso analítico. As condições ótimas para trabalhar com célula de camada delgada foram: vazão de $0,6 \mathrm{~mL} \mathrm{~min}^{-1}$ e alça de amostragem $100 \mu \mathrm{L}$, obtendo-se freqüência analítica de 55 determinações /hora. A repetibilidade do método, para injeções de NADH $25 \mu$ mol $L^{-1}$, foi de 1,6\% (18 injeções de $100 \mu \mathrm{L})$ e o limite de deteç̧ão estimado de $0,4 \mu \mathrm{mol} \mathrm{L} \mathrm{L}^{-1}(3 \mathrm{~S} / \mathrm{R})$.

O eletrodo modificado com filme eletropolimerizado com3,4-DHB pode ser utilizado por 3 dias consecutivos para determinação amperométrica de $\mathrm{NADH}$, conservando resposta linear na faixa de 0,015 $\leq[\mathrm{NADH}] \leq 0,21 \mathrm{~mol} \mathrm{~L}^{-1}$. Em sistemas de análise por injeção em fluxo, a faixa linear de resposta foi de $5 \times 10^{-6} \leq[\mathrm{NADH}] \leq 1,5 \times 10^{-4} \mathrm{~mol} \mathrm{~L}^{-1}$. Quando fora de uso o eletrodo deve ser armazenado em tampão fosfato, $\mathrm{pH} 7,8$. 


\section{REFERÊNCIAS BIBLIOGRÁFICAS}

[1] ELVING, P.J, SCHMAKEL, C.O, SANTHANAM, K.S.V, Nicotinamide-NAD sequence: redox processes and related behavior: behavior and properties of intermediate and final products, CRC-Critical Rewies in Anal. Chem., p. 1-67, 1976.

[2] KATAKIS, I, DOMINGUEZ, E., Catalytic electrooxidation of NADH for dehydrogenase amperometric biosensors, Mikrochim. Acta, 126, p.1132,1997 .

[3] BLAEDEL, W. J., JENKINS, R.A, Steady-state voltammetry at glassy carbon electrodes, Anal. Chem., v. 46, n. 13, p. 1952-1955, 1974.

[4] BLAEDEL, W. J., JENKINS, D. R. A., Study of the electrochemical oxidation of reduced nicotinamide adenine dinucleotide, Anal. Chem., v.47, n.8, p 1337-1343, 1975.

[5] AIZAWA, M., COUGHLIN, R.W., CHARLES, M., Electrochemical regeneration of nicotinamide adenine dinucleotide, Biochim. Biophys. Acta, 385, p. 362-370, 1975.

[6] BURNETT, J. N., UNDERWOOD, D. L., Electrochemical reduction of diphosphopyridine nucleotide, Biochemistry, 4, p. 2060-2064, 1965.

[7] LEDUC, P., THÉVENOT, D., Electrochemical properties of nicotinamide derivatives in aqueous solution, Electroanal. Chem. Interfacial Electrochem., 47, p. 543-546, 1973.

[8] MOIROUX, J., ELVING, .J.E., Effects of adsorption, electrode material and operational variables on oxidation of dihydronicotinamide adenine dinucleotide at carbon electrodes, Anal. Chem., v.50, n.8, p. 1056-1063, 1978.

[9] MOIROUX, J., ELVING, P.J., Optimization of the analytical oxidation of dihydronicotinamide adenine dinucleotide at carbon and platinum electrodes, Anal. Chem., v.51, n.3, p. 346-350, 1979.

[10] JAEGFELDT, H., Adsorption and electrochemical oxidation behaviour of $\mathrm{NADH}$ at clean platinum electrode, J. Electroanal. Chem., 110, p.295302, 1980.

[11] BLANKESPOOR, R.L., MILLER, L.L., Electrochemical oxidation of NADH kinetic control by product inhibition and surface coating, J. Electroanal. Chem., 171, p.231-241, 1984.

[12] ENGSTROM, R. C., Electrochemical pretreatment of glassy carbon electrode, Anal. Chem., 54, p. 2310-2314, 1982. 
[13] CENAS, N., ROZGAITÉ, J., POCIUS, A., KULYS, J., Electrocatalytic oxidation of NADH and ascorbic acid on electrochemically pretreated glassy carbon electrodes, J. Electroanal. Chem., 154, p. 121-128, 1983.

[14] SAMEC, Z., J.ELVING, P., Anodic oxidation of dihydronicotinamide adenine dinucleotide at solid electrodes, mediation by surface species,J. Electroanal. Chem., 144, p. 217-234, 1983.

[15] THOMA, L.C., GARY, D.C., Amperometric measurement of hexacyanoferrate(III)-coupled dehydrogenase reaction, Anal. Chim. Acta, 82, p. 265-272, 1976.

[16] ALIVISATOS, S.G.A., UNGAR, F., ABRAHAM, G., Non-enzymatic interactions of reduced coenzyme I with inorganic phosphate and certain other anions, Nature, 203, p.973-975, 1964.

[17]. STRANDJORD, P. E, CLAYSON, K.J., The control of inhibitory impurities in reduced nicotinamide adenine dinucleotide in lactate dehydrogenase assays, J. Lab. Clin. Med., 67, p. 144-153, 1966.

[18] KATEKAWA, E.; MAXIMIANO, F.;.RODRIGUES, L.L.; DELBEM, M.F.; SERRANO, S.H.P.; Electrochemical oxidation of NADH at a bare glassy carbon electrode in different supporting electrolytes, Anal. Chim. Acta, 385, p. 345-349, 1999.

[19] ROVER, L.; FERNANDES, J.C.B.; NETO, G.O., KUBOTA, L.T., KATEKAWA, E., SERRANO, S.H.P., Study of NADH stability using ultraviolet-visible spectrophotometric analysis and factorial design, Anal. Biochem. 260, p. 50-55, 1998.

[20] PARIENTE, F.; TOBALINA, F.; MORENO, G., HERNÁNDEZO, E L.; LORENZO, E., ABRUÑA, E H. D., Mechanistic studies of the electrocatalytic oxidation of NADH and ascorbate at glassy carbon electrodes modified with electrodeposited films derived from 3,4dihydroxybenzaldehyde, Anal. Chem., 69, p.4065-4075, 1997.

[21] ALBERY, W.J., FOULDS, A.W., HALL, K.J., HILLMAN, A.R., EGDALL, R.G., ORCHAND, A.F., Thionine coated electrode for photogalvanic cells, Nature, 282, p.793-797, 1979.

[22] JONES, J.B., TAYLOR, K.E., Nicotnamide coenzyme regeneration-rates of some 1,4-dihydropiridine pyridinium salt and flavin mononucleotide hydrogen-transfer reactions. Can. J. Chem., v.54, n.19, p.2974-2980, 1976.

[23] RODKEY, F. L., Oxidation-reduction potentials of diphosphopyridine nucleotide system, J. Biol. Chem., 213, p. 777-786, 1955. 
[24] OTTWAY, J.H., Some rate constant for the ohenazinemethosulphatecatalysed oxidation of reduced nicotinamide-adenine dinucleotide, Biochem. J., 99, p. 253-256,1966.

[25] MALINAUSKAS, A.A., KULYS, J.J., Alcohol, lactate and glutamate sensors based on oxidoreductases with regeneration of nicotinamide adenine dinucleotide, Anal. Chim. Acta, 98, p. 31-37, 1978.

[26] GOSH, R., QUAYLE, J. R., Phenazine ethosulfate as a preferred electron acceptor to phenazine methosulphate in dye-linked enzymes assays, Anal. Biochem., 99, p.112-117, 1979.

[27] WILLIAMS, D.C., SEITZ, W.R., Automated chemiluminescence method for determination the reduced form of nicotinamide adenine dinucleotide coupled to the measurement of lactate dehydrogenase activity, Anal. Chem., 48, p. 1478-1481, 1976.

[28] TORTENSSON, A., GORTON, LO, Catalytic oxidation of NADH by surfacemodified graphite electrodes, J. Electroanal. Chem., 130, p. 199-207, 1981.

[29] CAI, C.-X., XUE, K.-H., Electrocatalysis of NADH oxidation with electropolymerized filmes of nile blue A, Anal. Chim. Acta, 343, p. 69$77,1997$.

[30] ZHOU, D.-M., FANG, H.-Q., CHEN, H.-Y., JU, H.-X., WANG, Y., The electrochemical polymerization of methylene green and its electrocatalysis for the oxidation of NADH, Anal. Chim. Acta, 329, p.41$48,1996$.

[31] GORTON, L., Chemically modified electrodes for the electrocatalytic oxidation of nicotinamide coenzymes, J. Chem. Soc., Faraday Trans. 1, 82, p.1245-1258, 1986.

[32] CHI, Q., DONG, S., Electrocatalytic oxidation of reduced nicotinamide coenzymes at organic dye-modified electrodes, Electroanal., v.7, n.2, 1995.

[33] GORTON, L., TORTENSSON, A., JAEGFELDT, H., JOHANSSON, G., Electrocatalytic oxidation of reduced nicotinamide coenzymes by graphite electrodes modified with na adsorbed phenoxazinium salt, medola blue, J. Electroanal. Chem., 161, p.103-120, 1984.

[34] GORTON, L., JOHANSSON, G., TORTENSSON, A., A kinetic study of the reaction between dihydronicotinamide adenine dinucleotide (NADH) and an electrode modified by adsorption of 1,2-benzophenoxazine-7one. J. Electroanal. Chem., 196, p.84-92, 1985. 
[35] ALBERY, W.J., BARTLETT, P., An organic conductor electrode for the oxidation of NADH, J. Chem. Soc., Chem. Commun., p. 234-236, 1984.

[36] PERSSON, B., A chemically modified graphite electrode for electrocatalytic oxidation of reduced nicotinamide adenine dinucleotide based on a phenothiazine derivative, $3 \beta$-naphthoyl-toluidine blue $0, J$. Electroanal. Chem., 287, p.61-80, 1990.

[37] PERSSON, B., GORTON, L., A comparative study of some 3,7diaminophenoxazine derivatives and related compounds for electrocatalytic oxidation of NADH, J. Electroanal. Chem., 292, p.115138, 1990.

[38] NAGY, G., KAPUI AND, I., GORTON, L., Effect of surface-active agents on amperometric NADH measurements with chemically modified electrodes, Anal. Chim. Acta, 305, p.65-73, 1995.

[39] PESSOA, C.A., GUSHIKEM, Y., KUBOTA, L., GORTON, L., Preliminary e:ectrochemical study of phenothiazines and phenoxazines immobilized on zirconium phosphate, J. Electroanal. Chem., 431, p.23-27, 1997.

[40] HUAN, Z., PERSSON, B., GORTON, L., SAHN,I S., SKOTHEIM, T., BARTLETT, P., Redox polymers for electrocatalytic oxidation of NADH- cationic styrene and ethylenimine polymer, Electroanal., v.8, n.6, p.575-581, 1996.

[41] LOBO, M.J., MIRANDA, A.J., LÓPEZ-FONSECA, J. M., TUÑÓN, D P, Electrocatalytic detection of nicotinamide coenzymes by poly(oaminophenol)-and poly(o-phenylenediamine)-modified carbon paste electrodes, Anal. Chim. Acta, 325, p.33-42, 1996.

[42] ATTA, N.F., GALAL, A., KARAGOZLER, A.E., ZIMMER, H., RUBINSON, J.F., MARK JR, H. B., Voltammetric studies of the oxidation of reduced nicotinamide adenine dinucleotide at a conducting polymer electrode, $\mathrm{J}$. Chem. Soc. Chem. Commun, p. 1347 1349, 1990.

[43] SOMASUNDRUM, M.; BANNISTER, J.V., Mediatorless electrocatalysis at conducting polymer electrode: application to ascorbate and NADH measurement, J. Chem. Soc. Chem. Commun , p. 1629-1631,1993.

[44] CAI, C.-X., XUE, K.-H., Electrocatalysis of NADH oxidation with electropolymerized films of azure I, J. Electroanal. Chem, 427, p.147153, 1997.

[45] CuRulli, A., CORELLI, I., TRISCHITTA, O., PALlESCHI, G., Enzyme electrode probes obtained by electropolymerization of monomers with PMS and selected dehydrogenase enzymes, Talanta, 44, p.1659-1669, 1997. 
[46] TANG, H.T., HAJIZADEH, K., HALSLL, H.B., HEINEMAN, W.R., Flowinjection analysis with electrochemical detection of reduced nicotinamide adenine dinucleotide using 2,6-dichloroindophenol as a redox coupling agent, Anal. Biochem. 192, p.243-250, 1991.

[47] CHI, Q., DONG, S., Electrocatalytic oxidation and flow injection determination of reduced nicotinamide coenzyme at glassy carbon electrode modified by a polymer thin film. Analyst 119, p.1063-1066, 1994.

[48] SPRULES, S.D., HART, J.P., WRING, AS., PITTSON, R., Development of a disposable amperometric sensor for reduced nicotinamide adenine dinucleotide based on a chemically modified screen-printed carbon electrode, Analyst ,119, p.253-257, 1994.

[49] SPRULES, S.D., HART, J.P., PITTSON, R., WRING, A.S., Evaluation of a new disposable screen-printed sensor strip for the measurement of $\mathrm{NADH}$ and its modification to produce a lactate biosensor employing microliter volumes, Electroanal., v.8,n.6, p. 539-543, 1996.

[50] CHEN, H, YU, A, HAN, J., MI, Y, Catalytic oxidation of NADH at a methylene-green chemically modified electrode and FIA applications, Anal. Lett., v.28,n.9, p.1579-1591, 1995.

[51] ANGES, L., AZEVEDO, C.M.N., ARAKI, K.,. TOMA. H.E, Electrochemical detection of $\mathrm{NADH}$ and dopamine in flow analysis based on tetraruthenated porphyrin modified electrodes, Anal. Chim. Acta ,329, p.91-96, 1996.

[52] WO, Q., MASKUS, M., PARIENTE, F., TOBOLINA, F., FERNANDEZ, V.M., LORENZO, R., ABRUNA, H.D., Electrocatalytic oxidation of NADH at glassy carbon electrodes modified with transition metal complexes containing 1,10-phenanthroline-5,6-dione ligands, Anal. Chem., 68, p.3688-3698, 1996.

[53] FLOROU, A B., PRODROMIS, M.I., KARAYANNIS, M.I, KARAYANNIS, S.M.T., Electrocatalytic oxidation of NADH in flow analysis by graphite electrode modified with 2,6-dichlorophenolindophenol salts, Electroanal., v.10, n.18, p.1261-1263, 1998.

[54] AZEVEDO, C.M.N., Desenvolvimento de eletrodos modificados e métodos analíticos, São Paulo, USP, p.16,1999.

[55] KITANI, A, SO, Y., MILLER, L.L., An electrochemical study of the kinetics of NADH being oxidized by diimines derived from diaminobenzenes and diaminopyrimidines, J Am. Chem. Soc., 103, p.7636-7641, 1981. 
[56] CHI, Q., DONG, S., Electrocatalytic oxidation of reduced nicotinamide coenzymes at methylene green-modified electrodes and fabrication of amperometric alcohol biosensors, Anal. Chim. Acta, 285, p.125-133, 1994.

[57] RUBINSON, J.F., NEFF, S., MRK J.R, H.B., GALAL, A, ATTA, N.F., Characterization and investigation of the electrocatalytic properties of poly-p-phenylene modified electrodes, J. Electroanal. Chem., 384, p.1923, 1995.

[58] BARTLETT, P.N., BIRKIN, P.R.,. WALLACE, E.N.K, Oxidation of $\beta-$ nicotinamide adenine dinucleotide (NADH) at poly(aniline) coated electrodes, J Chem. Soc., Faraday Trans., v.93, n.10, p.1951-1960, 1997.

[59] WANG, J., PAMIDI P.V.A, JIANG, M., Low-potencial stable detection of $\beta$ NADH at sol-gel derived carbon composite electrodes, Anal. Chim. Acta, 360, p.171-178, 1998.

[60] CAI, C.X., XUE, K.H., Electrochemical polymerization of toluidine blue o and its electrocatalytic activity towards NADH oxidation, Talanta, 47, p.1107-1119, 1998.

[61] KARYAKIN, A A , BOBROVO, A O., KARYAKINO, E.E., Electroreduction of NAD to enzymatically active NADH at poly(neutral red) modified electrodes, J. Electroanal. Chem., 399, p.179-184, 1995.

[62] PARIENTE, F., LORENZO, E., ABRUÑA, E.H.D., Electrocatalysis of NADH oxidation with electropolimerized films of 3,4-dihydroxybenzaldehyde, Anal Chem., 66, p.4337-4344, 1994.

[63] KALCHER, K., KAUFFMANN, J.M., WANG, J., SVANCARA, I ., VYTRAS, K., NEUHOLD, C., YANG, Z., Sensors based on carbon paste in electrochemical analysis, a review with particular emphasis on the period 1990-1993, Electroanal., v.7, n.1, p.5-22, 1995.

[64] McCREERY, R. , Carbon electrodes: structural effects on electron transfer kinetics, Electroanal. Chemistry, Ed. Allen Bard, Marcel Dekker Inc., 17, p.221-375, 1991.

[65] BRETT, A.M.O., BRETT, C.M.A., Electroquímica princípios, métodos e aplicaçōes, Coimbra, Oxford University Press, 1996, p.198.

[66] ZUMAN,P., The Elucidation of Organic Electrodes Processes, Louis Meides ( ed ), Academia Press, London, 1969, p. 120

[67] REIS, B.F., Análise química por injeção em fluxo: vinte anos de desenvolvimento, Química Nova, v. 19, n. 1, p. 51-58, 1996. 
[68] REIS, B.F., GINÉ, M.F., KRONKA, E.A.M. A análise química por injeção e, fluxo contínuo, Química Nova v.12, n.1, p. 82-91, 1989.

[69] RUZICKA, J., E.H. HANSEN, Flow Injection Analysis (Chemical Analysis). John Wiley \& Sons, Inc, $2^{\text {nd }}$ ed., NY,1988.

[70] HANSE, E.D., Flow injection analysis: leaving its teen-years and maturing. A personal reminiscence of its conception and early development, Anal. Chim. Acta, 308, p.3-13, 1995.

[71] PERRIM, D.D.; DEMPSEY, B.; Buffer for $\mathrm{pH}$ and Metal lon Control, New York: Chapman and Hall Ltda:, 1974.

[72] PEDROTTI, J.J.; ANGNES, L.; GUTZ, I.G.R., Miniaturized reference electrodes with microporous polymer junctions, Electroanal.,v.8, n. 7, p. 673-675, 1996.

[73] GREEF, R., PEART, R., PETER, L.M., ROBINSON, J., Instrumental Methods in Electrochemistry, ed. Ellis, Horwodd, 1993, 359.

[74] PARIENTE, F., TOBALINA, F., DARDER, M., LORENZO, E., ABRUÑA, H.D., Electrodeposition of redox-active films of dihydroxybenzaldehydes and related analogs and their electrocatalytic activity towards NADH oxidation, Anal. Chem., 68, p.3135-3142, 1996.

[75] GAO, Z., SIOW, K.S., N.G., A., ZHANG, Y., Determination of ascorbic acid in mixture of ascorbic acid and uric acid at a chemically modified electrode, Anal. Chim. Acta, 343, p.49-57, 1997.

[76] HAPIOT, P.; PINSON, J., FRANCESCH, C.; MHAMDI, F.; ROLANDO, C., NETA, P. Oxidative dimerization of phenolic aldehydes related to lignin formation, J. Phys. Chem., 98, p.2641-2645, 1994.

[77] GOLDMAN, R., TSYRLOV, I.B., GROGAN, J., KAGAN, V.E.; Reactions of phenoxyl radicals with NADPH cytochrome P-450 oxidoreductase and NADPH reductions of the radicals and inhibition of the enzyme, Biochem. v.36, n. 11, p. 3186-3192 1997.

[78] GOLDMAN, R., BORS, W., MICHEL, C., DAY, B.W., KAGAN, V.E.; Environmental and nutrutional phenols: bioactivation of phenoxyl radicals and their cytotoxic and/or protective interactions with intracellular reductants, Environ. Nutr. Interact., v.1, n. 2, p. 97-118, 1997.

[79] PEDERSEN, K. M., KUMMEL, M, SOEBERG, E H, Monitoring and control of biological removal of phosphorous and nitrogen by flow injection analysers in a municipal pilot-scale waste-water treatment plant, Anal. Chim. Acta, 238, p.191-199, 1990. 